\title{
The Impact of Soda Taxes: Pass-through, Tax Avoidance, and Nutritional Effects*
}

\author{
Stephan Seiler Anna Tuchman \\ Imperial \\ College \\ Song Yao \\ Washington University \\ in St. Louis
}

This draft: October 3, 2020

We analyze the impact of a tax on sweetened beverages using a unique dataset of prices, quantities sold, and nutritional information across several thousand taxed and untaxed beverages for a large set of stores in Philadelphia and its surrounding area. We find the tax is passed through at an average rate of $97 \%$, leading to a $34 \%$ price increase. Demand in the taxed area decreases by $46 \%$ in response to the tax. A large amount of cross-shopping to stores outside of Philadelphia offsets more than half of the reduction in sales in the city and decreases the net reduction in sales of taxed beverages to only $22 \%$. We find no significant substitution to bottled water and modest substitution to untaxed natural juices. We show that tax avoidance through cross-shopping severely constrains revenue generation and nutritional improvement, thus making geographic coverage an important policy decision.

Keywords: Sin Taxes, Pass-Through, Tax Avoidance, Policy Evaluation, Tax Design. JEL codes: D04, D12, I18.

*We thank Hunt Allcott, Eric Anderson, Michael Best, Bryan Bollinger, Chris Conlon, Brett Gordon, Brett Hollenbeck, Sylvia Hristakeva, Carl Mela, Martin O'Connell, Peter Rossi, Bradley Shapiro, Yossi Spiegel, and Dmitry Taubinsky for insightful comments, as well as seminar participants at Boston University, CKGSB, Cornell, DePaul, ESMT Berlin, Federal Trade Commission, Imperial College, INSEAD, Northwestern, NYU, Santa Clara University, Stanford, UCL, UC Riverside, KU Leuven, University of Minnesota, University of Rochester, University of Washington, Washington University in St. Louis, and Yale SOM, and participants at the 2017 Marketing in Israel, 2018 Yale Customer Insights, 2018 INFORMS Marketing Science, and 2019 QME conferences for useful comments. Yuanchen Su and Weihong Zhao provided excellent research assistance. Thanks also to Piyush Chaudhari and the team at IRI for providing the data used in our analysis. All estimates and analyses in this paper based on Information Resources, Inc. data are by the authors and not by Information Resources, Inc. Please contact Seiler (stephan.a.seiler@gmail.com), Tuchman (anna.tuchman@kellogg.northwestern.edu), or Yao (songyao@wustl.edu) for correspondence. None of the authors received external funding for this paper. 


\section{Introduction}

The US has the highest rate of obesity among all developed countries (OECD (2017)). According to the Centers for Disease Control and Prevention (CDC), 36\% of Americans are clinically obese and another third are overweight (Ogden et al. (2015)). In 2008, the estimated annual medical cost of obesity in the US was $\$ 147$ billion (CDC (2016), Finkelstein et al. (2009)). Due to the prevalence of obesity in the US, taxes on sugar-sweetened beverages (SSBs) have recently gained in popularity. SSBs have been singled out for taxation because sugary drinks are the single largest source of added sugar in the average American's diet (National Cancer Institute (2018)). Berkeley, CA, was the first municipality to implement a 1-cent-per-ounce tax in March 2015. More recently, other cities and counties have implemented similar taxes, including Philadelphia, PA, Cook County, IL (covering Chicago and its suburbs) ${ }^{1}$. San Francisco, CA, Boulder, CO, and Seattle, WA. Several other cities (e.g., Washington, D.C., New York, NY, and Portland, OR) and the state of Connecticut have contemplated introducing similar taxes. Understanding the impact of such taxes is therefore important for policy-makers, as well as affected firms in the beverage industry and the retail sector.

In this paper, we use the case of Philadelphia as a testbed for understanding the impact of a tax on sweetened beverages. Philadelphia presents a particularly rich setting to study a sweetenedbeverage tax, because it is a large and demographically diverse city that is served by many different types of stores and chains. We base our analysis on a unique panel dataset that covers sales and prices of thousands of taxed and untaxed beverages at hundreds of stores ranging from small convenience stores to wholesale clubs in Philadelphia and its surrounding areas 2 We complement these data with local demographic information and hand-coded product-level nutritional information.

To fully understand the impact of the tax, we analyze its impact along various adjustment margins. The tax, which is levied at the distributor level, might not necessarily be passed through to consumers. Furthermore, consumers might substitute to untaxed beverages, or they might engage in tax avoidance by substituting purchases of sweetened drinks from Philadelphia stores to stores outside the taxed zone. The overall impact of the tax on nutritional intake as well as the ability to generate revenue depends on these various margins of adjustment. Therefore, to paint a complete picture of the impact of the tax, we analyze price and demand responses for taxed products, as well as substitutes in geographic and product space. Our analysis is based on a difference-in-differences framework that compares changes before and after the tax took effect in Philadelphia relative to a control group of stores outside of Philadelphia (we only include stores located at least 6 miles outside Philadelphia in the control group) $!^{3}$

Several key findings emerge from our analysis: (1) The tax is passed through at an average rate of $97 \%$, which corresponds to a $34 \%$ price increase. (2) The large increase in prices leads to a $46 \%$ reduction in the quantity purchased of taxed beverages in Philadelphia. However, over half of this reduction is offset by an increase in quantity purchased at stores up to 6 miles outside of

\footnotetext{
${ }^{1}$ The Cook County, IL, tax went into effect in August 2017 and was repealed four months later in December 2017.

${ }^{2}$ Our data do not cover point-of-consumption sales such as restaurants and bars.

${ }^{3}$ We provide evidence later in this paper that this distance threshold is appropriate.
} 
the city border. After taking into account cross-shopping, we find that net sales of taxed beverages only fell by $22 \%$. (3) We find no significant change in demand for bottled water, but a modest increase in sales of untaxed natural juices. Within the set of taxed products, demand decreases more for relatively healthier products, though the differential change in sales for healthier taxed products is not statistically significant. Due to the compositional changes in the demand for beverages, calories and sugars decrease by only $16 \%$ and $15 \%$ respectively, but these effect sizes are not statistically distinguishable from the $22 \%$ reduction in total quantity. (4) Purchase quantity decreases less in low-income neighborhoods, most likely because low income households are less likely to engage in cross-shopping. This explanation is supported by several data patterns, such as lower car ownership rates and a lower share of residents that commute outside of the city for work in low income neighborhoods.

Next, based on our estimates of demand elasticities and the pass-through rate, we analyze changes in tax policy design. We show that the current tax rate of 1.5 cents/oz is close to the revenue-maximizing tax rate, but a slightly higher tax rate of 2 cents/oz would lower sales of unhealthy taxed beverages at a modest cost in terms of tax revenue. The initially proposed rate of 3 cents/oz would have drastically shrunk tax revenue by $70 \%$ relative to the current tax rate. We also investigate the impact of eliminating cross-shopping by broadening the geographic coverage of the tax. We find that applying the tax to a larger geographical area has the potential to raise more tax revenue and at the same time lower the sales of taxed beverages. Thus, limiting cross-shopping by expanding the geographic coverage enhances the health and revenue benefits of the tax.

We draw several lessons from these analyses about the effectiveness of the Philadelphia tax and localized soda taxes more generally. First, the tax's effectiveness at reducing consumption of unhealthy products is hindered by tax avoidance through cross-shopping and compositional changes in demand toward relatively less healthy products. Second, geographic substitution to stores outside of Philadelphia also limits the tax's revenue generation capabilities. These findings undermine the position often taken by advocates of soda taxes, that they are a win-win because the city earns tax revenue if consumers keep buying, or consumers obtain health benefits if they reduce consumption. Third, we find that low income households are less likely to engage in tax avoidance via cross-shopping, potentially due to their limited access to transportation. While an analysis of consumer welfare across different income groups is outside of the scope of this paper, this finding highlights an important behavioral difference between low and high income households in how they react to a localized tax.

Our work contributes to an emerging literature at the intersection of marketing, economics, and health policy (e.g. Khan et al. (2016), Wang et al. (2016), Kim and KC (2019), Tuchman (2019)). More specifically, our paper fits into a stream of research that seeks to evaluate the effects of soda taxes on consumption decisions, firm pricing, and consumer health. A first set of papers relevant to our analysis are studies that use structural models and pre-tax data to predict the impact of a (hypothetical) soda tax (Wang (2015), Kifer (2015), Dubois et al. (2017), Allcott 
et al. (2019b) $) .4$ These papers vary in their estimated demand elasticities and their assumptions with regard to pass-through, and hence they differ in their conclusions about the effectiveness of soda taxes. A second set of studies analyzes the impact of soda taxes after their implementation. Within the US context, the most well-studied tax is the one implemented in Berkeley in 2014.5 A series of papers studies price pass-through and quantity reaction using manually collected prices (Falbe et al. (2015), Cawley and Frisvold (2017)), survey-based measures of consumption (Falbe et al. (2016)), and scanner data on prices and quantities sold (Silver et al. (2017), Rojas and Wang (2017), Bollinger and Sexton (2018)). They find pass-through rates between 25\% and $47 \%$ depending on the data source and methodology employed ${ }^{6}$ With regard to the estimated quantity reduction, the effect is small and insignificant in some studies and as large as $21 \%$ in others. In the case of Boulder, Cawley et al. (2018a) document a somewhat higher pass-through rate of $81 \%$. More recently, several studies focus on evaluating the soda tax in Philadelphia. Some early studies use manually collected prices and consumption surveys (Cawley et al. (2018c), Cawley et al. (2020), Cawley et al. (2018b)). In line with our findings, these papers find the tax is fully passed through, but they find no significant reduction in demand at stores in Philadelphia.

Compared to studies of the Berkeley tax and papers using surveys or hand-collected prices, our retail scanner data from Philadelphia provide a particularly rich setting to study the impact of a soda tax. Our data contain a large set of 357 stores from 11 different chains in Philadelphia (compared to the 10 stores from three chains in the Nielsen-Kilts store-level data for Berkeley), and our data cover all beverages sold at these stores. In addition, our data is representative of the universe of traditional retail stores in terms of geographic and format coverage (see Appendix A). Moreover, Philadelphia is a large and demographically diverse city. Both aspects together allow us to explore heterogeneity across stores, chains, and consumer demographics in more detail. Finally, Philadelphia represents a useful testbed for studying soda taxes, because its demographic composition is similar to the US average. Sixty-eight percent of Philadelphia's 1.5 million residents are considered overweight or obese (CDC (2013)), which is close to the rate of $66 \%$ for the entire US and much higher than the rate of $36 \%$ in Berkeley 7

A recent paper by Roberto et al. (2019) also uses store scanner data to analyze the impact of Philadelphia's soda tax on prices and volume sales. However, unlike our paper, it does not consider policy-relevant issues such as nutritional outcomes (Section 5) and the differential impact of the tax across income groups (Section 6), nor does it analyze the implications for tax policy design (Section

\footnotetext{
${ }^{4}$ Khan et al. (2016) and Griffith et al. (2018) apply a similar approach to analyze the impact of a tax on fat content.

${ }^{5}$ Another set of papers study soda taxes outside of the US. Grogger (2017), Aguilar et al. (2016), and Colchero et al. (2017) investigate the effects of SSB taxes in Mexico. Berardi et al. (2016) and Bergman and Hansen (2017) analyze soda taxes in France and Denmark. Relative to the more localized taxes in the US, the national implementation of these taxes makes inference more difficult because there is no obvious control group of stores that are unaffected by the tax.

${ }^{6}$ The studies based on scanner data are based on a larger set of products but a smaller set of stores. These differences in coverage might explain the differences in measured pass-through rates.

${ }^{7}$ City of Berkeley, "Health Status Report", City of Berkeley Public Health Division (2013). https://www.cityofberkeley.info/Health_Human_Services/Public_Health/2013_Health_Status_Report.aspx. accessed on January 20, 2018.
} 
7). Moreover, many of this paper's key findings differ substantially from ours and lead to different conclusions with regard to the effectiveness of the tax. Roberto et al. (2019) observe a more limited set of stores (grocery stores, mass merchants, and drug stores) and only analyze substitution to stores in Pennsylvania within 3 miles outside of the city border. Our cross-shopping effects are twice as large as theirs because our analysis allows for (and finds evidence of) cross-shopping at stores up to 6 miles outside of Philadelphia in both Pennsylvania and New Jersey. Roberto et al. (2019) also estimate a smaller price increase of $12 \%$ to $24 \%$ depending on store format, whereas we find a larger price change of $34 \%$, which corresponds to a $97 \%$ pass-through rate and is in line with the evidence from manually collected prices (Cawley et al. (2020)). Differences in estimates of both price and quantity response lead to drastically different elasticities (net of cross-shopping) of -1.7 in Roberto et al. (2019) relative to -0.6 in our analysis. In Appendix B, we provide a detailed comparison of our papers which decomposes the impact of various modeling choices and differences in the underlying data on the empirical results.

As mentioned above, our paper contributes to a burgeoning literature that studies questions at the intersection of marketing and health policy such as a fat tax (Khan et al. (2016)) and restrictions on advertising for hospitals (Kim and KC (2019)) and nicotine products (Tuchman (2019) and Wang et al. (2016)). This literature studies consumers' reactions to marketing causal variables (price and advertising) and considers the implications for consumers, firms, and regulators. Our analysis is also related to the extensive marketing literature on retail pass-through (e.g. Ailawadi and Harlam (2009), Besanko et al. (2005), McShane et al. (2016), Nijs et al. (2010), , as well as the literature on store choice and consumer search (e.g. Mojir and Sudhir (forthcoming), Yavorsky et al. (2020)). Finally, our paper is related to the literature on various other sin taxes such as taxes on alcohol (e.g. Conlon and Rao (2015), Conlon and Rao (2020), Miravete et al. (2017), Miravete et al. (2018)), cigarettes (e.g. Lovenheim (2008), Merriman (2010), Harding et al. (2012)), and cannabis (e.g. Jacobi and Sovinsky (2016), Hollenbeck and Uetake (2018)). Within this broader literature, our analysis is particularly relevant to the analysis of tax pass-through (Conlon and Rao (2020), Hollenbeck and Uetake (2018), Miravete et al. (2018)) and tax avoidance through cross-shopping (Ferris (2000), Asplund et al. (2007), Lovenheim (2008), Merriman (2010)).

The rest of this paper is organized as follows. In section 2, we provide additional details on the tax's implementation, and in section 3 , we describe the data and provide descriptive statistics. Section 4 presents the empirical approach and provides results for the impact of the tax on prices and quantities of taxed and untaxed products, and on cross-shopping behavior. In Sections 5 and 6 we analyze the impact on nutritional intake and the differential impact of the tax across different income groups. Section 7 compares our results to other studies of US soda taxes and discusses the implications of our findings for the design of soda taxes. Section 8 concludes. 


\section{Institutional Context}

In March 2016, Philadelphia Mayor Jim Kenney proposed a tax of 3 cents per ounce on sweetened beverages. After months of debate, the Philadelphia City Council voted on a scaled-down version of the tax in June 2016, and approved it with a vote of 13-4. A tax of 1.5 cents per ounce went into effect on January 1, 2017. According to a spokeswoman for the mayor, Kenney's primary reason for proposing the tax was to raise tax revenue, but she noted that the tax could also bring health benefits if it reduces the consumption of sweetened beverages (Esterl (2016)). In Philadelphia, pre-implementation projections predicted the tax would raise $\$ 92$ million in tax revenue in 20178 In practice, the city collected $\$ 79$ million in 2017 , falling short of the projection.

In terms of implementation, the tax is structured as a tax of 1.5 cents per ounce, which, for example, amounts to a tax of $\$ 1.01$ on a 2-liter bottle. In our data, the average pre-tax price of a 2-liter of soda in Philadelphia is $\$ 1.56$; thus, the tax is equal to almost two thirds of the pre-tax price of this product. Note that the tax is levied on distributors, not directly on consumers. Thus, the extent to which consumers feel the tax depends on how much of the tax is passed through the supply chain. Finally, Philadelphia's tax applies to both sugar-sweetened and artificially-sweetened beverages. Thus, both diet and regular soft drinks are taxed, as well as pre-sweetened coffee and tea drinks, sports drinks, energy drinks, and non-100\% fruit drinks that contain a caloric sweetener or non-nutritive sweetener 9

The decision to tax artificially sweetened beverages might seem surprising. From a health perspective, if the goal is to reduce calories consumed, taxing diet drinks that are a close substitute to SSBs could be counter-productive. In the case of Philadelphia, the mayor's office has acknowledged the primary purpose of the tax is to raise tax revenue, and hence the decision to include artificially-sweetened drinks was likely driven by financial motivations. Many other municipalities that introduced similar taxes (several Bay Area cities, Boulder, CO, and Seattle, WA) only tax drinks with caloric sweeteners.

\section{Data}

We analyze retail point-of-sale data collected by IRI, a large market-research firm. ${ }^{10}$ We supplement these data with nutrition information on products and demographic data. Each of these datasets is described in more detail below.

\footnotetext{
${ }^{8}$ The funds are earmarked to go to pre-K education programs, community schools, and improvements to parks, libraries, and recreation centers.

${ }^{9}$ Examples of caloric sweeteners include cane sugar, high fructose corn syrup, and honey. Examples of non-nutritive sweeteners include stevia, aspartame, sucralose, or saccharin. Drinks that are exempt from the tax include alcoholic beverages, beverages that are $100 \%$ juice, and drinks that are more than $50 \%$ milk by volume.

${ }^{10}$ IRI and the Nielsen Company are the two major producers of retail point-of-sale data in the US. Both companies compile price, sales and item description data from the scanner systems of cooperating retail outlets.
} 


\subsection{Data sources}

Retail Point-of-Sale Data The data cover the period from January 2015 through September 2018 and contain information on prices ${ }^{11}$ and quantity sold at the UPC/store/week level. We obtained data for all beverage categories, including untaxed beverages, which constitute potential substitutes. We observe the location and chain affiliation for each store 12 We focus our analysis on stores located in the city of Philadelphia and the four 3-digit ZIP codes that surround Philadelphia. We restrict the sample to stores that (i) entered the panel before January 1, 2016, and were tracked through at least December 31, 2017, and (ii) that belong to one of the 11 chains / groups of stores that operate stores both within the city and outside of the city. Our final dataset includes 357 stores located in Philadelphia and 870 stores located in the surrounding area around Philadelphia 13 Panel B of Table 1 lists the types of stores (grocery stores, drugstores, etc.) covered in our data and the number of stores observed for each chain. Figure 1 shows the geographic location of all stores. Philadelphia stores are shown in blue, whereas stores 0-6 miles outside the city limits are shown in green, and stores more than 6 miles outside the city are shown in red. More detailed descriptive statistics are provided in the next section.

At the most granular level, the data record sales at the UPC/store/week level. Across all stores and weeks, we observe a total of 17,582 individual UPCs due to the fact that many products are sold in various pack sizes and flavors. In our empirical analysis, we use data at a higher level of aggregation. We define a product as a brand/diet-status/pack-size combination and aggregate the UPC-level data up to this level, calculating total units sold and quantity-weighted prices at the product/store/week level. Thus, different flavors of the same brand (e.g., Cherry Coke and Vanilla Coke) are aggregated together ${ }^{14}$ After dropping infrequently purchased products for which prices are often missing, we are left with a total of 861 products (489 taxed and 372 untaxed) 15 We then further aggregate the data from the product/store/week level to the tax-status/store/week level. That is, we compute total quantity sold and average price separately for all taxed products and all untaxed products. We compute tax-status/store/week-level prices as a weighted average

\footnotetext{
${ }^{11}$ We compared our pricing data to a sample of manually collected prices in Philadelphia stores in order to verify that the price recorded in our data does include the tax. We found this to be the case for all but one retailer. At this retailer, the shelf price does include the tax, but the checkout receipt reports the tax as a separate line item. Consequently the IRI data records price net of the tax for this retailer (see Appendix C for more details and sample receipts). In order to recover this retailer's shelf price, which is the effective price paid, we add the 1.5 cents/oz tax to the prices recorded in our data for this retailer beginning in January 2017. We were able to discover this price difference because we observe retailer identities, which are typically unavailable for researchers working with IRI or similar data.

${ }^{12}$ For most stores, we observe the exact street address of each store and the exact chain affiliation. For the remaining stores, we only observe the location at the 5-digit ZIP-code level and the retailer type (Mass Merchant, Dollar Store, or Convenience Store). For the latter set of stores, we assume they are located at the centroid of their ZIP code. In Appendix $\mathrm{D}$ we show that our findings are not sensitive to measurement error that might arise from imprecise location data. When performing analyses at the chain level, we treat the unidentified mass merchants, dollar stores, and convenience stores as separate groups. We anonymize the chain affiliation per the request of our data provider.

${ }^{13}$ We provide details on how we select stores and UPCs in Appendix E

${ }^{14}$ Different flavors of the same brand are typically priced uniformly, and hence little information is lost when aggregating prices at this level.

${ }^{15}$ See Appendix E for details regarding the data cleaning.
} 


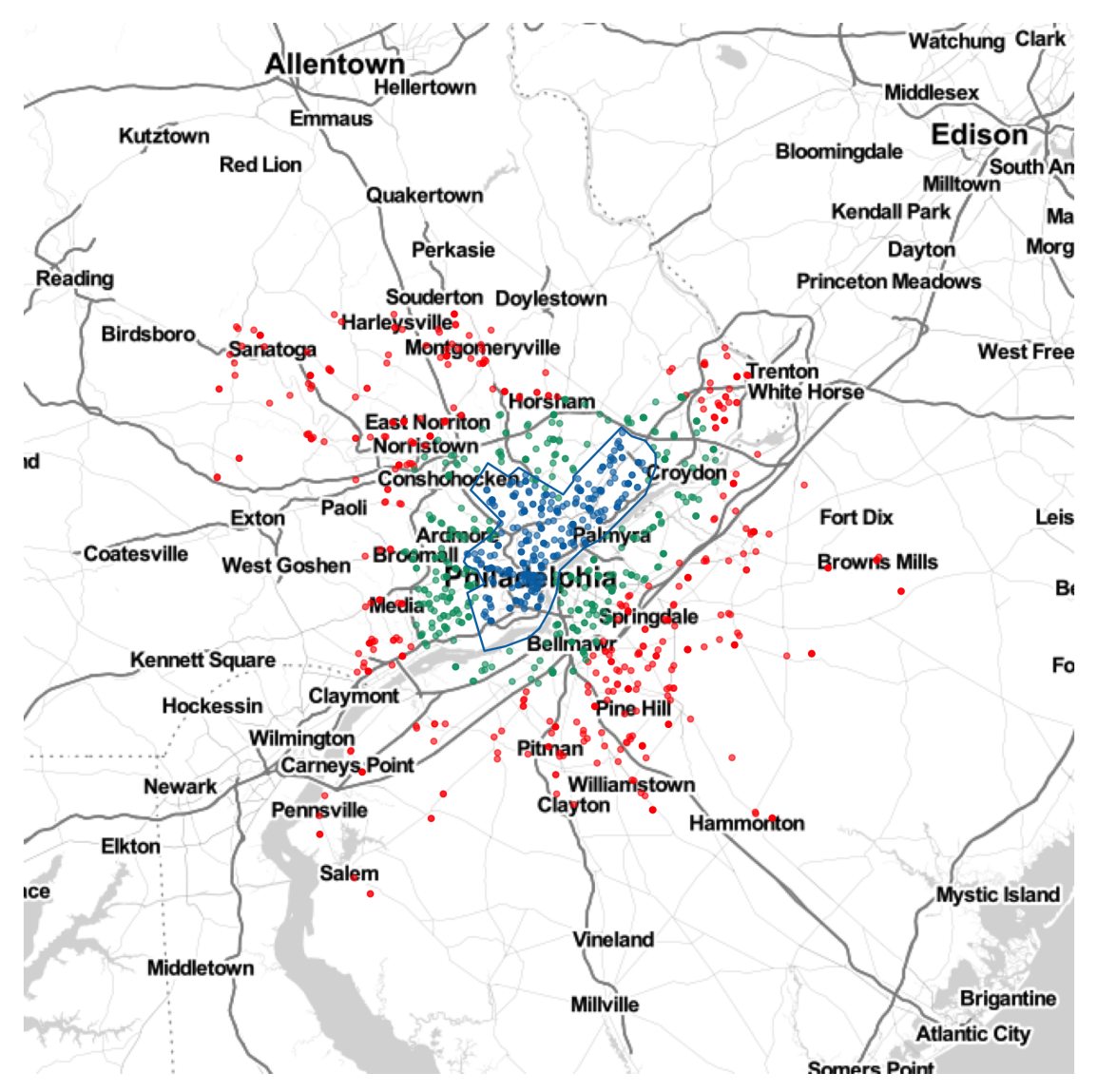

Figure 1: Stores Within and Outside of Philadelphia.

of product-level prices, where the weights are equal to market shares (in terms of total ounces sold) of products at each store in the pre-tax period. Total volume sold is obtained by aggregating product/store/week-level volume up to the tax-status/store/week level. When analyzing heterogeneity in the response to the tax, we separately compute (at the store/week level) average prices and total sales volume for different product pack sizes, for products with different calorie and sugar content, for individual categories (e.g., soda, energy drinks, etc.), and for different store formats.

Finally, we note that IRI does not track the full universe of stores in Philadelphia, but it does track a relatively large share of stores. In Appendix A, we show that the set of stores in our data is representative along key dimensions, namely, geographic coverage and coverage across different store formats. However, although our sample is representative with regard to retail formats and geographic coverage, the tax also affects sales of sweetened beverages at restaurants and vending machines which are not covered in our data 16 Our data also does not include sales of fountain drinks at retail stores. Based on publicly reported tax revenues (which are proportional to ounces

\footnotetext{
${ }^{16}$ The impact of the tax in the retail sector is likely to be different from the impact on restaurants. For instance, we find a large degree of cross-shopping at stores outside of Philadelphia. The ability to purchase large quantities and stockpile products is specific to the retail sector and we would therefore expect geographic tax avoidance to be a relatively less important issue for the restaurant sector where beverages are purchased for immediate consumption. Pricing and purchase patterns for small pack-sizes, which tend to be for immediate consumption, are likely to be most similar to patterns we expect to find at restaurants.
} 
sold of taxed beverages), we calculate that our data covers $28 \%$ of sales of taxed beverages. Based on coverage rates (see Appendix A for more details), we estimate that the retail sector as a whole accounts for a market share of $40-50 \%$ of all sales of sweetened beverages ${ }^{17}$ Our analysis should be interpreted as measuring the effect of the tax on purchases made in the retail sector.

Demographic Data We supplement the store-level sales data with highly localized demographic data. These data allow us to determine the demographics of each store's catchment area and explore whether the response to the tax varies as a function of local population characteristics. We obtained data on median household income, car ownership, and commute patterns from the Census Bureau's 2011-2015 American Community Survey (ACS), and data on obesity rates from the CDC (Manson et al. (2017)) 18 Both datasets vary at the census-tract level 19 We focus on income and obesity as sociodemographic measures because (i) past work suggests income may be correlated with price sensitivity and preference for sweetened beverages (Wang (2015)) and (ii) because obesity data allow us to analyze whether the consumers who could reap the largest health benefits from reducing consumption actually do so. We use the car ownership and commuter patterns data as measures of transportation costs. We assign demographic profiles to individual stores by calculating average characteristics (income, obesity rate, car ownership rate, and commuter share) in each store's catchment area. To this end, we identify all census tracts that are within a 1-mile radius of each store in our data, and calculate (population-weighted) average demographics for each store.

Ingredient and Nutrition Data Finally, we manually collect ingredient and nutrition information on all taxed and untaxed products contained in the retail sales data.20 For each product, we search for the list of ingredients and the nutrition facts label on the manufacturer and retailers' websites, and we record grams of sugars and calories for each UPC in the data. These data serve two purposes. First, the retail sales data do not have a field that indicates whether each product is subject to Philadelphia's tax. We use the ingredients list to determine the taxed status of each

\footnotetext{
${ }^{17}$ Due to concerns around data privacy we are not able to report exact coverage rates and therefore only report a range for the retail sector market share.

${ }^{18}$ Regarding car ownership, the survey asks, "How many automobiles, vans, and trucks of one-ton capacity or less are kept at home for use by members of this household?" We define car ownership as having access to at least one vehicle. The commute data are collected in collaboration with the Department of Transportation. The survey asks respondents to report the location of their home and workplace. Accordingly, for every pair of census tracts in our data, we are able to extract an estimate of the number of inbound and outbound commuters. The CDC reports model-based estimates of obesity rates at the census-tract level as part of their 500 Cities Project. Further detail on the CDC's methodology is available in its report, "500 Cities Project: Local Data for Better Health. Philadelphia, PA. 2014" (CDC/NCCDPHP/DPH/ESB (2016)). Obesity data are only available for census tracts within the city of Philadelphia.

${ }^{19}$ The city of Philadelphia has 384 census tracts. Census tracts cover, on average, 4,000 people, with individual census tracts ranging between 2,500 and 8,000 inhabitants.

${ }^{20}$ We are not able to locate nutrition information for all products in the data. Private-label products are especially challenging because we do not observe the name of the private-label brand. We drop products from our analysis if we are unable to obtain their ingredients list in order to confirm whether they are subject to the tax (such products make up less than $2 \%$ of the market share). If we can confirm a product's taxed status, but are not able to find its exact nutrition information, we fill in the nutrition information for that product with the average across similar products produced by the same brand (such imputation is necessary for products that make up $4.8 \%$ of the market share).
} 

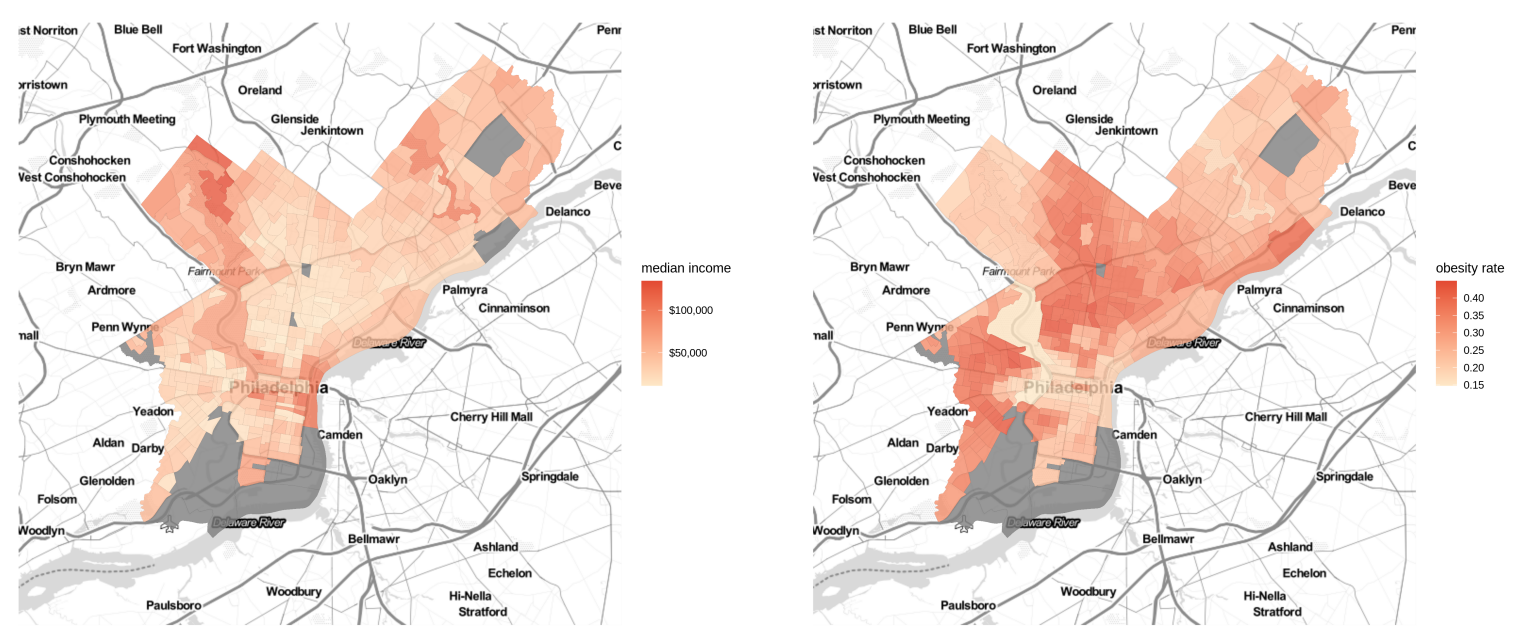

Figure 2: Variation in Income and Obesity Rates in Philadelphia. Grey regions indicate census tracts where no income and obesity information is recorded because there is little or no residential population.

product. Second, we use the nutrition data to evaluate the overall effect of the tax on sugar and calorie consumption.

\subsection{Descriptive Statistics}

Panel A in Table 1 provides descriptive statistics on the categories included in our data. As described earlier, despite the fact that the tax is often referred to as a "soda tax," it applies to all beverages that contain added sugar or an artificial sweetener (e.g., diet Mountain Dew made with sucralose and diet Snapple Peach Tea made with aspartame). We report market shares based on pre-tax sales in ounces in the first row of Panel A. Among taxed products, soda makes up about one third of all purchases, followed by juice and tea/coffee. Energy drinks, sports drinks, and taxed water (e.g., sweetened "Vitamin Water") make up a smaller market share. We provide a list of sample brands in each category at the bottom of Panel A. Notably, the three larger taxed categories are similar in terms of pricing and nutritional content. Sports drinks and taxed water are healthier and more expensive. Energy drinks are significantly more expensive.

Two types of beverages are not taxed. Out of those two, pure water constitutes the bulk of purchases in the pre-tax period. The second category is natural juices 21 They make up only $11 \%$ of untaxed beverage sales, but are notable because they contain similar amounts of sugar and more calories relative to taxed juices. In terms of overall market share, untaxed products are purchased slightly more frequently than taxed beverages.

Panel B in Table 1 describes the characteristics of different stores in our sample. These can broadly be divided into grocery stores, mass merchants, drugstores, and convenience stores. Two residual types of stores with smaller market shares are dollar stores and a wholesale club chain.

\footnotetext{
${ }^{21}$ Juice products from concentrate are included in this untaxed category as long as the sugar content is comparable to freshly extracted juice and no sweetener is added.
} 


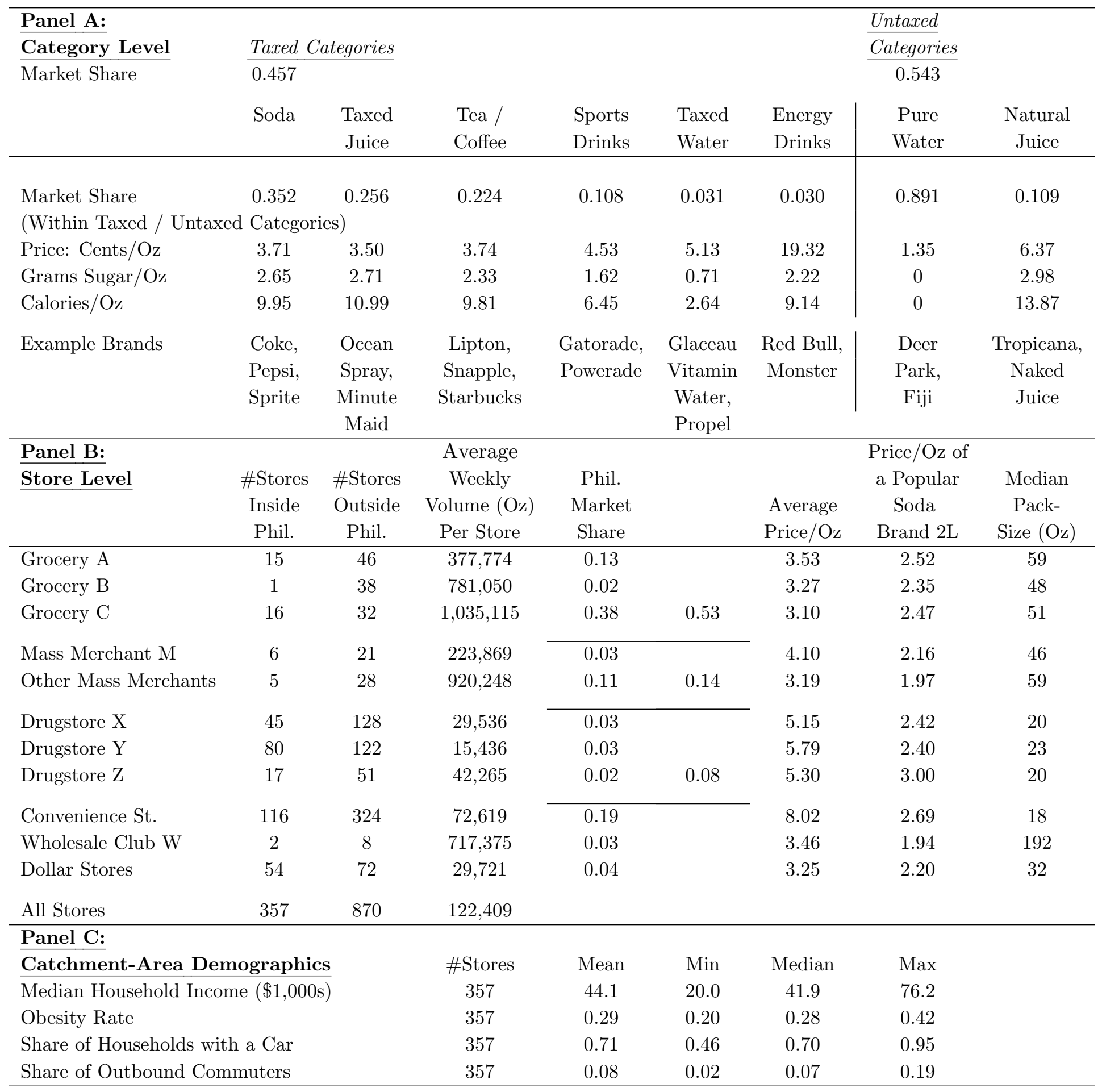

Table 1: Descriptive Statistics. Market shares and prices in Panels A and B are based on pre-tax data.

Each row in the table indicates an anonymized chain belonging to one of these categories of stores. As mentioned previously, the categories "other mass merchants," convenience stores, and dollar stores pool together stores with different chain affiliations and independent stores. The first two 
columns in the table report counts of stores within and outside the city of Philadelphia. The third column displays the average weekly volume per store of taxed beverages in the pre-tax period 22 and the fourth column reports total market share. Grocery stores, mass merchants, and the wholesale club all sell a relatively large volume on a per-store basis, and despite the fact that relatively fewer of these stores exist, these retail formats account for over two thirds of purchase volumes. Drugstores, dollar stores, and convenience stores sell a much lower volume per store. Due to the relatively larger number of stores, they jointly account for about $30 \%$ of sales. Finally, the average price per ounce is significantly higher in the smaller stores, largely because they tend to sell smaller pack sizes that are significantly more expensive on a per-unit basis. We illustrate this difference in assortment across store types in the final two columns of Panel B. These columns show that the price for the same product, in this case a 2-liter bottle of a popular soda brand, only differs marginally across stores, but the smaller stores tend to sell smaller pack sizes ${ }^{23}$

Finally, Panel C in Table 1 summarizes the variation in local demographics for the stores in Philadelphia. We see significant variation in income and obesity rates, as well as car ownership rates and the share of residents that commute to locations outside of Philadelphia. Income and obesity rates are highly correlated (corr. = -0.8). We provide some graphical evidence for this negative correlation in Figure 2. In Appendix F, we show most chains are present in neighborhoods with different income levels.

\section{Descriptive Graphical Evidence: Impact of the Tax on Price and Quantity Sold of} 2-Liter Bottles of a Popular Soda Brand As a precursor to the more systematic empirical analysis below, we illustrate the effect of the tax on price and quantity sold for one of the most popular products in our sample: a 2-liter bottle of a popular soda brand. The top graph in Figure 3 plots the average weekly prices of the product at stores in Philadelphia and surrounding control stores outside Philadelphia from January 2015 to September 2018. The product was priced at a similar level both within and outside the city before January 2017, and the weekly price series appear to be highly correlated. When the tax went into effect on January 1, 2017, the average price in the city increased significantly, while the price remained at a lower level in control stores outside the city 24 Correspondingly, the bottom graph of Figure 3 depicts the average weekly unit sales of the same product at stores in Philadelphia and control stores outside the city. The weekly unit sales inside and outside Philadelphia followed parallel trends over time before the tax. After January 1, 2017, unit sales experienced a substantial drop inside the city ${ }^{25}$

\footnotetext{
${ }^{22}$ Relative volume differences and market shares across chains / types of stores are similar for untaxed products.

${ }^{23}$ Many beverages are priced in a highly non-linear way. For example, a 2-liter (67.6 oz) bottle of Coca-Cola is often sold at the identical (or only marginally different) price as a 20-oz bottle.

${ }^{24}$ Prices continue to increase in the treatment group in the first four months after the tax is implemented. This pattern is visible in Figure 3 and also holds true on average across all taxed products. The pattern is driven by heterogeneity in adoption behavior across retailers. While some retail chains adjust prices immediately, others adjust with a delay or in a gradual fashion. In our main analysis we omit this four month adjustment period. In Appendix $\mathrm{G}$ we show that the price and quantity reaction to the tax is stable over time after the first four months.

${ }^{25}$ The bottom graph in Figure 3 shows the week-on-week variation in sales decreases in the post-tax period. We explore this pattern further in Appendix $\mathrm{H}$.
} 

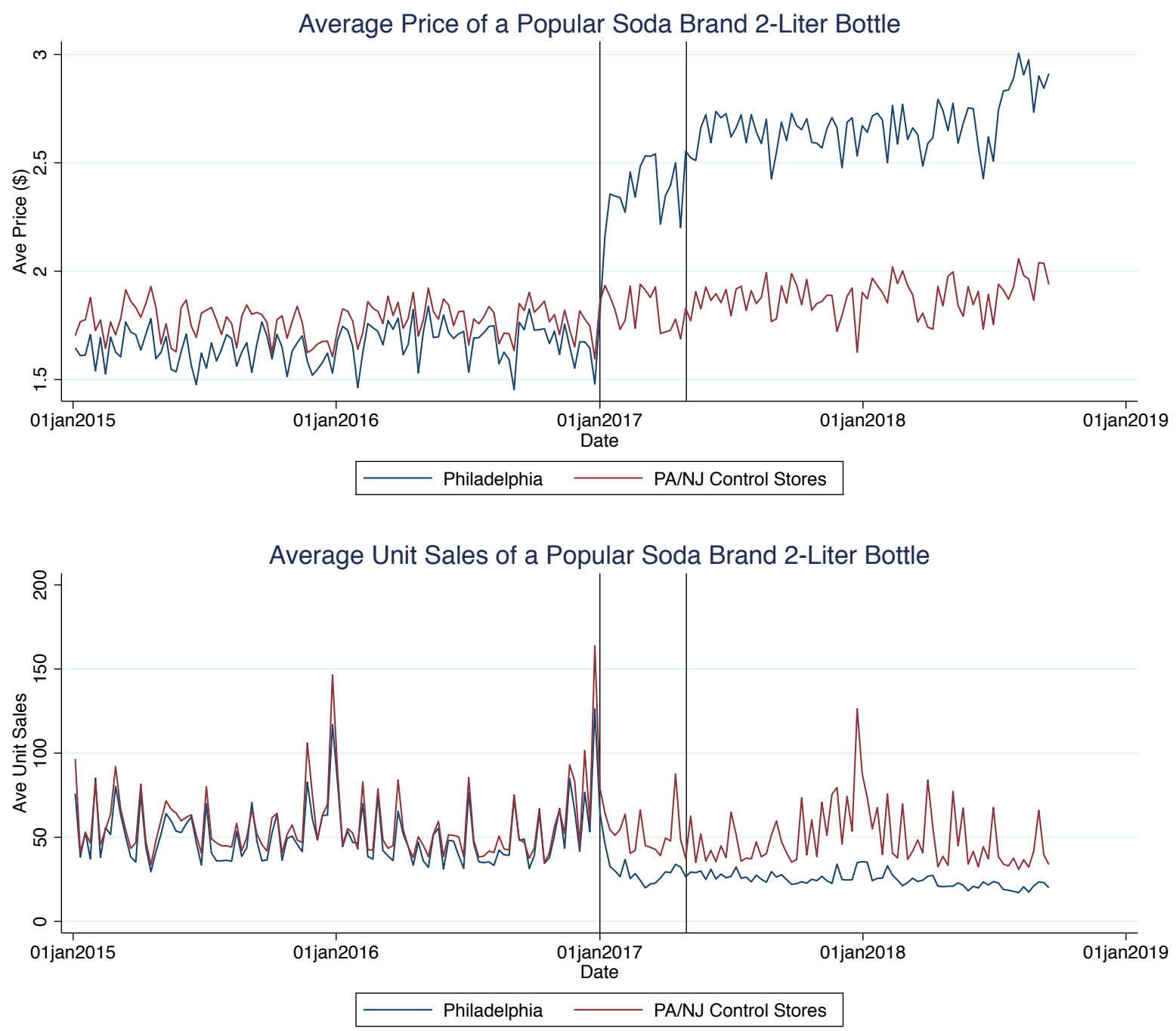

Figure 3: Unit Price and Sales of 2-Liter Bottles of a Popular Soda Brand. The black vertical lines indicate the tax's introduction and the end of the four month "adjustment period" that we omit from our main analyses (see Section 4 and Appendix G).

\section{Estimation and Results}

Our identification strategy is based on a difference-in-differences approach that compares the change in various outcome measures at stores in Philadelphia against stores in the surrounding 3-digit ZIP codes. In all regressions (unless stated otherwise), we only include stores that are located more than 6 miles away from the city limits in the control group (see Figure 1), to ensure the control group is not affected by the treatment through cross-shopping behavior. We later show 6 miles constitutes an appropriate choice of distance. Our choice of control group has two advantages. 
First, the control-group stores are relatively close to the city of Philadelphia and hence likely to experience similar demand shocks. For example, we expect our control group stores will experience similar weather patterns and similar surges in demand due to local events like sports games. In addition, all of our treatment and control group stores are located in the same television DMA and thus consumers in both groups will be exposed to the same TV advertising. In Appendix I. we provide supporting evidence for the validity of the parallel trends assumption based on pre-tax data. Second, choosing stores from a nearby area ensures the chain affiliations of stores in the city are represented in the control group. Therefore, we are able to use stores of the same chain outside of Philadelphia as a control group for stores of the same chain in the city.

Formally, we estimate regressions based on the following general structure:

$$
y_{s t}=\alpha\left(\text { Philly }_{s} \times \text { AfterTax }\right)+\gamma_{s}+\delta_{t}+\varepsilon_{s t},
$$

where the unit of observation is a store/week $(s, t)$ combination. $\gamma_{s}$ and $\delta_{t}$ are store and week fixed effects, and $\varepsilon_{s t}$ denotes the regression error. Phillys denotes a dummy that is equal to 1 if store $s$ is located in Philadelphia, and AfterTax $x_{t}$ is a dummy that is equal to 1 for any week after the tax went into effect. The difference-in-differences coefficient $\alpha$ is the main coefficient of interest. $y_{s t}$ denotes various outcome variables such as price, quantity sold, and so on.

We also explore heterogeneity in the impact of the tax along various dimensions such as chain identity, local demographics, and the competitive environment. To this end, we implement the following regression framework:

$$
\begin{aligned}
y_{s t}= & \tilde{\alpha}_{0}\left(\text { Philly }_{s} \times\right. \text { AfterTax } \\
& +\left(\text { AfterTax }_{t} \times \mathbf{X}_{s}\right)^{\prime} \tilde{\boldsymbol{\beta}}+\tilde{\gamma}_{s}+\tilde{\delta}_{t}+\tilde{\varepsilon}_{s t},
\end{aligned}
$$

where $\tilde{\gamma}_{s}$ and $\tilde{\delta}_{t}$ are store and week fixed effects and $\tilde{\varepsilon}_{s t}$ denotes the regression error. The vector $\mathbf{X}_{s}$ denotes a set of store characteristics, and $\tilde{\boldsymbol{\beta}}$ denotes a vector of coefficients capturing the change in the outcome in stores outside of Philadelphia after the tax took effect as a function of $\mathbf{X}_{s}$. The vector $\tilde{\boldsymbol{\alpha}}_{\mathbf{1}}$ captures the differential change in the outcome in Philadelphia stores relative to stores outside of the city as a function of $\mathbf{X}_{s}$. The coefficient $\tilde{\alpha_{0}}$ denotes the baseline, that is, an un-interacted, difference-in-differences estimate.26

We employ two-way clustered standard errors at the store and the week level in all regressions. In Appendix J, we show robustness to higher levels of clustering both along the geographic and time dimensions. Finally, we note a brief adjustment period during which price pass-through and the quantity decrease are slightly lower. After the first 4 months, the impact of the tax does not vary over time for any of the outcomes we analyze below ${ }^{27}$ We analyze these dynamic adjustment

\footnotetext{
${ }^{26}$ In some specifications below, we include an exhaustive set of dummies along a specific dimension, and hence no $\tilde{\alpha_{0}}$ term is included. Also, note that the estimation equation does not include "un-interacted" $\mathbf{X}_{s}$ terms because we include a full set of store dummies.

${ }^{27}$ We also test for differences in behavior in the months immediately before the tax, but find no evidence for behavioral changes during this time period. We therefore retain the entire pre-tax period in our sample. See
} 
patterns in detail in Appendix G. In our main regressions, we omit the first four months after the tax went into effect in order to focus on the impact of the tax after the initial adjustment.

We first analyze the impact of the tax on prices and quantities sold of taxed products. We then turn to analyzing substitution to untaxed beverages and to stores outside of Philadelphia, which are not subject to the tax.

\subsection{Price Reaction and Pass-Through}

To measure pass-through, we use price in cents/oz at store $s$ in week $t$ as the outcome measure. The difference-in-differences coefficient in this regression denotes the estimated price change in cents per ounce due to the tax. Remember the tax is equal to 1.5 cents per ounce. Hence, a coefficient of 1.5 would correspond to full pass-through, and dividing the coefficient by 1.5 yields the percentage pass-through rate. All results are based on the average price for all taxed products. Results from the base specification in equation (1) are reported in column (1) of Table 2 and show an average pass-through of 1.45 cents per oz, corresponding to a $97 \%$ average pass-through rate. Relative to an average pre-tax price of 4.26 cents/oz, this pass-through rate constitutes a $34 \%$ increase in price.

Next, we explore heterogeneity by allowing the pass-through coefficient to differ along various dimensions. In column (2) of Table 2, we report results from a regression that includes interactions of the after-tax dummy times the Philadelphia dummy with a full set of of chain dummies for the 11 different chains / groups of stores in our sample ${ }^{28}$ We find pass-through rates are fairly consistent across chains. Apart from two exceptions, the increase in price per ounce lies between 1.16 and 1.78 (77\% and 119\% pass-through). Mass Merchant $\mathrm{M}$ and Drugstore $\mathrm{Z}$ have significantly smaller passthrough rates ${ }^{29}$ and overall mass merchandisers have a lower pass-through rate than other retail formats. Column (3) shows the same regression using the log of price per ounce as the dependent variable. The pass-through rate documented in column (2) translates into a 30\%-40\% price increase in most stores. The price increase in percentage terms is somewhat lower in convenience stores and drugstores, despite a similar pass-through rate. This difference in the price increase occurs because those retail formats tend to sell smaller pack sizes, which, on average, have a higher price per ounce (see the last column in Table 1, Panel B). We note that due to large coefficient values in the log specifications in columns (3) - (6), applying the transformation $\exp ($ coefficient $)-1$ is necessary to obtain the percentage change. When discussing percentage results in the paper, we always apply this transformation 30

\footnotetext{
Appendix G for details.

${ }^{28}$ To simplify exposition, we do not report the coefficient vector $\tilde{\boldsymbol{\beta}}$ pertaining to $\left(\right.$ AfterTax $\left.x_{t} \times \mathbf{X}_{s}^{\prime}\right)$ terms for any of the regressions in columns (2) - (6) of Table 2 .

${ }^{29}$ The two chains jointly make up less than $5 \%$ of market share. Mass Merchant $\mathrm{M}$ and Drugstore $\mathrm{Z}$ pass the tax through only for soda, and not for other taxed categories. Furthermore, Drugstore Z initially does not increase soda prices and then increases them by approximately 1 cent per ounce in late May 2017.

${ }^{30}$ For example, the estimated effect for Grocery A in column (3) corresponds to a $37.3 \%$ change: $\exp (0.317)-1=$ $37.3 \%$.
} 


\begin{tabular}{|c|c|c|c|c|c|c|}
\hline & (1) & $(2)$ & (3) & (4) & $(5)$ & (6) \\
\hline Dependent & & & $\log$ & $\log$ & $\log$ & $\log$ \\
\hline Variable & Price/Oz & Price/Oz & Price/Oz & Price/Oz & Price/Oz & Price/Oz \\
\hline Philadelphia $\times$ AfterTax & $\begin{array}{c}1.449^{* * *} \\
(0.022)\end{array}$ & & & & & \\
\hline $\begin{array}{l}\text { Grocery A } \\
\times \text { Philadelphia } \times \text { AfterTax }\end{array}$ & & $\begin{array}{c}1.355^{* * *} \\
(0.018)\end{array}$ & $\begin{array}{c}0.317^{* * *} \\
(0.008)\end{array}$ & $\begin{array}{c}0.326^{* * *} \\
(0.011)\end{array}$ & $\begin{array}{c}0.332^{* * *} \\
(0.009)\end{array}$ & $\begin{array}{c}0.308^{* * *} \\
(0.008)\end{array}$ \\
\hline $\begin{array}{l}\text { Grocery B } \\
\times \text { Philadelphia } \times \text { AfterTax }\end{array}$ & & $\begin{array}{c}1.290^{* * *} \\
(0.005)\end{array}$ & $\begin{array}{c}0.320^{* * *} \\
(0.001)\end{array}$ & $\begin{array}{c}0.332^{* * *} \\
(0.009)\end{array}$ & $\begin{array}{c}0.330^{* * *} \\
(0.004)\end{array}$ & $\begin{array}{c}0.311^{* * *} \\
(0.003)\end{array}$ \\
\hline $\begin{array}{l}\text { Grocery C } \\
\times \text { Philadelphia } \times \text { AfterTax }\end{array}$ & & $\begin{array}{c}1.780^{* * *} \\
(0.051)\end{array}$ & $\begin{array}{c}0.442^{* * *} \\
(0.011)\end{array}$ & $\begin{array}{c}0.450^{* * *} \\
(0.012)\end{array}$ & $\begin{array}{c}0.450^{* * *} \\
(0.012)\end{array}$ & $\begin{array}{c}0.424^{* * *} \\
(0.012)\end{array}$ \\
\hline $\begin{array}{l}\text { Mass Merchant M } \\
\times \text { Philadelphia } \times \text { AfterTax }\end{array}$ & & $\begin{array}{c}0.655^{* * *} \\
(0.122)\end{array}$ & $\begin{array}{c}0.144^{* * *} \\
(0.027)\end{array}$ & $\begin{array}{c}0.151^{* * *} \\
(0.031)\end{array}$ & $\begin{array}{c}0.156^{* * *} \\
(0.027)\end{array}$ & $\begin{array}{c}0.131^{* * *} \\
(0.029)\end{array}$ \\
\hline $\begin{array}{l}\text { Other Mass Merchants } \\
\times \text { Philadelphia } \times \text { AfterTax }\end{array}$ & & $\begin{array}{c}1.155^{* * *} \\
(0.011)\end{array}$ & $\begin{array}{c}0.308^{* * *} \\
(0.005)\end{array}$ & $\begin{array}{c}0.315^{* * *} \\
(0.008)\end{array}$ & $\begin{array}{c}0.319^{* * *} \\
(0.006)\end{array}$ & $\begin{array}{c}0.295^{* * *} \\
(0.005)\end{array}$ \\
\hline $\begin{array}{l}\text { Drugstore X } \\
\times \text { Philadelphia } \times \text { AfterTax }\end{array}$ & & $\begin{array}{c}1.492^{* * *} \\
(0.038)\end{array}$ & $\begin{array}{c}0.258^{* * *} \\
(0.009)\end{array}$ & $\begin{array}{c}0.266^{* * *} \\
(0.011)\end{array}$ & $\begin{array}{c}0.271^{* * *} \\
(0.010)\end{array}$ & $\begin{array}{c}0.247^{* * *} \\
(0.009)\end{array}$ \\
\hline $\begin{array}{l}\text { Drugstore } Y \\
\times \text { Philadelphia } \times \text { AfterTax }\end{array}$ & & $\begin{array}{c}1.377^{* * *} \\
(0.025)\end{array}$ & $\begin{array}{c}0.216^{* * *} \\
(0.006)\end{array}$ & $\begin{array}{c}0.224^{* * *} \\
(0.009)\end{array}$ & $\begin{array}{c}0.226^{* * *} \\
(0.007)\end{array}$ & $\begin{array}{c}0.200^{* * *} \\
(0.007)\end{array}$ \\
\hline $\begin{array}{l}\text { Drugstore Z } \\
\times \text { Philadelphia } \times \text { AfterTax }\end{array}$ & & $\begin{array}{c}0.342^{* * *} \\
(0.031)\end{array}$ & $\begin{array}{c}0.062^{* * *} \\
(0.006)\end{array}$ & $\begin{array}{c}0.072^{* * *} \\
(0.010)\end{array}$ & $\begin{array}{c}0.072^{* * *} \\
(0.007)\end{array}$ & $\begin{array}{c}0.048^{* * *} \\
(0.007)\end{array}$ \\
\hline $\begin{array}{l}\text { Wholesale Club } \\
\times \text { Philadelphia } \times \text { AfterTax }\end{array}$ & & $\begin{array}{c}1.398^{* * *} \\
(0.013)\end{array}$ & $\begin{array}{c}0.336^{* * *} \\
(0.003)\end{array}$ & $\begin{array}{c}0.349^{* * *} \\
(0.011)\end{array}$ & $\begin{array}{c}0.346^{* * *} \\
(0.005)\end{array}$ & $\begin{array}{c}0.326^{* * *} \\
(0.006)\end{array}$ \\
\hline $\begin{array}{l}\text { Dollar Stores } \\
\times \text { Philadelphia } \times \text { AfterTax }\end{array}$ & & $\begin{array}{c}1.557^{* * *} \\
(0.032)\end{array}$ & $\begin{array}{c}0.389^{* * *} \\
(0.007)\end{array}$ & $\begin{array}{c}0.397^{* * *} \\
(0.010)\end{array}$ & $\begin{array}{c}0.396^{* * *} \\
(0.007)\end{array}$ & $\begin{array}{c}0.369^{* * *} \\
(0.010)\end{array}$ \\
\hline $\begin{array}{l}\text { Convenience Stores } \\
\times \text { Philadelphia } \times \text { AfterTax }\end{array}$ & & $\begin{array}{c}1.626^{* * *} \\
(0.032)\end{array}$ & $\begin{array}{c}0.183^{* * *} \\
(0.003)\end{array}$ & $\begin{array}{c}0.192^{* * *} \\
(0.008)\end{array}$ & $\begin{array}{c}0.194^{* * *} \\
(0.006)\end{array}$ & $\begin{array}{c}0.170^{* * *} \\
(0.004)\end{array}$ \\
\hline \multicolumn{2}{|c|}{$\begin{array}{l}\text { Distance (in Miles) to Nearest Untaxed Store } \\
\times \text { Philadelphia } \times \text { AfterTax }\end{array}$} & & & $\begin{array}{l}-0.004 \\
(0.003)\end{array}$ & & \\
\hline $\begin{array}{l}\text { Income } \\
\times \text { Philadelphia } \times \text { AfterTax }\end{array}$ & & & & & $\begin{array}{c}-0.024^{* * *} \\
(0.008)\end{array}$ & \\
\hline $\begin{array}{l}\text { Obesity Rate } \\
\times \text { Philadelphia } \times \text { AfterTax }\end{array}$ & & & & & & $\begin{array}{c}0.033^{* * *} \\
(0.009)\end{array}$ \\
\hline$\left(\text { AfterTax }_{t} \times \mathbf{X}_{s}\right)^{\prime}$ Interactions & $\mathrm{n} / \mathrm{a}$ & Yes & Yes & Yes & Yes & Yes \\
\hline Store FE & Yes & Yes & Yes & Yes & Yes & Yes \\
\hline Week FE & Yes & Yes & Yes & Yes & Yes & Yes \\
\hline Observations & 144,700 & 144,700 & 144,700 & 144,700 & 144,700 & 144,700 \\
\hline Stores & 832 & 832 & 832 & 832 & 832 & 832 \\
\hline Weeks & 176 & 176 & 176 & 176 & 176 & 176 \\
\hline
\end{tabular}

Table 2: Impact on Prices and Pass-through Rate Estimates. Interactions with an aftertax dummy (the $\left(A f t e r T a x_{t} \times \mathbf{X}_{s}^{\prime}\right)$ term) are included in columns (2) - (6), but not reported separately. One exception is the obesity variable in column (6). We have no obesity data outside of Philadelphia and hence no $\left(\right.$ Obesity $_{s} \times$ AfterTax $)$ term is included. 
In the remaining columns of Table 2, we explore other factors that may drive within-chain variation in pass-through. In column (4), we investigate whether the competitive environment affects pass-through. To analyze the reaction to a change in the competitive environment, we analyze whether the distance to the nearest untaxed store outside of Philadelphia predicts price changes. We show later that stores outside of Philadelphia which are not subject to the tax do not adjust prices after the tax and therefore the tax generates a large price-wedge between stores inside Philadelphia and outside of the city ${ }^{31}$ As a simple measure of competition, we therefore include the distance to the nearest untaxed store (with the appropriate interactions) in the regression. We find the distance to the nearest untaxed store does not predict a differential price reaction, and the estimated coefficient is small in magnitude.

In the final two columns of Table 2, we investigate whether income and obesity rates in the store's catchment area (1-mile radius around the store) are predictive of pass-through. To facilitate interpretation, we use re-scaled versions of the income and obesity variables that range from 0 to 1 across all stores in Philadelphia. We find that prices increase more in low-income and high-obesity areas ${ }^{32}$ Hence, from a health policy point of view, one might be encouraged by the higher increase in high-obesity areas. On the other hand, the differential price increase suggests that low-income households need to pay a relatively higher price to purchase taxed beverages. Further, although both coefficients are statistically significant, they are relatively small in magnitude 33

In summary, we find some heterogeneity in pass-through across chains, the competitive environment does not predict differential pass-through, and local demographics explain a small part of the variation in pass-through across store locations 34

\subsection{Quantity Reaction}

Next, we analyze changes in quantity sold after the tax. As in the previous section, we use the framework outlined in equations (1) and (2), but use quantity sold (measured in ounces) as the dependent variable. The first column of Table 3 shows an average decrease of 56,000 ounces per store in the total volume of taxed beverages that were sold in Philadelphia. This effect is large in magnitude and constitutes a $46 \%$ reduction relative to the average pre-tax level of weekly sales of 122,000 ounces per store (see Panel B in Table 1).

\footnotetext{
${ }^{31}$ We prefer this metric to other measures of competition, such as the number of nearby stores, because the latter measures differences in competition that exist before and after the tax. In contrast, our metric captures changes in the competitive environment. We did also estimate regressions using the number of competing stores within a certain radius (we consider radii of $1,2,3$, and 4 miles) around the focal store and find that for most radius definitions, the number of competing stores does not predict a differential price or quantity reaction.

${ }^{32}$ Due to the imprecise location information for some chains, both demographic variables (which are based on stores' catchment areas) might be subject to measurement error. We explore the possibility of such measurement error in Appendix D,

${ }^{33}$ The standard deviation of the re-scaled income (obesity) variable is equal to $0.26(0.27)$. Hence, a one-standarddeviation shift in either variable leads to a change in the price adjustment of less than $1 \%$. We re-iterate that income and obesity are strongly negatively correlated (correlation coefficient of -0.8), and hence when we include both variables, estimates become noisier.

${ }^{34}$ We also report the same analysis using the price for soda rather than all taxed products as the dependent variable in Table A11 in the appendix and find largely similar results.
} 


\begin{tabular}{|c|c|c|c|c|c|c|}
\hline & (1) & $(2)$ & $(3)$ & (4) & $(5)$ & (6) \\
\hline Dependent & Ounces & Ounces & Log & $\log$ & $\log$ & $\log$ \\
\hline Variable & Sold & Sold & Ounces & Ounces & Ounces & Ounces \\
\hline Philadelphia $\times$ AfterTax & $\begin{array}{c}-56,192^{* * *} \\
(9,742)\end{array}$ & & & & & \\
\hline $\begin{array}{l}\text { Grocery A } \\
\times \text { Philadelphia } \times \text { AfterTax }\end{array}$ & & $\begin{array}{c}-207,363^{* * *} \\
(34,502)\end{array}$ & $\begin{array}{c}-0.733^{* * *} \\
(0.068)\end{array}$ & $\begin{array}{c}-0.819 * * * \\
(0.077)\end{array}$ & $\begin{array}{c}-0.652^{* * *} \\
(0.077)\end{array}$ & $\begin{array}{c}-0.725^{* * *} \\
(0.070)\end{array}$ \\
\hline $\begin{array}{l}\text { Grocery B } \\
\times \text { Philadelphia } \times \text { AfterTax }\end{array}$ & & $\begin{array}{c}-369,605^{* * *} \\
(10,383)\end{array}$ & $\begin{array}{c}-0.674^{* * *} \\
(0.012)\end{array}$ & $\begin{array}{c}-0.792^{* * *} \\
(0.042)\end{array}$ & $\begin{array}{c}-0.609^{* * *} \\
(0.027)\end{array}$ & $\begin{array}{c}-0.665^{* * *} \\
(0.016)\end{array}$ \\
\hline $\begin{array}{l}\text { Grocery } \mathrm{C} \\
\times \text { Philadelphia } \times \text { AfterTax }\end{array}$ & & $\begin{array}{c}-728,854^{* * *} \\
(82,272)\end{array}$ & $\begin{array}{c}-1.173^{* * *} \\
(0.068)\end{array}$ & $\begin{array}{c}-1.251^{* * *} \\
(0.065)\end{array}$ & $\begin{array}{c}-1.111^{* * *} \\
(0.071)\end{array}$ & $\begin{array}{r}-1.157^{* * *} \\
(0.074)\end{array}$ \\
\hline $\begin{array}{l}\text { Mass Merchant } M \\
\times \text { Philadelphia } \times \text { AfterTax }\end{array}$ & & $\begin{array}{l}-23,083 \\
(24,797)\end{array}$ & $\begin{array}{l}-0.110 \\
(0.109)\end{array}$ & $\begin{array}{l}-0.181 \\
(0.130)\end{array}$ & $\begin{array}{l}-0.033 \\
(0.112)\end{array}$ & $\begin{array}{l}-0.098 \\
(0.110)\end{array}$ \\
\hline $\begin{array}{l}\text { Other Mass Merchants } \\
\times \text { Philadelphia } \times \text { AfterTax }\end{array}$ & & $\begin{array}{c}-406,541^{* * *} \\
(65,340)\end{array}$ & $\begin{array}{c}-0.529 * * * \\
(0.078)\end{array}$ & $\begin{array}{c}-0.609^{* * *} \\
(0.085)\end{array}$ & $\begin{array}{c}-0.461^{* * *} \\
(0.080)\end{array}$ & $\begin{array}{c}-0.518^{* * *} \\
(0.080)\end{array}$ \\
\hline $\begin{array}{l}\text { Drugstore } \mathrm{X} \\
\times \text { Philadelphia } \times \text { AfterTax }\end{array}$ & & $\begin{array}{c}-7,899 * * * \\
(1,234)\end{array}$ & $\begin{array}{c}-0.290^{* * *} \\
(0.041)\end{array}$ & $\begin{array}{c}-0.371^{* * *} \\
(0.051)\end{array}$ & $\begin{array}{c}-0.212^{* * *} \\
(0.048)\end{array}$ & $\begin{array}{c}-0.280^{* * *} \\
(0.043)\end{array}$ \\
\hline $\begin{array}{l}\text { Drugstore Y } \\
\times \text { Philadelphia } \times \text { AfterTax }\end{array}$ & & $\begin{array}{c}-610^{* * *} \\
(188)\end{array}$ & $\begin{array}{l}-0.002 \\
(0.034)\end{array}$ & $\begin{array}{r}-0.082^{*} \\
(0.043)\end{array}$ & $\begin{array}{c}0.063 \\
(0.041)\end{array}$ & $\begin{array}{l}0.013 \\
(0.039)\end{array}$ \\
\hline $\begin{array}{l}\text { Drugstore Z } \\
\times \text { Philadelphia } \times \text { AfterTax }\end{array}$ & & $\begin{array}{c}26,169^{* * *} \\
(4,311)\end{array}$ & $\begin{array}{c}0.558^{* * *} \\
(0.079)\end{array}$ & $\begin{array}{c}0.457^{* * *} \\
(0.083)\end{array}$ & $\begin{array}{c}0.621^{* * *} \\
(0.080)\end{array}$ & $\begin{array}{c}0.570^{* * *} \\
(0.083)\end{array}$ \\
\hline $\begin{array}{l}\text { Wholesale Club } \\
\times \text { Philadelphia } \times \text { AfterTax }\end{array}$ & & $\begin{array}{c}-423,042^{* * *} \\
(35,987)\end{array}$ & $\begin{array}{c}-0.878^{* * *} \\
(0.062)\end{array}$ & $\begin{array}{c}-1.004^{* * *} \\
(0.081)\end{array}$ & $\begin{array}{c}-0.796^{* * *} \\
(0.074)\end{array}$ & $\begin{array}{c}-0.869^{* * *} \\
(0.061)\end{array}$ \\
\hline $\begin{array}{l}\text { Dollar Stores } \\
\times \text { Philadelphia } \times \text { AfterTax }\end{array}$ & & $\begin{array}{c}-16,234^{* * *} \\
(1,670)\end{array}$ & $\begin{array}{c}-0.568^{* * *} \\
(0.034)\end{array}$ & $\begin{array}{c}-0.656^{* * *} \\
(0.044)\end{array}$ & $\begin{array}{c}-0.519 * * * \\
(0.038)\end{array}$ & $\begin{array}{c}-0.550^{* * *} \\
(0.041)\end{array}$ \\
\hline $\begin{array}{l}\text { Convenience Stores } \\
\times \text { Philadelphia } \times \text { AfterTax }\end{array}$ & & $\begin{array}{c}-7,131^{* * *} \\
(1,531)\end{array}$ & $\begin{array}{c}-0.108^{* * *} \\
(0.019)\end{array}$ & $\begin{array}{c}-0.196^{* * *} \\
(0.035)\end{array}$ & $\begin{array}{l}-0.035 \\
(0.034)\end{array}$ & $\begin{array}{c}-0.096^{* * *} \\
(0.023)\end{array}$ \\
\hline $\begin{array}{l}\text { Distance (in Miles) to Nearest U } \\
\times \text { Philadelphia } \times \text { AfterTax }\end{array}$ & taxed Store & & & $\begin{array}{c}0.040^{* * *} \\
(0.014)\end{array}$ & & \\
\hline $\begin{array}{l}\text { Income } \\
\times \text { Philadelphia } \times \text { AfterTax }\end{array}$ & & & & & $\begin{array}{c}-0.106^{* *} \\
(0.044)\end{array}$ & \\
\hline $\begin{array}{l}\text { Obesity Rate } \\
\times \text { Philadelphia } \times \text { AfterTax }\end{array}$ & & & & & & $\begin{array}{l}-0.030 \\
(0.041)\end{array}$ \\
\hline$\left(\text { AfterTax }_{t} \times X_{s}\right)^{\prime}$ Interactions & $\mathrm{n} / \mathrm{a}$ & Yes & Yes & Yes & Yes & Yes \\
\hline Store FE & Yes & Yes & Yes & Yes & Yes & Yes \\
\hline Week FE & Yes & Yes & Yes & Yes & Yes & Yes \\
\hline Observations & 144,700 & 144,700 & 144,700 & 144,700 & 144,700 & 144,700 \\
\hline Stores & 832 & 832 & 832 & 832 & 832 & 832 \\
\hline Weeks & 176 & 176 & 176 & 176 & 176 & 176 \\
\hline
\end{tabular}

Table 3: Impact on Quantity Sold. Interactions with an after-tax dummy (the $\left(\right.$ AfterTax $\left.x_{t} \times \mathbf{X}_{s}^{\prime}\right)$ term) are included in columns (2) - (6), but not reported separately. One exception is the obesity variable in column (6). We have no obesity data outside of Philadelphia and hence no (Obesitys $\times$

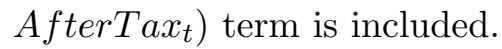


Notable heterogeneity exists in this effect across chains. In columns (2) and (3), we report results using total quantity and the logarithm of total quantity as the dependent variable, respectively. The chains that sold large quantities prior to the tax, namely, grocery stores, mass merchants, and the wholesale club, all experience large decreases in sales of $41 \%$ to $69 \% 35$ Among the smallervolume chains, only dollar stores experience a similar decrease. Drugstores and convenience stores instead experience a more modest decrease or no decrease in volume sold. Looking at the patterns documented in Panel B of Table 1 and the price results in Table 2, this pattern has two likely explanations. First, price increased less in percentage terms at drugstores and convenience stores due to a higher pre-tax price level. Second, those stores tend to sell smaller pack sizes, which are more likely to be for immediate consumption, and hence consumers might be less price sensitive for such purchases. Finally, we singled out Mass Merchant M and Drugstore Z in the previous section because those two chains are characterized by significantly lower price increases. Consistent with this pattern, we find that Mass Merchant M experiences no quantity decrease, and quantity sold actually increases at Drugstore Z. This increase is likely due to the fact that Drugstore $\mathrm{Z}$ has the lowest pass-through rate of all stores, and hence becomes relatively more attractive to consumers after the tax goes into effect.

Next, we turn to the competitive environment and find that distance to the nearest untaxed store does have a positive and significant impact on quantity changes (see column (4)). Therefore, stores that are further away from untaxed stores outside of the city experience a smaller decrease in quantity. The least competitive location according to this measure is a store that is located 3.7 miles from the nearest untaxed store. Other things equal, the quantity decrease at this store is 15 percent smaller than the would-be decrease if that store were instead located just next to an untaxed store. We later show that stores outside of the city experience an increase in demand after the tax is implemented. Our results suggest that quantity declines more at Philadelphia stores where geographic substitution is more likely.

Results based on interactions with income and obesity rates are reported in columns (5) and (6). We find quantity decreases more in high-income areas, whereas obesity rates do not predict a differential quantity response. The relationship between income and changes in quantity is relatively large in magnitude. Quantity decreases by approximately $10 \%$ more in the highest-income area relative to the lowest-income area 36 The direction of the correlation with income is surprising

\footnotetext{
${ }^{35}$ As mentioned before, we apply the transformation $\exp ($ coef ficient $)-1$ to translate the regression coefficients into percentage changes.

${ }^{36}$ We find similar income effects when estimating the regression separately for each store format (i.e. grocery stores, drug stores, etc.), but most estimates are not statistically significant due to smaller sample sizes in the format-level regressions. We also directly test whether price elasticities differ as a function of income by regressing log quantity on $\log$ price where price is instrumented with the Philadelphia $\times$ AfterTax dummy. We further include an interaction of $\log$ price and income and an additional instrument that interacts the Philadelphia $\times$ AfterTax dummy with income. Using this framework allows us to relate quantity response as a function of income to the relevant price changes induced by the tax. The coefficient on the log price interaction with income is negative and significant (coefficient of -0.52 and standard error of 0.24 , the baseline un-interacted log price coefficient is equal to -0.66 ), and hence demand is more elastic in high income areas. Note that here we reference store-level elasticities in order to illustrate differential responsiveness across the income spectrum, whereas the elasticity reported in section 7 compares the aggregate volume change to the average price change across all stores in Philadelphia.
} 
because we would expect high-income households to be less price sensitive, and hence reduce consumption less in response to the tax. Moreover, we saw in Table 2 that prices increased somewhat less in high-income areas, and hence the smaller price increase should lead to a lower-quantity reaction. Furthermore, prior research (see Wang (2015) and Dubois et al. (2017)) predicts a larger reaction of low-income households to a counterfactual soda tax. One possible explanation for our finding is that high-income households face lower transportation costs, either because they tend to live closer to an untaxed store or because they have easier access to transportation. We find that the income effect remains of similar magnitude when we also include an interaction with the distance to the nearest untaxed store in the regression and is not statistically significantly different from the estimate reported in column (5). Thus, distance alone does not explain the income effect. However, it is possible that high-income households have easier access to transportation, and thus are able to avoid the tax by driving to stores outside of the city to stock up on sweetened drinks. We discuss this point in more detail in section $6{ }^{37}$

\subsection{Substitution to Untaxed Beverages}

So far we have documented that the tax was almost fully passed through to retail prices and that the quantity of taxed beverages sold in Philadelphia decreased by $46 \%$. We now turn to analyzing whether consumers substitute to other products in reaction to the tax-induced price increase. In our context, two channels for substitution are possible. Consumers might substitute to other untaxed beverages or drive outside of the city to purchase sweetened beverages at stores that are not subject to the tax.

We first analyze demand for untaxed beverages as a potential channel of substitution based on the same regression framework as in the case of prices and quantities of taxed products. When analyzing quantity sold of all untaxed beverages in column (1) of Table 4, we find a decrease of 4,521 ounces in the average store in Philadelphia. The effect is statistically insignificant and small in magnitude. Relative to the average pre-tax volume of untaxed beverages of 146,000 , the decrease constitutes a $3.1 \%$ change in demand.

When analyzing bottled water and natural juice separately in columns (2) and (3), we find a statistically significant increase of $9 \%$ in the sales of natural juice, whereas sales of bottled water do not change significantly. We note the market share of natural juice is relatively small, and hence the increase of 1,400 ounces per store is modest when compared to the decrease of 56,000 ounces of taxed beverages documented earlier. Nevertheless, it is interesting that among untaxed beverages, natural juices, which contain more calories and sugar than most taxed beverages, experience an increase in demand.

In columns (4) to (6), we analyze price changes among untaxed beverages. We find that, on

\footnotetext{
${ }^{37}$ In Table $\mathrm{A} 12$ in the appendix, we present results from the quantity regression for the soda category. Results are very similar with regards to overall effect magnitude and patterns of heterogeneity along various dimensions. The only meaningful difference is a larger quantity reaction for Mass Merchant $\mathrm{M}$ in the soda category. This finding is consistent with the earlier finding that Mass Merchant $\mathrm{M}$ only increased prices for soda and not for other taxed categories.
} 


\begin{tabular}{|c|c|c|c|c|c|c|}
\hline & $\begin{array}{c}\text { All Untaxed } \\
\text { Beverages } \\
\text { (1) }\end{array}$ & $\begin{array}{c}\text { Water } \\
(2)\end{array}$ & $\begin{array}{c}\text { Natural } \\
\text { Juice } \\
(3)\end{array}$ & $\begin{array}{c}\text { All Untaxed } \\
\text { Beverages } \\
\text { (4) }\end{array}$ & $\begin{array}{c}\text { Water } \\
(5)\end{array}$ & $\begin{array}{l}\text { Natural } \\
\text { Juice } \\
\text { (6) }\end{array}$ \\
\hline Dependent Variable & $\begin{array}{l}\text { Ounces } \\
\text { Sold }\end{array}$ & $\begin{array}{c}\text { Ounces } \\
\text { Sold }\end{array}$ & $\begin{array}{l}\text { Ounces } \\
\text { Sold }\end{array}$ & Price $/ O z$ & Price $/ \mathrm{Oz}$ & Price/Oz \\
\hline $\begin{array}{l}\text { Average Pre-tax } \\
\text { Quantities / Prices }\end{array}$ & 146.017 & 130.736 & 15.281 & 1.88 & 1.35 & 6.37 \\
\hline Philadelphia $\times$ AfterTax & $\begin{array}{l}-4,521 \\
(7,125)\end{array}$ & $\begin{array}{l}-5,740 \\
(7,201)\end{array}$ & $\begin{array}{c}1,388^{* *} \\
(543)\end{array}$ & $\begin{array}{c}0.063^{* * *} \\
(0.010)\end{array}$ & $\begin{array}{c}0.027^{* * *} \\
(0.010)\end{array}$ & $\begin{array}{c}0.343^{* * *} \\
(0.032)\end{array}$ \\
\hline Store FE & Yes & Yes & Yes & Yes & Yes & Yes \\
\hline Week FE & Yes & Yes & Yes & Yes & Yes & Yes \\
\hline Observations & 144,209 & 143,931 & 133,005 & 144,209 & 143,931 & 133,005 \\
\hline Stores & 829 & 827 & 764 & 829 & 827 & 764 \\
\hline Weeks & 176 & 176 & 176 & 176 & 176 & 176 \\
\hline
\end{tabular}

Table 4: Price and Quantity Reaction of Untaxed Beverages. Some stores do not offer all categories of beverages, and hence the number of observations differs slightly across columns.

average, prices increase by 0.027 cents per ounce for bottled water and by 0.343 cents per ounce for natural juices. Although both coefficients are statistically significant, the effect for water is small in magnitude ${ }^{38}$ The larger increase in the price of natural juice could be an equilibrium response to increased demand for natural juices due to consumers substituting away from taxed beverages 39

\subsection{Geographic Substitution}

Next, we analyze whether consumers chose to drive outside of Philadelphia to purchase at stores that were not subject to the tax. To analyze the extent of cross-shopping at stores outside of Philadelphia, we employ the basic framework laid out in equation (1). However, rather than excluding stores within 6 miles of the city border, we now include those stores and estimate separate treatment effects for them. Thus, we continue to treat stores more than 6 miles outside of the city as the control group.

We first estimate a regression that allows for separate effects within 0-2, 2-4, and 4-6 miles outside of the city. Results from this regression are reported in the first column of Table 5 and show that quantity sold increases significantly for stores up to 6 miles outside of the city limits. Compared to the decrease of 56,000 ounces of taxed beverages at the average store in Philadelphia, we find an even larger increase of 64,000 ounces/store in stores up to 2 miles away from the city.

\footnotetext{
${ }^{38}$ In comparison, the price for taxed beverages goes up by 1.45 cents per ounce (see column (1) of Table 2 .

${ }^{39}$ Some retailers might have mistakenly applied the tax to some products that are not intended to be taxed. For example, Karen Meleta, a vice president at the ShopRite grocery chain, acknowledged in a January 2017 interview with Philadelphia magazine that some products (including plain mineral water and a natural lime juice) had been mislabeled (Fiorillo (2017)). In the article, Meleta explains that "we literally had to go through all of our drink products by hand to determine which ones would be subject to the tax. It's very confusing and complicated. If you read the original regulations, where there was some confusion was that the original regulation actually says that caloric sweeteners may also include sugars from concentrated fruits or vegetable juices that are in excess of what would be expected from fruits or vegetables. [...] We reached out to the city and asked how were were [sic] supposed to calculate this. How do we know if something has been reconstituted to its original sweetness level?"
} 


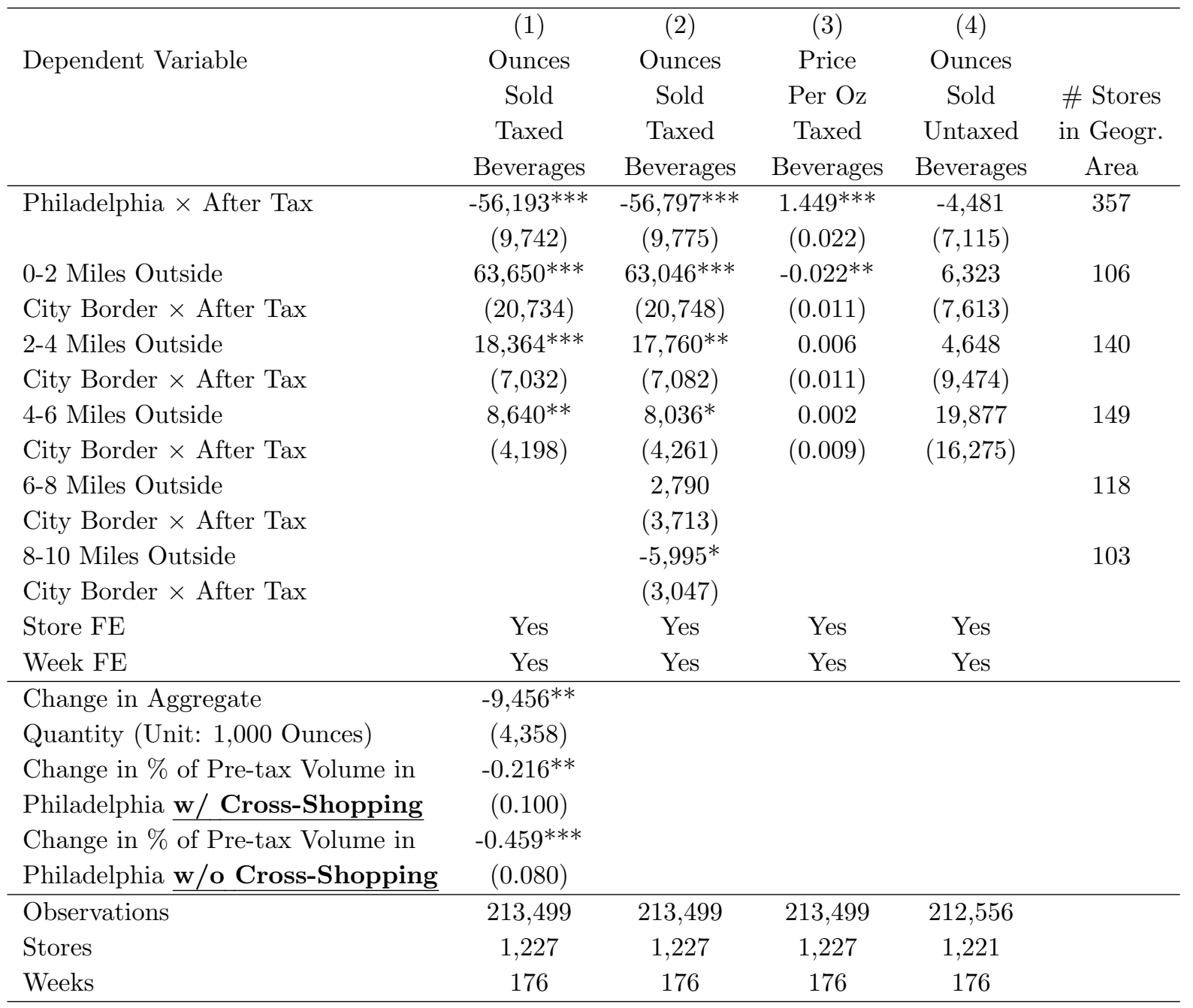

Table 5: Quantity and Price Reaction in Stores Near the City Border. Some stores do not offer all categories of beverages, and hence the number of observations differs slightly across columns. Reported store counts in the right-most column are for stores that sell taxed products.

Stores up to 4 and 6 miles outside of Philadelphia experienced smaller increases in sales. Because the number of stores varies across geographical areas, we need to weigh the different coefficients in column (1) appropriately in order to assess the aggregate change in quantity. In the lower panel of Table 5, we report the total weekly decrease in quantity in Philadelphia and stores less than 6 miles outside of the city, which is equal to 9.5 million ounces and constitutes a $22 \%$ decrease relative to the total weekly volume sold in Philadelphia prior to the tax. The effect is statistically significant at the $5 \%$ level. When focusing on stores in Philadelphia only, we find a much larger decrease in quantity of $46 \%$. The difference between the "Philadelphia only" and "Philadelphia plus 6 miles outside" percentage decrease is statistically significant. Therefore, to measure the aggregate quantity change correctly, accounting for cross-shopping behavior is important.

Figure 4 presents a graphical representation of the regression in column (1). The top graph shows the average store-level sales in each group. This graph shows that average sales in all three 
geographic areas track each other closely prior to the tax. Once the tax is implemented, sales in stores in the 0-2 miles band near the city increase relative to stores more than 6 miles away, whereas sales in stores in Philadelphia decrease. To avoid clutter, we do not show the two curves for stores 2-4 and 4-6 miles outside of the city. The bottom graph of Figure 4 illustrates the aggregate change in volume by plotting the total sales volume in Philadelphia and the entire "cross-shopping area" 0-6 miles outside of the city relative to the control group. Specifically, we isolate the change in the two "treated" regions by differencing average store sales in the control group from average store sales in Philadelphia and from average store sales in the 0-6 mile band outside the city. Then we scale up average store sales by the the number of stores within each area (both time series are normalized to zero in the first week). Consistent with our regression analysis above, the graph shows that the increase in volume in the area 0-6 miles outside of the city offsets about half of the volume reduction in Philadelphia.

We next probe whether stores farther than 6 miles outside of Philadelphia also experience an increase in quantity by adding two additional terms for stores 6-8 and 8-10 miles outside of the city, respectively. Stores that are located more than 10 miles away from the city limit serve as the control group. Results from this regression are reported in column (2) of Table 5 and show no significant increase in quantity at stores farther than 6 miles away from the city border 40 These estimates provide evidence that stores more than 6 miles away from the city constitute a valid control group that is not indirectly affected by the tax due to cross-shopping.

In column (3) of Table 5, we assess whether prices react differently in areas within a specific distance of the city. We find that prices at stores within 0-6 miles outside of Philadelphia remain almost unchanged despite the large increase in quantity sold in those geographic areas. In fact, in stores within 2 miles, we find a small but statistically significant decrease in prices. We also find that sales of untaxed products do not change at stores near the city border (see column (4)).

Finally, to better understand the consumer behavior underlying the documented cross-shopping effects, we analyze data on commuter patterns. We first note that 64,500 individuals commute from Philadelphia to the region 0-6 miles outside of the city, and hence it is plausible that part of the cross-shopping effect is driven by outbound commuters that are able to relatively easily shift their purchases to stores outside of Philadelphia. Next, we explore whether stores in Philadelphia that serve a higher proportion of commuters experience a larger decrease in purchase quantity. To do so, we re-estimate our earlier quantity regression (see column (3) of Table 3), but also include an interaction of the share of commuters in each store's catchment area with the Philadelphia $\times$ AfterTax dummy. We find that the commuter share is predictive of the demand decrease, and the quantity decrease is about $14 \%$ larger in the store with the highest commuter share relative to the store with the lowest commuter share 41 Taken together, these patterns suggest that commuters

\footnotetext{
${ }^{40}$ The 8 - to 10 -mile coefficient is significant only at the $10 \%$ level and has a negative sign.

${ }^{41}$ We use a re-scaled version of the commuter share variable that ranges from 0 to 1 across all stores in Philadelphia. The coefficient on the interaction between re-scaled commuter share and the Philadelphia $\times$ AfterTax dummy is -0.155 and the standard error is 0.047 . We also explore how the number of commuters from Philadelphia is related to the change in purchase quantity at stores outside of the city. We find that stores located in areas with more commuters from Philadelphia experience a larger increase in purchases; however, commuter counts have limited
} 


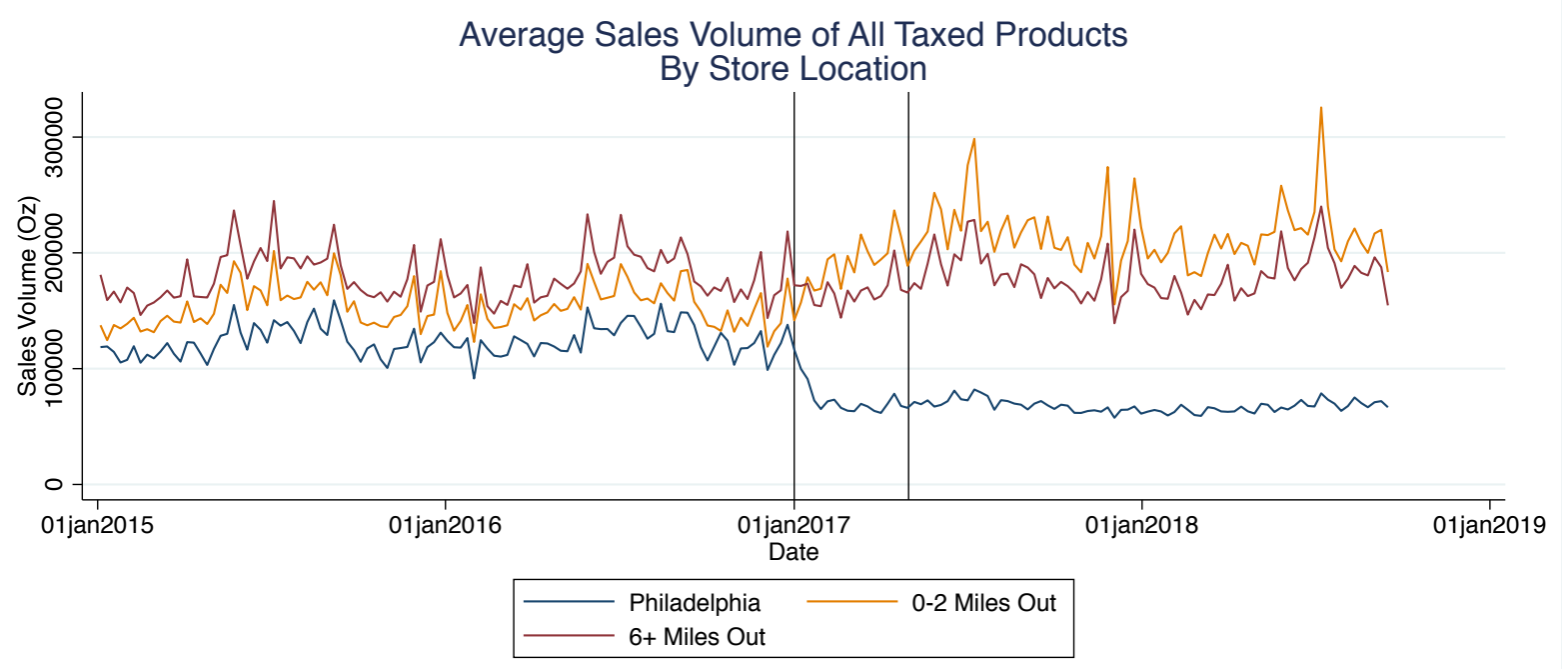

Total Sales Volume of All Taxed Products

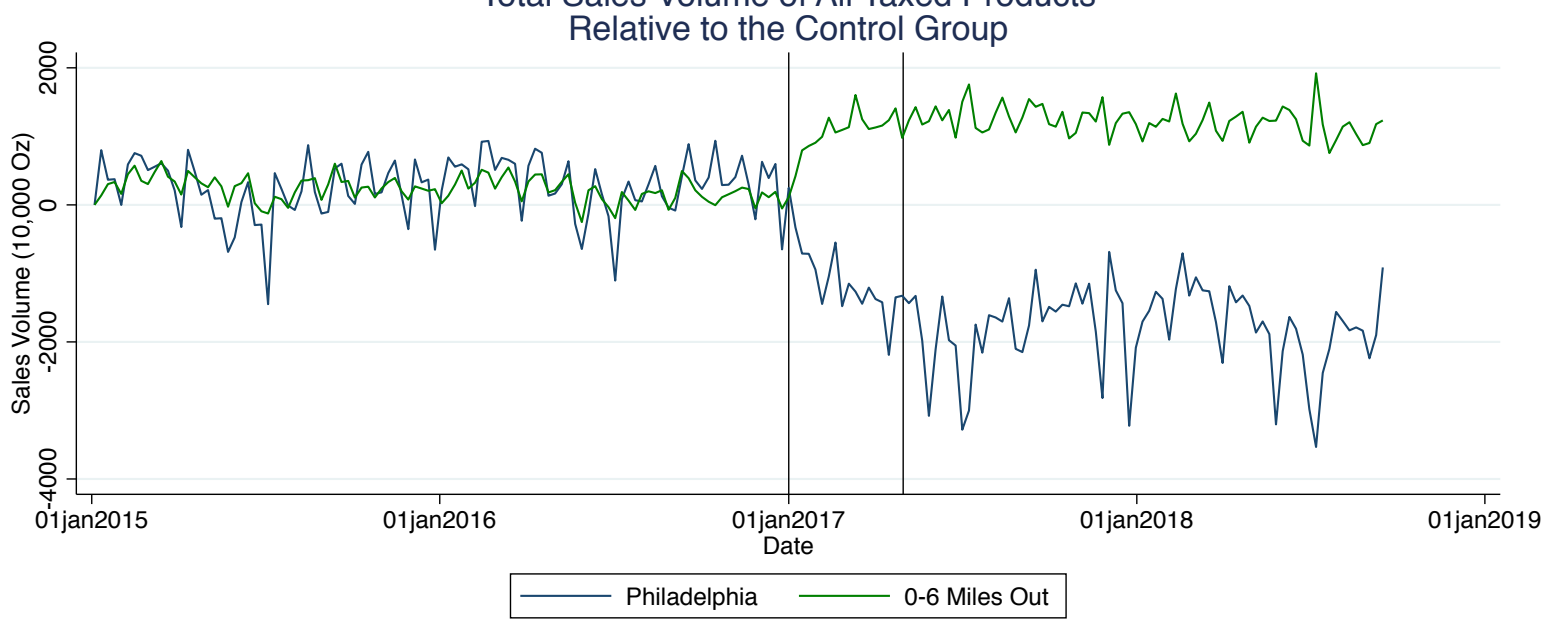

Figure 4: Taxed Beverage Sales in Philadelphia and Surrounding Area Stores over Time. The top graph shows average sales at stores in the 3 different geographic areas. The lower graph shows total sales at stores in each area relative to the control group. (Each week displays the difference between average sales in the control group and each of the two areas, multiplied by the number of stores in each area.) Both time series in the lower graph are normalized to zero in the first week. The black vertical lines indicate the tax's introduction and the end of the four month "adjustment period" that we omit from our main analyses (see Section 4 and Appendix G).

likely play an important role in generating the large cross-shopping effect documented above.

In the appendix we include additional analyses related to geographic substitution. First, we analyze possible changes in cross-shopping behavior after the tax goes into effect. Such changes in behavior could occur because consumers might engage in cross-shopping immediately after the tax goes into effect but find that doing so in the long run is inconvenient. We present this analysis in explanatory power with regard to changes in demand in stores outside of Philadelphia once we account for each store's distance to Philadelphia. 
Appendix G. Our analysis shows that after a brief adjustment period of four months (which are omitted from our main regressions above), quantities sold stabilized and show no sign of further adjustments between May 2017 and September 2018. Second, we look for evidence of basketlevel substitution by analyzing sales of milk in Appendix $\mathrm{K}$. We find some evidence of basket-level substitution at grocery stores and wholesale clubs, but do not find evidence of this substitution at other store formats. Further, even at grocery stores and wholesale clubs, the effect is small in magnitude and corresponds to a substitution of $5 \%$ of milk sales from stores in Philadelphia to stores just outside the city.

Heterogeneity across Pack Sizes and Categories In this section, we separately investigate the demand response for small and large pack sizes, as well as for the various taxed categories presented in Panel A of Table 1. We focus on results for quantity because price pass-through is similar across pack sizes and categories 42

We start by investigating heterogeneity in the demand response for small versus large pack sizes. We define small pack sizes as products with a container size of 20 ounces or less. Such products can be qualified as on-the-go beverages and are often sold close to the checkout register in supermarkets or in convenience stores or drugstores. Columns (1) and (2) of Table 6 replicate the cross-shopping regression specification from the previous section, based on sales of only small or large pack sizes, respectively. We find significantly smaller reductions in sales of small-pack sizes compared to large pack-sizes at stores in Philadelphia, and we find that consumers do not engage in cross-shopping for small pack-sizes. Demand for small pack-size products decreases by $10 \%$ at stores in Philadelphia, but there is no increase in sales outside of the city. This finding is in contrast to larger pack sizes, for which demand decreases by $53 \%$ in Philadelphia. However, a large part of this decrease is offset by an increase at stores outside of the city. This pattern of heterogeneity across pack sizes is intuitive because the costs of traveling to a store outside of the city are presumably too high when purchasing a beverage that is intended for immediate consumption. On the other hand, for large pack sizes, which consumers are more likely to store for future consumption, the benefits in terms of price savings are significantly larger 43

Despite the difference in demand response, the elasticity of demand is quite similar for large and small pack sizes, when cross-shopping is taken into account. To see that the two demand elasticities are similar, note that the average pre-tax price per ounce is equal to 10.10 (3.54) for small (large) pack sizes due to highly non-linear pricing across pack sizes. The tax is passed through at an almost identical rate across pack sizes and leads to a $15 \%$ (40\%) increase in price and thus an elasticity of -0.64 (-0.60) for small (large) pack sizes. Therefore, elasticities are similar when cross-shopping is accounted for. However, when focusing on Philadelphia sales only, demand for large pack sizes

\footnotetext{
${ }^{42}$ The average increase in price per ounce due to the tax is equal to 1.51 (1.42) for small (large) pack sizes and varies between 1.30 (taxed juice) and 1.68 (sports drinks) across categories.

${ }^{43} \mathrm{~A}$ similar picture emerges when we analyze cross-shopping separately for larger (grocery stores, mass merchants, wholesale clubs) and smaller (drug stores, conveniences stores, dollar stores) store formats. We find a decrease before (after) accounting for cross-shopping of $61 \%$ (27\%) for larger store formats and 10\% (6\%) for smaller store formats. The decrease in purchases after accounting for cross-shopping is statistically significant in both cases.
} 


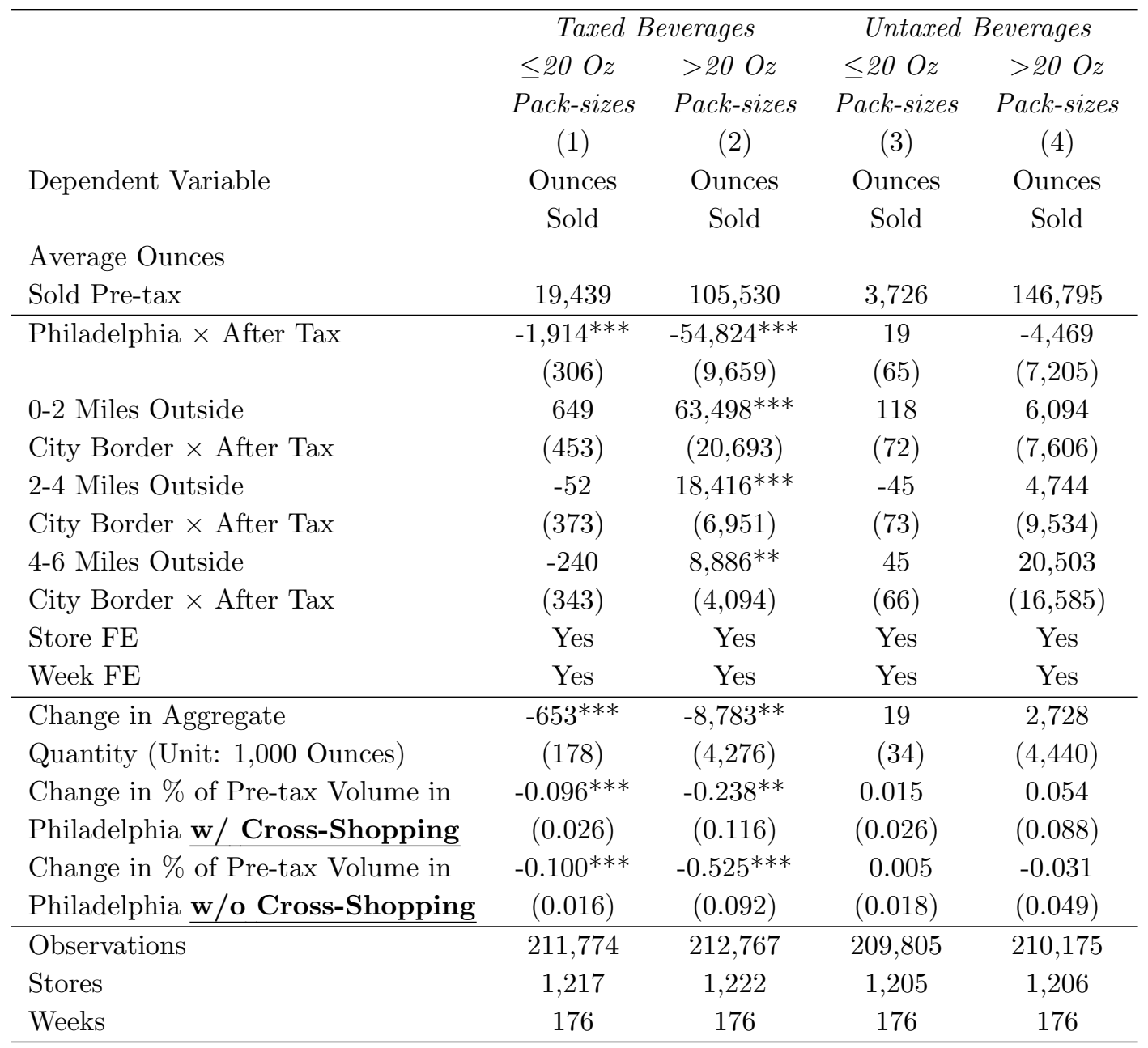

Table 6: Demand Response for Small and Large Pack Sizes. Some stores do not offer all pack sizes, and hence the number of observations differs slightly across columns.

appears more elastic.

We also test whether the absence of cross-shopping for small pack sizes leads to substitution to healthier beverages. As shown in columns (3) and (4), which report cross-shopping regressions based on small and large pack sizes of untaxed beverages, we find no evidence of substitution toward untaxed beverages for either set of products. When focusing on demand for natural juice (not reported in the table), we do find a significant positive effect for large pack sizes. We find no significant change in the sales of bottled water for either small or large pack sizes.

Next, we investigate heterogeneity in demand response across product categories. Similar to our analysis of differences across pack sizes, we now estimate the cross-shopping regression specification separately for the six categories of beverages that are subject to the tax. The results are presented in Table 7. Interestingly, we find heterogeneous demand patterns across categories. For soda, crossshopping is pervasive: the reduction in soda sales in the city is completely offset by an increase in sales outside the city. The other five categories are characterized by a much smaller degree of crossshopping. The category with the second-highest proportion of cross-shopped volume is Tea/Coffee, 


\begin{tabular}{lcccccc}
\hline & Soda & Taxed & Tea & Sports & Taxed & Energy \\
& & Juice & Coffee & Drinks & Water & Drinks \\
& $(1)$ & $(2)$ & $(3)$ & $(4)$ & $(5)$ & $(6)$ \\
& Ounces & Ounces & Ounces & Ounces & Ounces & Ounces \\
Dependent Variable & Sold & Sold & Sold & Sold & Sold & Sold \\
& & & & & & \\
Average Ounces & 43,529 & 32,950 & 28,638 & 14,229 & 5,015 & 3,693 \\
Sold Pre-tax & $-18,711^{* * *}$ & $-16,902^{* * *}$ & $-12,213^{* * *}$ & $-6,609^{* * *}$ & $-3,341^{* * *}$ & $-552^{* * *}$ \\
\hline Philadelphia $\times$ After Tax & $(3,910)$ & $(3,365)$ & $(2,132)$ & $(1,184)$ & $(463)$ & $(111)$ \\
& $42,768^{* * *}$ & $8,790^{* * *}$ & $9,658^{* * *}$ & $2,881^{* *}$ & 245 & -140 \\
0-2 Miles Outside & $(13,401)$ & $(3,106)$ & $(3,404)$ & $(1,416)$ & $(649)$ & $(121)$ \\
City Border $\times$ After Tax & $12,818^{* * *}$ & $2,733^{* *}$ & $2,208^{* *}$ & 928 & 17 & -165 \\
2-4 Miles Outside & $(4,246)$ & $(1,061)$ & $(1,018)$ & $(940)$ & $(473)$ & $(119)$ \\
City Border $\times$ After Tax & $6,424^{* *}$ & 1,132 & 226 & 910 & 189 & -162 \\
4-6 Miles Outside & $(2,539)$ & $(691)$ & $(731)$ & $(668)$ & $(423)$ & $(122)$ \\
City Border $\times$ After Tax & Yes & Yes & Yes & Yes & Yes & Yes \\
Store FE & Yes & Yes & Yes & Yes & Yes & Yes \\
Week FE & 605 & $-4,371^{* * *}$ & $-2,878^{* * *}$ & $-1,674^{* * *}$ & $-852^{* * *}$ & $-258^{* * *}$ \\
\hline Change in Aggregate & $(2,141)$ & $(1,223)$ & $(865)$ & $(488)$ & $(186)$ & $(65)$ \\
Quantity (Unit: 1,000 Ounces) & 0.039 & $-0.392^{* * *}$ & $-0.294^{* * *}$ & $-0.356^{* * *}$ & $-0.634^{* * *}$ & $-0.199^{* * * *}$ \\
Change in \% of Pre-tax Volume in & $(0.139)$ & $(0.110)$ & $(0.088)$ & $(0.104)$ & $(0.138)$ & $(0.050)$ \\
Philadelphia w / Cross-Shopping & $-0.434^{* * *}$ & $-0.521^{* * *}$ & $-0.432^{* * *}$ & $-0.469^{* * *}$ & $-0.669^{* * *}$ & $-0.151^{* * *}$ \\
Change in \% of Pre-tax Volume in & $(0.091)$ & $(0.104)$ & $(0.075)$ & $(0.084)$ & $(0.093)$ & $(0.030)$ \\
Philadelphia w/o Cross-Shopping & 213,499 & 205,997 & 211,183 & 198,208 & 169,429 & 212,619 \\
\hline Observations & 1,227 & 1,183 & 1,213 & 1,139 & 971 & 1,222 \\
Stores & 176 & 176 & 176 & 176 & 176 & 176 \\
Weeks & & & & & 0 & \\
\hline
\end{tabular}

Table 7: Demand Response across Categories. Some stores do not offer all categories of beverages, and hence the number of observations differs slightly across columns.

for which $32 \%$ of the volume reduction in Philadelphia is offset by cross-shopping. The share of cross-shopping in the soda category is significantly different from the shares of cross-shopping in all other taxed categories 44

\section{$5 \quad$ Nutritional Intake}

Next, we analyze the impact of the tax on nutritional intake, namely on calories and grams of sugar. Because there is heterogeneity in calorie and sugar content both among taxed and untaxed beverages, calorie and sugar intake does not necessarily need to change by the same magnitude as sales of taxed beverages. In this section we therefore investigate whether changes in nutritional intake differ significantly from the observed $22 \%$ reduction in quantity (net of cross-shopping).

To analyze nutritional intake, we calculate the total number of calories and grams of sugar

\footnotetext{
${ }^{44}$ We test whether the share of cross-shopping (relative to the decrease at stores in Philadelphia) for soda differs from each of the other categories in Table 7 through a series of pairwise tests. The null hypotheses of equal cross-shopping shares are rejected for all pairwise comparisons.
} 


\begin{tabular}{|c|c|c|c|}
\hline & All Beverages & $\begin{array}{c}\text { Low Calorie } \\
\text { Taxed Beverages } \\
\text { (2) }\end{array}$ & $\begin{array}{c}\text { High Calorie } \\
\text { Taxed Beverages } \\
(3)\end{array}$ \\
\hline Dependent Variable & Calories & $\begin{array}{l}\text { Ounces } \\
\text { Sold }\end{array}$ & $\begin{array}{l}\text { Ounces } \\
\text { Sold }\end{array}$ \\
\hline Average Pre-Tax & & & \\
\hline Quantities / Calories & $1,392,713$ & 52,280 & 71,836 \\
\hline Philadelphia * After Tax & $\begin{array}{c}-523,176^{* * *} \\
(95,954)\end{array}$ & $\begin{array}{c}-24,755^{* * *} \\
(4,200)\end{array}$ & $\begin{array}{c}-31,537^{* * *} \\
(5,907)\end{array}$ \\
\hline 0-2 Miles Outside & $636,965^{* * *}$ & $19,184^{* * *}$ & $44,625^{* * *}$ \\
\hline City Border ${ }^{*}$ After Tax & $(204,752)$ & $(6,950)$ & $(14,347)$ \\
\hline 2-4 Miles Outside & $192,558^{* * *}$ & $5,538^{*}$ & $12,817^{* * *}$ \\
\hline City Border * After Tax & $(68,405)$ & $(2,900)$ & $(4,253)$ \\
\hline 4-6 Miles Outside & $93,293^{* *}$ & 2,741 & $5,876^{* *}$ \\
\hline City Border * After Tax & $(42,916)$ & $(1,807)$ & $(2,543)$ \\
\hline Store FE & Yes & Yes & Yes \\
\hline Week FE & Yes & Yes & Yes \\
\hline Change in Aggregate Quantity & $-78,397^{*}$ & $-5,615$ & $-3,859$ \\
\hline (Unit: 1,000 Ounces / Calories) & $(42,954)$ & $(1,800)$ & $(2,723)$ \\
\hline Change in $\%$ of Pre-tax Volume in & $-0.158^{*}$ & $-0.306^{* * *}$ & -0.153 \\
\hline Philadelphia w/ Cross-Shopping & $(0.087)$ & $(0.098)$ & $(0.108)$ \\
\hline Change in $\%$ of Pre-tax Volume in & $-0.377 * * *$ & $-0.480 * * *$ & $-0.445^{* * *}$ \\
\hline Philadelphia w/o Cross-Shopping & $(0.069)$ & $(0.081)$ & $(0.083)$ \\
\hline Observations & 213,499 & 213,008 & 213,499 \\
\hline Stores & 1,227 & 1,224 & 1,227 \\
\hline Weeks & 176 & 176 & 176 \\
\hline
\end{tabular}

Table 8: Impact on Nutritional Intake. High calorie beverages are defined as products with $\geq 10$ calories/oz (the median value for calorie content across all taxed products).

sold via beverage sales at the store/week level. Both variables are obtained by simply adding up calories and sugar across all beverage products sold in a given store/week. We intentionally do not distinguish between taxed and untaxed categories, because we want to analyze changes in total calories and grams of sugar from all beverage sales. We analyze the impact of the tax on nutritional intake in Table 8 based on the specification used in the previous sections to account for cross-shopping. We find that calories from beverages drop by 16\%. In Table A14 in the appendix, we replicate this regression using sugar content as the dependent variable and find a decrease of 15\%. The estimates for both calories and sugar are smaller in magnitude than the impact on sales of taxed beverages, but contain the sales effect of $22 \%$ in their confidence intervals.

The calories regression differs in effect magnitude from the earlier cross-shopping regression based on quantity sold (see Table 5) for two reasons. First, we observe a statistically significant increase in the sales of untaxed natural juices, which are high in calories (see Table 4). Second, nutritional content varies within the set of taxed products. Therefore, if the decrease in quantity is driven predominantly by a decrease in healthier, low-calorie variants of taxed products, the 
percentage decrease in calories will be lower than the raw quantity decrease. We test for a differential response among more / less healthy taxed products by replicating the cross-shopping regression specification, based on sales of only high- or low-calorie taxed products ${ }^{45}$ The results in columns (2) and (3) of Table 8 show that high-calorie products experienced a smaller net decrease after accounting for cross-shopping compared to low-calorie products, but the difference in demand response is not statistically significant 46

Therefore, while we find a significant increase in sales of high-calorie untaxed natural juices, we do not have enough power to estimate differential effects for low- and high- calorie taxed beverages, nor can we distinguish the calorie and sugar reduction from the somewhat larger estimated reduction in sales of taxed beverages. Despite these power issues, we think the directional results are informative for policy-makers who aim to understand the nutritional impact of beverage tax policies. If consumers have a preference for product characteristics such as sugar or calorie content, it follows that substitution will occur between taxed and untaxed products that are more similar along that specific dimension. For example, if consumers substitute from sugary taxed beverages to untaxed beverages that are high in sugar, this behavior will lead to a lower reaction in nutritional content than the corresponding quantity change ${ }^{47}$ The increase in sales of natural juices with high sugar and calorie content provides some evidence that this type of substitution occurs.

We also note that our analysis assesses the impact of the tax on nutrients consumed in the form of beverages purchased at retail stores. It is conceivable that consumers also change their food consumption in response to the tax. On one hand, consumers might substitute away from sweetened beverages to other sugary and high-calorie foods. Alternatively, the tax could lead to a decrease in consumption of sugary and high-calorie foods if the tax makes "eating healthy" more salient. Because we do not have access to data on all food purchases, such an analysis is outside the scope of this paper.

\section{Differential Impact by Income}

In this section, we explore how the tax affects different income groups. We documented earlier that quantity decreases more in stores that are located in high-income areas (see column (5) of Table 3). In general, there are three factors that might influence how demand in areas with different income profiles reacts to the tax: (a) price sensitivity, (b) preferences for sweetened beverages, (c) transportation costs. We take as given that low income households tend to be more price sensitive, and therefore a lower quantity reaction in low income areas has to be driven either by differences in preferences for sweetened beverages or differences in transport costs. Based on a series of data patterns, we argue that the latter channel is likely to be the key driver of the differential reaction

\footnotetext{
${ }^{45}$ We classify products that contain less than/more than the median level (10 calories/oz) as low/high-calorie products.

${ }^{46}$ In Table A14 in the appendix, we replicate the set of regressions in Table 8 using sugar content as the dependent variable and find quantitatively very similar results.

${ }^{47}$ As pointed out by Zhen et al. (2014) and Grummon et al. (2019), this limitation of the policy may be mitigated by directly taxing sugar content rather than the volume of products with any sugar content.
} 
by income. In other words, the reason demand decreases less in low income areas is because low income households find it more costly to shift their purchases to stores outside of Philadelphia.

A first piece of evidence to support this hypothesis comes from other related studies on demand for sweetened beverages and nutritional inequality. Wang (2015) and Dubois et al. (2017) estimate models of demand that allow for differences in price sensitivity, as well as preferences for sweetened beverages. Both papers find that low income households are more price sensitive and have a stronger preference for sweetened beverages. When simulating the impact of a tax, they find that the price sensitivity effect dominates and low-income consumers react more strongly to a soda tax. Both papers simulate a national tax, and hence transportation costs do not play a role in their setting. Thus, if our setting is comparable to theirs with the exception of transportation costs, it must be the case that higher transport costs make low income households react less to the tax. In a related paper that explores the causes of nutritional inequality, Allcott et al. (2019a) analyze data from the 2009 National Household Travel Survey and find that urban households in the bottom income quartile tend to travel shorter distances for shopping trips than urban households in other income groups. This fact is consistent with our hypothesis that low income consumers face higher transportation costs for shopping trips.

To explore this further, we analyze variables that directly capture transportation costs of Philadelphia residents, namely car ownership and the local share of outbound commuters (traveling outside of the city to work). Both variables are collected at the census tract level, and we correlate the share of car owners and outbound commuters (relative to local population size) with tract-level median income. We find that both variables are positively correlated with median income across census tracts in Philadelphia. The correlation coefficient of income with share of car ownership (share of commuters) is equal to $0.38(0.56)$.

Finally, we investigate whether we detect cross-shopping patterns that suggest that different income groups are more or less likely to engage in cross-shopping. To this end, we analyze heterogeneity in the demand increase at stores outside of the city border as a function of the income level of nearby census tracts inside Philadelphia. If high-income consumers are more likely to travel to stores outside of Philadelphia, we should see a larger increase in demand at border stores near highincome areas in Philadelphia. We test this prediction by adding interactions of the border-store dummies with income in nearby areas in Philadelphia (and the after-tax dummy). We find that higher income in nearby areas in Philadelphia is associated with a larger increase in demand at border stores. However, the interaction effect with income is only statistically significant for stores 0-1 miles outside of the city border. For stores further outside of the city, we find positive interaction effects, but they are imprecisely estimated ${ }^{48}$ We present the results from regressions that

\footnotetext{
${ }^{48}$ Specifically, we estimate a regression that replicates column (1) in Table 5 , but add two interaction terms for the 0- to 2-mile and 2- to 4-mile distance bands of border stores with the income level in nearby areas in Philadelphia (and the post-tax dummy). We compute this income variable by calculating the average of the median income level at all census tracts in Philadelphia that are within 4 miles of the store. The coefficients on both interaction terms are positive but not statistically significant. We then split the distance bands more finely into bands of $0-1,1-2,2-4$, and 4-6 miles and include interactions of the three closest bands with the income level in nearby areas in Philadelphia (and the post-tax dummy). In that specification, we find the coefficient on the interaction term for stores in the 0-
} 
allow for heterogeneity in demand effects as a function of income in nearby areas in Philadelphia in Table A13 in the appendix.

To summarize, we provide several pieces of evidence that suggest that the reason demand decreases less in low-income areas is because low-income households face higher transportation costs. We show that low-income households are less likely to own cars or commute outside the city to work. Meanwhile, border-stores outside the city that are closer to high-income Philadelphia neighborhoods tend to experience a higher increase in sales after the tax.

\section{Summary and Implications for Policy Design}

In this section we briefly re-cap the empirical findings presented in the previous sections and contrast them with findings from other studies of soda taxes in the US. We then explore the implications of observed elasticities, the amount of cross-shopping, and other estimated quantities on tax design choices such as the tax rate and geographic coverage of the tax.

\subsection{Summary of Results \& Comparison to Other Studies}

We find a pass-through rate of $97 \%$ (a $34 \%$ price increase) and a quantity decrease of $46 \%$ at stores in Philadelphia. At stores 0-6 miles outside of the city, prices remain unchanged, but demand increases due to cross-shopping. Net of cross-shopping, quantity decreases by only $22 \%$. Taken together, the estimated price and quantity reactions imply an elasticity of aggregate quantity sold in Philadelphia of $-46 \% / 34 \%=-1.35$ and an elasticity net of cross-shopping of $-22 \% / 34 \%=-0.65$. While the first elasticity is the relevant one with regard to assessing tax revenue, the latter elasticity is relevant when assessing the impact on total sales of taxed beverages and hence changes in nutritional intake.

Various studies of the Berkeley tax find more limited pass-through between $25 \%$ and $47 \%$ and a small (sometimes statistically insignificant) reduction in quantity. Several papers (Cawley and Frisvold (2017), Rojas and Wang (2017), Bollinger and Sexton (2018)) speculate that lower pass-through occurs because cross-shopping constrains retailers from raising their prices. Because Berkeley is much smaller than Philadelphia (18 vs. 134 square miles), cross-shopping could be a stronger force in this setting. Bollinger and Sexton (2018) document some amount of cross-shopping, but based on only one supermarket outside of the taxed area. Notably, the elasticity (with regard to quantity sold in Berkeley) implied by the estimates in Bollinger and Sexton (2018) is quite high (between -2 and -3), which might indicate a greater degree of cross-shopping. The difference between the Berkeley studies and our estimates for Philadelphia point towards the potentially important role of geographical coverage as a tax design choice, which we explore in more detail below.

Our results are largely in line with two recent studies that analyze the Philadelphia tax based on more limited data. Cawley et al. (2020) manually collect prices for a small set of products before and after the tax and document full pass-through at stores in Philadelphia. Cawley et al. (2018b) to 1-mile distance band is statistically significant at the $5 \%$ level. 
use a consumption survey to assess changes in purchases. The paper finds an insignificant decrease in Philadelphia and a significant increase in purchases made at stores just outside of the city. Directionally, these findings are consistent with our study, but we estimate a significant decrease in purchases in Philadelphia, in addition to a significant increase in demand at stores near the city.

One study that warrants a more detailed comparison is Roberto et al. (2019), which also uses retail scanner data to analyze the impact of Philadelphia's sweetened beverage tax. Several of their findings differ substantially from ours because store coverage in our sample is more comprehensive and because of differences in modeling choices ${ }^{49}$ In order to provide a comprehensive account of what is driving these differences, we conduct a detailed comparison of our findings in Appendix B. Here, we focus on highlighting the differences in key estimates. Roberto et al. (2019) find that $24 \%$ of their estimated reduction in sales in Philadelphia is offset by an increase in sales in border stores, leading to a net reduction in volume of $38 \%$. In contrast, we find that $52 \%$ of the sales reduction in Philadelphia is offset by cross-shopping, leading to a $22 \%$ reduction in net volume 50 Roberto et al. (2019) also find a smaller price increase of $12 \%$ to $24 \%$ depending on store format, whereas we find a larger price change of $34 \%$, which corresponds to a $97 \%$ pass-through rate and is in line with the evidence from manually collected prices (Cawley et al. (2020) 51 Differences in the estimated impact on both prices and quantities lead to drastically different elasticities of -1.7 in Roberto et al. (2019) versus -0.6 in our data. As we show in more detail below, the elasticity is an important input to understanding how sales and tax revenue behave as a function of the tax rate. Moreover, the impact of changes in geographic coverage depend crucially on the magnitude of the estimated cross-shopping effect.

To the best of our knowledge, we are the first study to explicitly analyze the impact of a soda tax on nutritional intake, namely sugar and calories. We find evidence for compositional changes in demand that lead to a smaller decrease in sugar and calories relative to the decrease in quantity. While statistically we cannot distinguish the sugar / calorie decrease from the decrease in quantity, we do find (statistically significant) evidence for one of the underlying drivers of the compositional change in demand: an increase in sales of untaxed natural juice. Overall, we cautiously interpret our nutritional findings as suggestive of an overestimation of nutritional effects when using the quantity reaction of taxed beverages as a stand-in for changes in nutritional intake.

\footnotetext{
${ }^{49}$ In addition to the retail formats they observe, we also observe 116 convenience stores, 54 dollar stores, and 2 wholesale club stores that together account for $26 \%$ of the pre-tax volume sales in our Philadelphia data (see Table 1). Furthermore, we find that convenience stores which account for $19 \%$ of our pre-tax volume sales experience only a $10 \%$ decrease in sales, which is substantially smaller than the decrease at grocery stores and mass-merchants (see Table 3).

${ }^{50}$ These differences are due to the fact that Roberto et al. (2019) test for cross-border shopping by analyzing Pennsylvania stores within 3 miles of the Philadelphia border. (They do not observe data for stores more than 3 miles outside the city limits, nor do they observe nearby stores in New Jersey.) In contrast, we find evidence of significant increases in sales up to 6 miles outside of the city limits, as well as evidence of cross-shopping at stores in both Pennsylvania and New Jersey.

${ }^{51}$ Price differences are partially driven by sample differences, but also by differences in how average prices are computed. We use volume-weights based on pre-tax data, while Roberto et al. (2019) compute a simple average across UPCs. Furthermore, we adjust prices at one retailer that records the soda tax separately so that our price variable reflects the actual price paid by consumers (see footnote 11 and Appendix C).
} 
Finally, our research documents the heterogeneous impact of the tax on different income segments. We show that stores in high-income neighborhoods in Philadelphia experience a smaller sales reduction than those in low-income neighborhoods. This finding differs from the extant literature's prediction that low-income consumers would reduce their consumption more than high-income consumers in response to a counterfactual national soda tax (Wang (2015); Dubois et al. (2017)). Our analysis suggests that the difference is likely driven by the fact that Philadelphia's localized soda tax leads to a significant amount of cross-border shopping and high-income consumers face lower transportation costs and therefore engage more in cross-shopping.

\subsection{Policy Design}

Next, we take the insights gained from the Philadelphia tax and assess what we can learn from those findings about the design of sweetened-beverage taxes more broadly. The handful of taxes that have gone into effect in recent years vary along three dimensions. First, the tax rate varies from 1 cent per ounce in Berkeley and San Francisco to 2 cents per ounce in Boulder, CO. Second, the geographic area covered by the tax varies from small cities such as Berkeley or Boulder to larger cities such as Philadelphia and even an entire county (Cook County, IL). Third, some cities tax only sugar-sweetened beverages, whereas others also apply the tax to artificially (non-sugar) sweetened beverages (i.e., diet drinks).

Below, we discuss how changes along each of the three dimensions impact tax revenue and sales of taxed beverage:52, the two outcomes emphasized by the Philadelphia mayor's office Esterl (2016)). Due to the nature of our data, we do not attempt to integrate these elements into a unified welfare assessment of the tax (such as the one provided by Allcott et al. (2019b)), but instead trace out the effect of changes in tax policy design on these outcomes.

Inference Regarding the Impact of Tax-Policy Design Before assessing policy design choices, we briefly discuss why the evidence regarding the impact of the Philadelphia tax is particularly useful to assess the impact of counterfactual tax policy choices. In particular, we believe the variation induced by the Philadelphia tax allows us to learn about policy relevant measures that are harder to estimate using pre-tax data alone.

An important obstacle to evaluating the impact of localized taxes based on pre-tax price variation is the fact that short-term product-specific price variation is unlikely to trigger consumers to switch stores. Identifying the extent of cross-shopping with pre-tax data is difficult because most short-run price changes are due to promotions on individual items, and store switching due to those price changes is predicated on consumers knowing about prices prior to the store-switching decision. Indeed, when using only the pre-tax period of our data, we find that the elasticity of store-level demand with respect to the average price of competing stores within a 2-mile radius is equal to 0.083 and not statistically significant. In contrast, when basing the same elasticity on

\footnotetext{
${ }^{52}$ We focus on sales of taxed beverages rather than nutritional outcomes in this section because we find changes in calories and sugars are not significantly different from the impact on quantity (see Section 5 . .
} 
variation in prices induced by the tax, we estimate a statistically significant elasticity of 0.96353 Therefore, our data allow us to better assess the extent of cross-shopping triggered by a permanent price increase. We also note that the literature on store choice typically does not measure how store choice reacts to price changes for specific products, but focuses on aspects like distance to the store and stores' overall pricing strategies (Hoch et al. (1994), Bell et al. (1998)). This emphasis is presumably related to the fact that large and persistent price changes for specific products or categories, such as the one induced by the tax, are rare 54

Other challenges that arise when extrapolating from pre-tax data include how to infer long-run elasticities from short-run price variation and how to model the supply-side in such a way to yield accurate estimates of tax pass-through 5 5ecause we estimate price and quantity changes (and therefore the elasticity) based on a long-run price change, dealing with the difference between shortand long-run elasticities is unnecessary. Similarly, because we observe tax pass-through directly in the data, our counterfactual analysis is less sensitive to specific supply-side modeling assumptions.

Tax Rate To predict outcomes under counterfactual tax rates, we assume a constant pass-through rate and a linear demand curve 56 The constant pass-through of close to one can be seen as the result of a simple cost-based pricing rule where retailers simply pass any cost change through to consumers 57 Because we want to analyze the impact of different tax rates on aggregate price and quantity reactions and their implication for revenue generation, we focus on capturing the shape of the aggregate demand and supply relationships and do not specify the underlying preferences of consumers and a model of supply-side price setting. We note that several of our findings below

\footnotetext{
${ }^{53}$ In detail, we first use only the pre-tax period of our data (i.e., from January 2015 to December 2016) and regress $\log$ quantity on the $\log$ of own-price and the $\log$ of the average price of all competitors within a 2-mile radius around the store (and store fixed effects). We find the impact of competitors' prices is equal to 0.083 (standard error of 0.057 ) and not statistically significant. We then estimate the same regression, but isolate the variation in prices induced by the tax using instrumental variables. Specifically, we estimate the same regression as before, but use pre- and post-tax data and instrument own- and competitor price with interactions of all store dummies with the post-tax dummy. We find that in the latter case, the cross-price elasticity between stores is equal to 0.963 (standard error of $0.174)$.

${ }^{54}$ Another related paper is Goli and Chintagunta (2019), which studies the impact of a different type of "large shock" on store choice. The paper analyzes how the decision of CVS to stop carrying tobacco products affects store choice.

${ }^{55}$ In the context of storable products such as sweetened beverages, short-term elasticities tend to be larger than long-run elasticities due to stockpiling (Erdem et al. (2003), Hendel and Nevo (2006)). Other papers that estimate demand for sweetened beverages based on pre-tax data employ various approaches to obtain long-run price elasticities. Wang (2015) estimates a dynamic demand model with inventory holdings. Dubois et al. (2017) focus on on-the-go beverage sizes for which stockpiling is less likely to occur. Allcott et al. (2019b) use quarterly data and show that there are no effects of lagged prices, leading them to conclude that quarterly level estimation seems to be sufficient for estimating long-run elasticities.

${ }^{56}$ Data from the initially lower price increase in January-April 2017 (which is not used in our main empirical analysis) provides support for the linear demand assumption. In particular, when plotting the relationship of price and quantity for three different data points, the pre-tax period, the period during January-April 2017, and the period after April 2017, we find that the relationship is close to linear. Alternative demand functions such as log-linear do not fit the data as well.

${ }^{57}$ Our pass-through assumption is similar to the one in Allcott et al. (2019b), who assume a constant pass-through rate of 1 . A simple pricing rule that passes any cost increase through to consumers could be the result of managerial costs associated with price setting, similar to the uniform pricing practices documented by DellaVigna and Gentzkow (2019).
} 
hold the tax rate constant at the current rate or are based on tax rates close to the current rate. We deem these findings to be more reliable because our assumptions are more likely to hold locally. Predictions for counterfactual tax rates that are further away from the current rate should be interpreted more cautiously. Finally, when using the observed elasticity of demand in our calculations, we assume that quantity response is entirely driven by price changes rather than changes in other marketing variables. In Appendix L, we discuss potential non-price effects in more detail and explain why the quantity changes we observe are likely to be a direct response to a change in price.

The assumptions outlined above lead to the following expression for tax revenue as a function of the tax rate $\tau$ :

$$
\begin{aligned}
\text { TaxRevenue } & =\tau \times Q(0) \times\left[1+\eta_{q p} \frac{p(\tau)-p(0)}{p(0)}\right] \\
& =\tau \times Q(0) \times\left[1-1.35 \frac{0.97 \tau}{4.26}\right],
\end{aligned}
$$

where $Q(0)$ denotes quantity sold when no tax is imposed $(\tau=0), \eta_{q p}$ denotes the elasticity of quantity sold in Philadelphia with respect to price, and $p(\tau)$ denotes the price level at tax rate $\tau$. The second line follows by substituting in the following quantities from our earlier regressions: (1) elasticity: $\eta_{q p}=-46 \% / 34 \%=-1.35 ;(2)$ pass-through rate: $p(\tau)-p(0)=\frac{1.45}{1.5} \tau=0.97 \tau ;$ and $(3)$ pre-tax price level: $p(0)=4.26$.

Similarly, total sales of taxed beverages are given by the following relationship:

$$
\begin{aligned}
Q(\tau) & =Q(0) \times\left[1+\tilde{\eta}_{q p} \frac{p(\tau)-p(0)}{p(0)}\right] \\
& =Q(0) \times\left[1-0.65 \frac{0.97 \tau}{4.26}\right]
\end{aligned}
$$

where $\tilde{\eta}_{q p}=-22 \% / 34 \%=-0.65$ denotes the elasticity net of cross-shopping.

Using equation (3) we can derive the revenue-maximizing tax rate and, more generally, the relationship between tax revenue and the tax rate $\tau$. We plot this relationship in Figure 5. We find the revenue-maximizing tax rate is equal to 1.63 cents per ounce 58 The Laffer curve shows that the actual tax rate of 1.5 cents per ounce in Philadelphia generates revenue that is equal to $99 \%$ of the revenue generated at the revenue-maximizing tax rate. A lower tax rate of 1 cent per ounce generates $85 \%$ of potential revenue, whereas a higher rate of 2 cents per ounce generates $95 \%$ of potential tax revenue. A tax as high as 3 cents per ounce (which was contemplated in Philadelphia) would generate $30 \%$ of the maximum possible tax revenue. Therefore, even if the sole goal of the tax is revenue generation, high tax rates are sub-optimal because they severely shrink the tax base.

\footnotetext{
${ }^{58}$ Because the revenue-maximizing rate is close to the current tax rate and requires only a small extrapolation, this finding is less sensitive to our assumptions of constant pass-through and demand elasticity.
} 


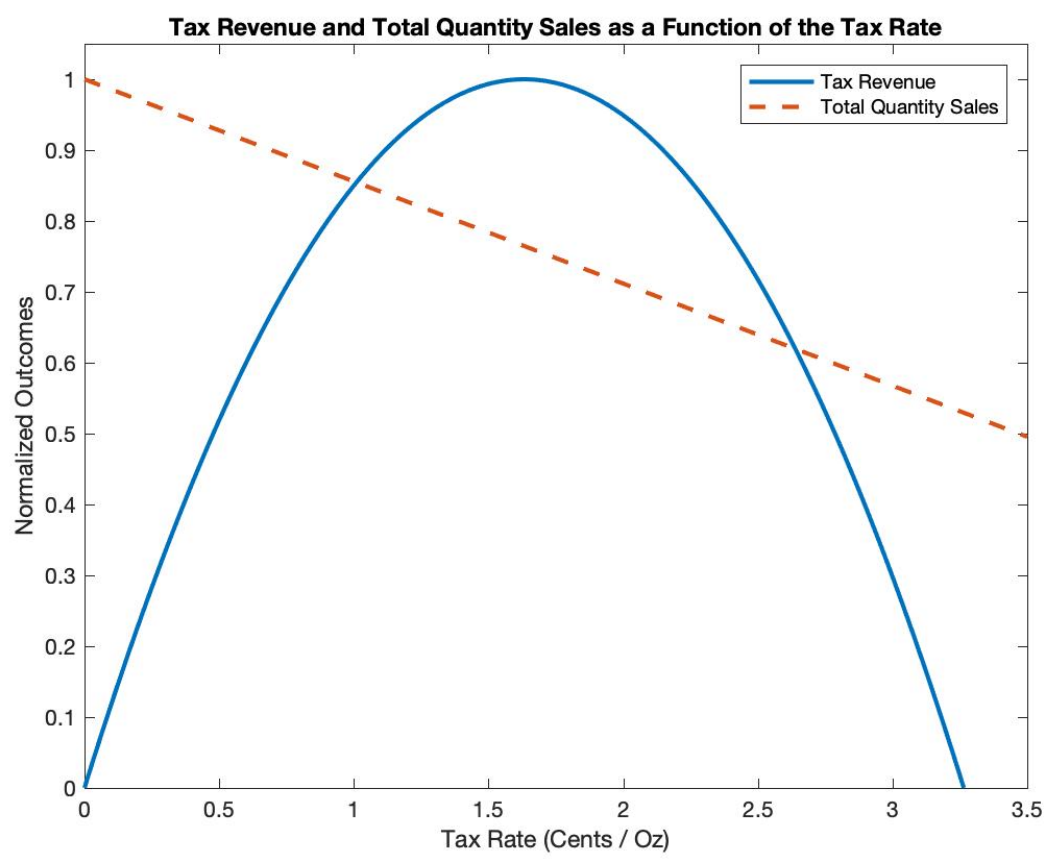

Figure 5: Predicted Tax Revenue and Total Quantity Sales as a Function of the Tax Rate. Tax revenue is normalized relative to the maximum revenue, which is earned with a tax rate of 1.63 cents/oz. Total quantity sales are normalized relative to baseline sales without a tax.

Based on equation (4), Figure 5 also shows the relationship between beverage sales and the tax rate. We find that at the revenue maximizing rate of 1.63 cents per ounce, taxed beverage sales are reduced by $24 \%$. A tax rate of either 1 or 2 cents per ounce would reduce sales by $15 \%$ and $30 \%$ respectively.

In summary, Philadelphia levied a tax that is close to the revenue maximizing tax rate, whereas the initially proposed tax of 3 cents per ounce would have shrunk revenue severely. We note that if policy makers pursue the dual goals of raising revenue and lowering consumption of taxed beverages, any increase of the tax rate up to the revenue-maximizing rate would lead to an improvement along both dimensions. Any further increase would continue to lead to lower sales of taxed beverages, but at the expense of lower revenues. Hence if the sole goal was to raise revenue, the current tax is close to optimal. A higher relative weight on nutritional improvement would suggest raising the tax rate further. For instance, raising the tax rate to 2 cents per oz would lower revenue by only 5 percentage points, but decrease sales of taxed beverages by $30 \%$ instead of $22 \%$.

Geographical Coverage One of our key empirical findings is the large amount of substitution to sweetened beverages purchased at stores outside of Philadelphia. The extent to which consumers are able to engage in such cross-shopping is, of course, a function of the proximity of stores that are not subject to the tax. If a soda tax were to be implemented, for instance, at the state or national level, engaging in cross-shopping would become much harder for consumers (Allcott et al. (2019c)). 
To assess the change in purchases of taxed beverages when cross-shopping is eliminated, we first note that the impact on the aggregate demand elasticity in Philadelphia can be bounded. If all consumers who currently cross-shop instead ceased to purchase taxed beverages altogether, the elasticity of demand in Philadelphia would remain at -1.35. Instead, if all cross-shoppers switched to buying taxed beverages at stores in Philadelphia, the elasticity of demand in Philadelphia would be equal to the elasticity of demand net of cross-shopping, -0.65. To demonstrate how tax revenue and sales of taxed beverages vary depending on assumptions regarding the behavior of cross-shoppers, we plot how various metrics change as we vary the share of cross-shoppers that switch to purchasing in Philadelphia from 0 to 1 and hence the aggregate elasticity of demand in Philadelphia from -1.35 to -0.65 .

The top left graph in Figure 6 plots the revenue maximizing tax rate, which varies between 1.63 cents per ounce at an elasticity of -1.35 (as described above) and 3.47 cents per ounce if the elasticity is equal to -0.65 . The top right graph plots tax revenue as a function of the elasticity of demand in Philadelphia. The dashed line shows tax revenues assuming the observed tax rate of 1.5 cents per ounce is held fixed. Assuming all cross-shoppers stop buying altogether, tax revenues would be unchanged. As the proportion of cross-shoppers that substitute purchases into Philadelphia increases, demand in Philadelphia becomes more inelastic and tax revenue increases. If all cross-shoppers substituted their purchases back to stores in Philadelphia, tax revenue would be 1.45 times higher than the tax revenue generated currently. Moreover, the solid line shows that the possible gains in terms of tax revenue are substantially higher once we set the tax to the revenue-maximizing rate for a given elasticity value.

The bottom graph in Figure 6 traces out the implied reduction in quantity sales of taxed beverages under different scenarios with regard to cross-shopping. Again, the dashed line represents the change in sales under the observed tax rate. If cross-shoppers stop buying taxed beverages altogether, the elasticity of demand in Philadelphia is -1.35 and quantity decreases by $46 \%$ (the observed decrease in Philadelphia). As the proportion of cross-shoppers who substitute their purchases to Philadelphia stores increases, demand in Philadelphia becomes more inelastic, and we see a smaller decrease in quantity. At the extreme, if all cross-shoppers switched to purchasing taxed beverages at stores in Philadelphia, the demand elasticity would be -0.65 and quantity would decrease by only $22 \%$. Interestingly, when we allow the tax rate to be set to the revenue maximizing level across the spectrum of elasticities, we find that sales of taxed beverages are fairly constant, regardless of whether cross-shoppers continue to buy or not 59 Under revenue maximizing tax rates, quantity sales are about $50 \%$ lower than pre-tax levels, which represents a large improvement relative to the observed $22 \%$ reduction when cross-shopping is feasible and the tax rate is 1.5 cents/ounce.

Based on this analysis, we conclude that applying the tax to a larger geographical area has the

\footnotetext{
${ }^{59}$ This relationship is driven by two forces that work in opposite directions and cancel each other out. Going from left to right in the bottom graph of Figure 6, we increase the share of cross-shoppers that switch to purchasing at stores in Philadelphia, thus increasing the sales of taxed beverages when holding the tax rate fixed. However, increasing the share of cross-shoppers that switch to purchasing at stores in Philadelphia also leads to a higher revenue-maximizing tax rate, which acts as an opposing force that depresses sales of taxed beverages.
} 
potential to raise more tax revenue and at the same time lower the sales of taxed beverages 60 If cross-shoppers stop buying altogether and the tax is kept fixed at the current rate, tax revenue would remain unchanged, but we would see large improvements in nutritional intake due to a decrease in sales of taxed beverages. If some cross-shoppers substitute their purchases back into the city, tax revenue would increase and we would see more modest improvements in nutritional intake, relative to the current setting with cross-shopping. When allowing the tax rate to adjust to the revenue-maximizing rate, both revenue gains and the reduction in sales of taxed beverages are larger than under the current tax rate. These patterns illustrate that regardless of the specific policy goals, cross-shopping is detrimental to both the ability to raise tax revenue and to reduce purchases of unhealthy beverages.

Product Coverage Apart from the geographic dimension, the tax base could also be altered along the product dimension. Among the existing soda tax regimes, most cities tax only sugarsweetened beverages, but exclude artificially sweetened drinks, whereas Philadelphia also taxes artificially sweetened drinks. Unfortunately, our data is less suitable to analyze the impact of product coverage because the Philadelphia tax does not induce a change in the relative price of diet and SSBs, and estimating cross-elasticities between those two sets of products is therefore difficult. However, elsewhere in the literature, estimates show that consumers are more likely to substitute from SSBs to diet drinks than to bottled water (see, e.g., Wang (2015) and Allcott et al. (2019b)). Therefore, if taxing only SSBs, we would expect a larger degree of substitution away from SSBs. The smaller tax base would therefore lead to lower tax revenue, but nutritional intake would likely improve. Contrary to changes in geographical coverage, product coverage decisions are therefore likely to impact health and revenue goals differently.

\section{Conclusion}

We use detailed scanner data from a large set of stores in Philadelphia to evaluate the impact of a sweetened-beverage tax. We find the tax is almost fully passed through at most stores. Although the aggregate consumption of taxed beverages decreases, the magnitude of the decrease is reduced considerably because many consumers avoid the tax by cross-shopping. Furthermore, the large amount of cross-shopping reduces the tax base and therefore limits the ability to raise tax revenue. To the best of our knowledge, we are the first to explore the impact of a soda tax on nutritional intake. We document compositional changes in demand, which lead to smaller nutritional gains relative to quantity gains, though the difference is not statistically significant. Finally, purchase quantity decreases less in low-income neighborhoods, most likely because low-income households are less likely to engage in cross-shopping at stores outside of the city.

\footnotetext{
${ }^{60}$ We note that a full evaluation of a tax that is applied to a larger geographical area such as a state-level tax, would have to take tax revenue and demand effects in areas outside of Philadelphia into account as well. Such an analysis is outside of the scope of this paper.
} 

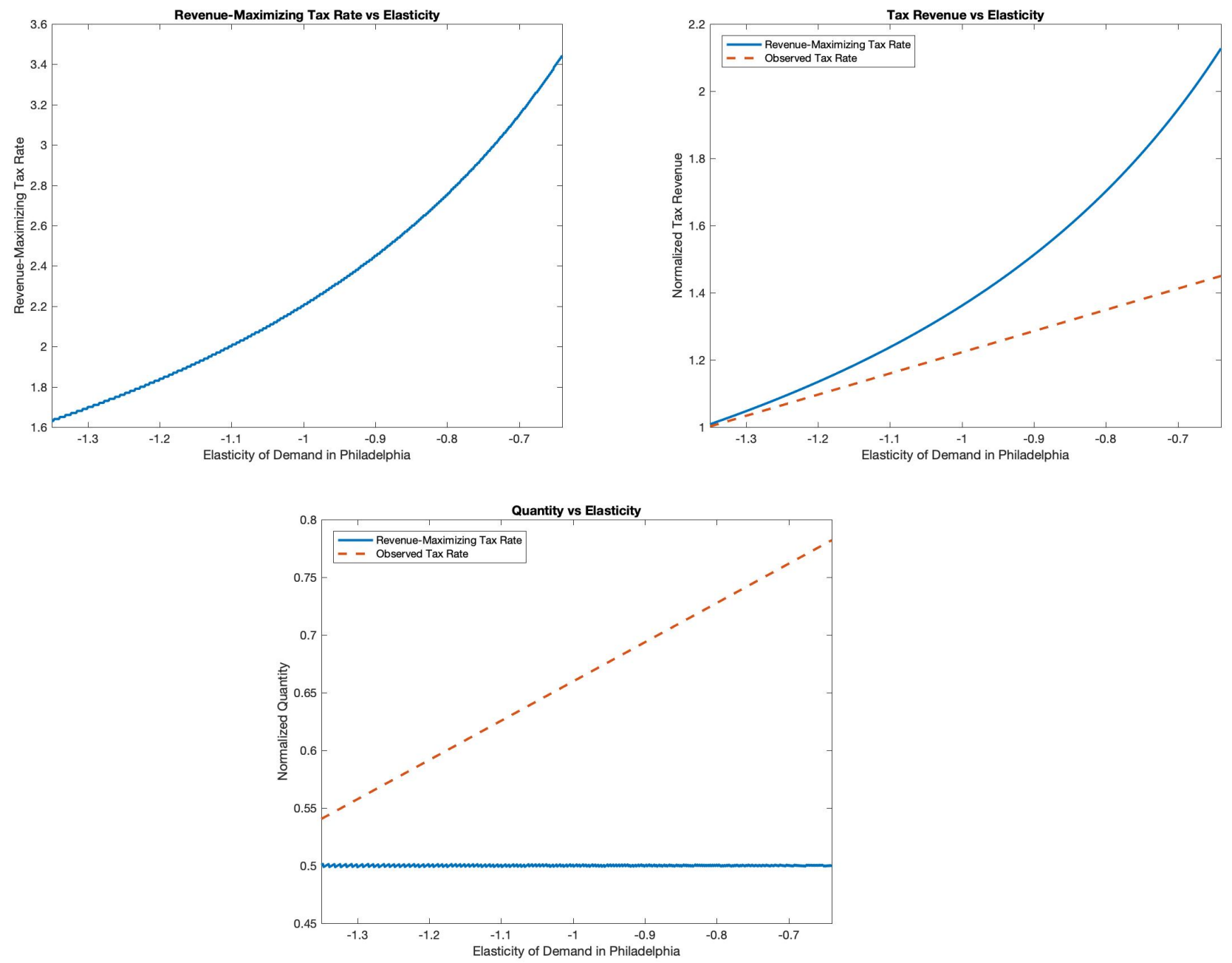

Figure 6: Predicted Outcomes as a Function of the Elasticity of Demand in Philadelphia. From left to right, the share of cross-shoppers that switch to purchasing at stores in Philadelphia ranges from 0 to $100 \%$, and hence the implied elasticity of demand in Philadelphia ranges from -1.35 to -0.65 . Tax revenue is normalized relative to the revenue earned at the observed elasticity of demand in Philadelphia (-1.35) and the observed tax rate (1.5 cents / oz). Quantity is normalized relative to total pre-tax sales at stores in Philadelphia.

Our findings in the case of the Philadelphia tax also provide lessons with regard to the broader question of how to design soda taxes or other types of sin taxes. If taxes are levied over a small geographic area (as is the case for all current US soda taxes), cross-shopping leads to relatively elastic demand and thus high tax rates will be sub-optimal for generating revenue because they reduce the tax base. Furthermore, broadening the tax base along the geographic dimension will likely generate greater tax revenue and lead to larger nutritional improvements.

Our results are also relevant for managers in the retail sector who aim to understand the consequences of soda taxes that might be implemented in other cities. First, the prevalence of crossshopping suggests that retail chains are losing less revenue than the sales decrease in Philadelphia. 
All chains in our sample have a footprint in both Philadelphia and the area near the city border, and thus they may recover some of the lost sales in Philadelphia at stores outside the city. Second, stores outside of Philadelphia (especially those within 2 miles of the border) experience large increases in demand and hence cross-shopping effects are important for inventory management. Finally, it appears that stores in our sample are not responding to differences in the threat of cross-shopping by adjusting their pricing differentially. Most notably, stores that are located close to the city border in Philadelphia lose more demand but exhibit similar pass-through rates to stores further away from the border. Our findings suggest that more granular pricing strategies that take cross-shopping into account could benefit retailers. 


\section{References}

Aguilar, A., E. Gutierrez, And E. Seira (2016): "Taxing to Reduce Obesity," Working Paper.

Ailawadi, K. L. And B. A. Harlam (2009): "Retailer Promotion Pass-Through: A Measure, Its Magnitude, and Its Determinants," Marketing Science, 28, 782-791.

Allcott, H., R. Diamond, J.-P. Dubé, J. Handbury, I. Rahkovsky, and M. Schnell (2019a): "Food Deserts and the Causes of Nutritional Inequality," The Quarterly Journal of Economics, 134, 1793-1844.

Allcott, H., B. B. Lockwood, And D. Taubinsky (2019b): "Regressive Sin Taxes, with an Application to the Optimal Soda Tax," Quarterly Journal of Economics.

— (2019c): "Should We Tax Soda? An Overview of Theory and Evidence," Journal of Economic Perspectives.

Asplund, M., R. Friberg, and F. Wilander (2007): "Demand and distance: Evidence on cross-border shopping," Journal of Public Economics, 91, 141-157.

Bell, D. R., T.-H. Ho, And C. S. TAng (1998): "Determining Where to Shop: Fixed andVariable Costs of Shopping," Journal of Marketing Research, 35, 352-369.

Berardi, N., P. Sevestre, M. Tepaut, and A. Vigneron (2016): "The impact of a 'soda tax' on prices: evidence from French micro data," Applied Economics, 48, 3976-3994.

Bergman, U. M. and N. L. Hansen (2017): "Are Excise Taxes on Beverages Fully Passed Through to Prices? The Danish Evidence," Working Paper, University of Copenhagen.

Besanko, D., J.-P. Dube, and S. Gupta (2005): "Own-Brand and Cross-Brand Retail PassTHrough," Marketing Science, 24, 123-137.

Blattberg, R. And S. Neslin (1990): Sales Promotion: Concepts, Methods and Strategies, Prentice Hall, 2nd ed.

Bollinger, B. and S. E. Sexton (2018): "Local Excise Taxes, Sticky Prices, and Spillovers: Evidence from Berkeley's Soda Tax," Working Paper.

Cawley, J., C. Crain, D. Frisvold, and D. Jones (2018a): "The Pass-Through of the Largest Tax on Sugar-Sweetened Beverages: The Case of Boulder, Colorado," NBER Working Paper.

Cawley, J. And D. Frisvold (2017): "The Incidence of Taxes on Sugar-Sweetened Beverages: The Case of Berkeley, California," Journal of Policy Analysis and Management, 36, 302-326.

Cawley, J., D. Frisvold, A. Hill, And D. Jones (2018b): "The Impact of the Philadelphia Beverage Tax on Purchases and Consumption by Adults and Children," NBER Working Paper. 
- (2020): "The Impact of the Philadelphia Beverage Tax on Prices and Product Availability," Journal of Policy Analysis and Management, 39, 605-628.

Cawley, J., B. Willage, And D. Frisvold (2018c): "Pass-Through of a Tax on SugarSweetened Beverages at the Philadelphia International Airport," JAMA, the Journal of the American Medical Association, 319.

CDC (2013): "Communities Putting Prevention to Work: Philadelphia, Pennsylvania," Online Report.

(2016): "Adult Obesity Facts," Online Report.

CDC/NCCDPHP/DPH/ESB (2016): "500 Cities Project: Local Data for Better Health. 2014. Philadelphia, PA," Tech. rep.

Colchero, M. A., J. Rivera-Dommarco, B. M. Popkin, and S. W. NG (2017): "In Mexico, Evidence of Sustained Consumer Response Two Years after Implementing a Sugar-Sweetened Beverage Tax," Health Affairs, 36, 564-571.

Conlon, C. T. And N. S. Rao (2015): "The Price of Liquor is Too Damn High: Alcohol Taxation and Market Structure," Working Paper.

(2020): "Discrete Prices and the Incidence and Efficiency of Excise Taxes," American Economic Journal: Economic Policy, forthcoming.

DellaVigna, S. and M. Gentzkow (2019): "Uniform Pricing in US Retail Chains," Quarterly Journal of Economics, 134, 2011-2084.

Dubois, P., R. Griffith, And M. O'Connell (2017): "How well targeted are soda taxes," Working Paper.

Erdem, T., S. Imai, And M. Keane (2003): "Brand and Quantity Choice Dynamics Under Price Uncertainty," Quantitative Marketing and Economics, 1, 5-64.

Esterl, M. (2016): "Philadelphia Mayor to Propose Soda Tax," The Wall Street Journal.

Falbe, J., N. Rojas, A. H. Grummon, and K. A. Madsen (2015): "Higher Retail Prices of Sugar-Sweetened Beverages 3 Months After Implementation of an Excise Tax in Berkeley, California," American Journal of Public Health, 105, 2194-2201.

Falbe, J., H. R. Thompson, C. M. Becker, N. Rojas, C. E. McChulloch, and K. A. Madsen (2016): "Impact of the Berkeley Excise Tax on Sugar-Sweetened Beverage Consumption," American Journal of Public Health.

FerRIs, J. S. (2000): "The Determinants of Cross Border Shopping: Implications for Tax Revenues and Institutional Change," National Tax Journal, 53, 801-824. 
Finkelstein, E. A., J. G. Trogdon, J. W. Cohen, and W. Dietz (2009): "Annual Medical Spending Attributable to Obesity: Payer- and Service-Specific Estimates," Health Affairs, 28.

Fiorillo, V. (2017): "ShopRite VP Respondes to Accusations of Price-Gouging and Fraud," Philadelphia.

Goli, A. And P. K. Chintagunta (2019): "What Happens When a Retailer Drops a Product Category? Investigating the Consequences of Ending Tobacco Sales," Working Paper.

Griffith, R., L. Nesheim, and M. O'Connell (2018): "Income effects and the welfare consequences of tax in differentiated product oligopoly," Quantitative Economics, 9, 305-341.

Grogger, J. (2017): "Soda Taxes and the Prices of Sodas and Other Drinks: Evidence from Mexico," American Journal of Agricultural Economics, 99, 481-498.

Grummon, A. H., B. B. Lockwood, D. Taubinsky, and H. Allcott (2019): "Designing better sugary drink taxes," Science, 365, 989-990.

Harding, M., E. Leibtag, And M. F. Lovenheim (2012): "The Heterogeneous Geographic and Socioeconomic Incidence of Cigarette Taxes: Evidence from Nielsen Homescan Data," American Economic Journal: Economic Policy, 4, 169-198.

Hendel, I. And A. Nevo (2006): "Measuring the Implications of Sales and Consumer Inventory Behavior," Econometrica, 74, 1637-1673.

Hoch, S. J., X. Drèze, And M. E. Purk (1994): "EDLP, Hi-Lo, and Margin Arithmetic," Journal of Marketing, 58, 16-27.

Hollenbeck, B. And K. Uetake (2018): "Taxation and Market Power in the Legal Marijuana Industry," Working Paper.

Jacobi, L. And M. Sovinsky (2016): "Marijuana on Main Street? Estimating Demand in Markets with Limited Access," American Economic Review, 106, 2009-2045.

Khan, R., K. Misra, And V. Singh (2016): “Will a Fat Tax Work?" Marketing Science, 35, $10-26$.

Kifer, A. (2015): "The Incidence of a Soda Tax, in Pennies and Pounds," Working Paper.

KIm, T. AND D. KC (2019): "The Impact of Hospital Advertising on Patient Demand and Health Outcomes," Marketing Science.

Lovenheim, M. F. (2008): "How far to the border?: The extent and impact of cross-border casual cigarette smuggling." National Tax Journal, 61, 7-33. 
Manson, S., J. Schroeder, D. Van Riper, and S. Ruggles (2017): IPUMS National Historical Geographic Information System: Version 12.0 [Database], Minneapolis: University of Minnesota.

McShane, B. B., C. Chen, E. T. Anderson, And D. I. Simester (2016): "Decision Stages and Asymmetries in Regular Retail Price Pass-Through," Marketing Science, 35, 619-639.

Merriman, D. (2010): "The Micro-geography of Tax Avoidance: Evidence from Littered Cigarette Packs in Chicago," American Economic Journal: Economic Policy, 2, 61-84.

Miravete, E. J., K. Seim, And J. Thurk (2017): "One Markup to Rule Them All: Taxation by Liquor Pricing Regulation," Working Paper.

(2018): "Market Power and the Laffer Curve," Econometrica, 86, 1651-1687.

Mojir, N. And K. Sudhir (forthcoming): "A Model of Multipass Search: Price Search Across Stores and Time," Management Science.

National Cancer Institute (2018): "Sources of Calories from Added Sugars among the U.S. Population, 2005-06," Tech. rep., Epidemiology and Genomics Research Program website.

Nijs, V., K. Misra, E. T. Anderson, K. Hansen, and L. Krishnamurthi (2010): "Channel Pass-Through of Trade Promotions," Marketing Science, 29, 250-267.

OECD (2017): "Obesity Update 2017," Technical Report.

Ogden, C. L., M. D. Carroll, C. D. Fryar, and K. M. Flegal (2015): "Prevalence of Obesity Among Adults and Youth: United States, 2011-2014," NCHS Data Brief, 219.

Roberto, C., H. Lawman, M. LeVasseur, N. Mitra, A. Peterhans, B. Herring, and S. N. Bleich (2019): "Association of a Beverage Tax on Sugar-Sweetened and Artificially Sweetened Beverages with Changes in Beverage Prices and Sales at Chain Retailers in a Large Urban Setting," JAMA, the Journal of the American Medical Association, 321, 1799-1810.

Rojas, C. And E. Wang (2017): "Do Taxes for Soda and Sugary Drinks Work? Scanner Data Evidence from Berkeley and Washington," Working Paper.

SeILER, S. And S. YaO (2017): "The Impact of Advertising along the Conversion Funnel," Quantitative Marketing and Economics, 15, 241-278.

Silver, L. D., S. W. NG, S. Ryan-Ibarra, L. S. Taillie, M. Induni, D. R. Miles, J. M. Poti, And B. M. Popkin (2017): "Changes in prices, sales, consumer spending, and beverage consumption one year after a tax on sugar-sweetened beverages in Berkeley, California, US: A before-and-after study," PLoS Medicine.

Taylor, R. L. C., S. Kaplan, S. B. Villas-Boas, and K. Jung (2019): "Soda Wars: The Effect of a Soda Tax Election on University Beverage Sales," Economic Inquiry, forthcoming. 
Thomassen, Ø., H. Smith, S. Seiler, And P. Schiraldi (2017): "Multi-Category Competition and Market Power: A Model of Supermarket Pricing," American Economic Review, 107, 23082351.

Tuchman, A. E. (2019): "Advertising and Demand for Addictive Goods: The Effects of ECigarette Advertising," Marketing Science, 38, 994-1022.

WANG, E. Y. (2015): "The impact of soda taxes on consumer welfare: implications of storability and taste heterogeneity," The RAND Journal of Economics, 46, 409-441.

Wang, Y., M. Lewis, And V. Singh (2016): "The Unintended Consequences of CounterMarketing Strategies: How Particular Anti-Smoking Measures May Shift Consumers to More Dangerous Cigarettes," Marketing Science, 35, 545-575.

Yavorsky, D., E. Honka, And M. K. Chen (2020): "Consumer Search in the U.S. Auto Industry: The Value of Dealership Visits," Working Paper.

Zhen, C., I. F. Brissette, And R. R. Ruff (2014): "By Ounce or by Calorie: The Differential Effects of Alternative Sugar-Sweetened Beverage Tax Strategies," American Journal of Agricultural Economics, 96, 1070-1083. 


\begin{tabular}{lccc}
\hline $\begin{array}{l}\text { Geographic } \\
\text { Coverage }\end{array}$ & $\begin{array}{c}\text { Diff. in } \\
\text { Coverage Rate } \\
\text { Phil. Minus } \\
\text { Miles Outside }\end{array}$ & $\begin{array}{c}\text { P-value } \\
\text { Diff. } \\
\text { in Means } \\
\text { Test }\end{array}$ \\
\hline All Stores & 0.006 & 0.793 & \\
Small Format & 0.034 & 0.220 & \\
Large Format & -0.098 & 0.068 & \\
Grocery Stores & -0.096 & 0.128 & \\
Mass Merchants & 0.000 & 1.000 & P-value \\
Wholesale Clubs & 0.111 & 0.588 & Diff. \\
Drug Stores & -0.059 & 0.147 & in Means \\
Convenience Stores & 0.039 & 0.322 & Test \\
Dollar Stores & 0.068 & 0.315 & 0.535 \\
\hline \multirow{2}{*}{ Store Format } & Diff. in & & \\
Coverage & Small Minus & &
\end{tabular}

Diff. in Coverage Rate Relative to Convenience Stores

\begin{tabular}{cccccc} 
Drug & Dollar & Grocery & Mass & Wholes. & \\
Stores & Stores & Stores & Merch. & Club & \\
\hline 0.247 & 0.117 & 0.001 & 0.325 & 0.367 & 0.000 \\
\hline
\end{tabular}

Table A1: Coverage in IRI (versus Universe of Stores). Coverage rates calculated as the fraction of stores (of a particular type) that are tracked by IRI.

\section{A Store Coverage in IRI Data}

In this section, we assess whether our sample of stores is representative of all stores located in Philadelphia and the surrounding areas. To this end, we obtained data from IRI on the universe of stores in the relevant geographic areas. Out of all the stores listed, only a subset have their volume and prices tracked by IRI. Relative to the primary data used throughout the paper, the list of stores is cross-sectional and does not contain information on store entry and exit. We therefore assess how tracked stores (regardless of when they enter or exit) compare to the universe of stores.

Due to concerns about data privacy, we do not report coverage rates in levels, but only report differences in coverage rates between various groups of stores. Out of all potential stores, more than $60 \%$ are tracked by IRI. We assess selection into being tracked along two dimensions that are particularly relevant for our analysis, namely, along the geographic dimension and across store formats. Geographic coverage, which we analyze in the top panel of Table A1, is particularly important because we contrast the change in demand in Philadelphia with the change in stores near the city border when calculating the change in total demand. When considering all types of stores, we find the coverage is very similar. The difference between coverage in Philadelphia and 
coverage up to 6 miles outside the city is only 0.6 percentage points, and this difference is not statistically significant. We also assess geographic coverage by store format, first by small versus large stores (small-format stores comprise Drug Stores, Convenience Stores, and Dollar Stores; large-format stores comprise Grocery Stores, Mass Merchants, and Wholesale Club Stores) and then separately for the six different formats. We do not find a significant difference in coverage for any of these groups of stores.

In the lower panel of Table A1, we focus on the format dimension. The most important aspect in terms of coverage by format is larger versus smaller formats of stores, because larger stores sell significantly more quantity of taxed beverages than do smaller stores as documented in Table 1 . Furthermore, quantity decreases more at larger stores in reaction to the tax (see Table 3), partly because large stores tend to sell larger pack sizes (which are more affected by cross-shopping). We find that coverage rates for large- and small-format stores are not significantly different from each other. We note that when splitting the sample more granularly into six separate formats, we do find significant differences in coverage. However, we regard this more granular split as less relevant for our main regression results, because coverage at the more aggregate level of large- and small-format stores does not differ.

As a final check, we use the coverage rates by format and geography to re-weight the results from some of our main regressions. First, we apply geography-specific weights to the cross-shopping regressions 61 In the case of column (1) of Table 5, we find the re-weighted effect with (without) cross-shopping is equal to a $21 \%(46 \%)$ reduction in quantity compared to a $22 \%(46 \%)$ reduction without re-weighting. We also compute the average pass-through and quantity change based on weighting the chain-specific results in column (2) of Table 2 and column (2) of Table 3 by the appropriate format-specific weights (based on the six different formats) ${ }^{62}$ We find the weighted (unweighted) pass-through is equal to 1.481 (1.449) and the weighted (unweighted) quantity change is equal to $-61,959(-56,192)$.

\section{B Detailed Comparison to Roberto et al. (2019)}

Roberto et al. (2019)'s analysis of the Philadelphia tax uses similar retail scanner data, but their data is less comprehensive than ours both geographically and in terms of the retail formats observed in the data. Where their analysis overlaps with ours, effect magnitudes sometimes differ substantially and hence our conclusions with regard to the effectiveness of the tax are different.

\footnotetext{
${ }^{61}$ In order to re-weight the cross-shopping regression, we multiply the various geography-specific coefficients (Philadelphia, 0-2 mile band, etc.) by the number of stores in the universe of stores rather than the number of stores in the sample.

${ }^{62}$ We re-weight quantity and price effects using the estimates from the price and quantity regressions with chainspecific effects (column (2) of Tables (2) and (3)). Based on those regression estimates, we compute the average effect by taking a weighted average of the chain-specific effects. The weights are given by the number of stores associated with a given format in the store universe, adjusted for the prevalence of chains within a given format. For example, for grocery stores, the calculation would be: $\left(\beta_{A} \times w_{A}+\beta_{B} \times w_{B}+\beta_{C} \times w_{C}\right) \times \#$ GroceryStoresInUniverse where $w_{j}=\left(\frac{\# \text { stores } j}{\# \text { storesA+\#stores } B+\# \text { storesC }}\right)$. This calculation re-scales the effects up to the full universe of stores, while giving more weight to estimates for formats that are more prevalent within the city.
} 
This appendix describes how our samples differ and explains why these differences generate different estimates for price pass-through, quantity reduction, and price elasticities.

Differences in the Data Although Roberto et al. (2019) also analyze retail scanner data from the same data provider (IRI), our samples are not identical.

1. In addition to the retail formats observed by Roberto et al. (2019), we also observe 116 convenience stores, 54 dollar stores, and 2 wholesale club stores that together account for $26 \%$ of the pre-tax volume sales in our Philadelphia data (see Table 1). In Appendix A, we show that our sample is representative of the Philadelphia retail landscape in terms of the distribution of large- and small-format retailers.

2. With regard to stores outside of Philadelphia that may benefit from cross-shopping, Roberto et al. (2019) observe stores in Pennsylvania that are located within 3 miles of the Philadelphia border. They do not observe data for stores more than 3 miles outside the city limits, nor do they observe nearby stores in New Jersey. Furthermore, within the geography 0-3 miles outside Philadelphia in Pennsylvania, we observe 72 pharmacies, supermarkets, and mass merchant stores while Roberto et al. (2019) only observe 5163

3. Roberto et al. (2019) analyze data from 2016 - 2017. Our sample runs from 2015 through September 2018, so we observe an additional year of data in the pre-tax period and an additional 9 months of data in the post-tax period. Our longer panel allows us to document evidence of a short-term adjustment period and omit this adjustment period from our main estimates, while Roberto et al. (2019)'s post-tax period includes this four-month adjustment period 64

4. We compute and analyze volume-weighted prices, while Roberto et al. (2019) compute a simple average price across UPCs.

5. We observe retail chain identities (which are typically anonymized), which allows us to account for the fact that one retailer's price was recorded net of the tax in the data (see footnote 11 and the discussion in Appendix C).

6. The two papers use different control groups. Roberto et al. (2019) use Baltimore stores as a control group, while we use stores $6+$ miles outside Philadelphia that lie in the 3 -digit zip

\footnotetext{
${ }^{63}$ Our store counts are very similar within the city of Philadelphia (our final sample includes 180 pharmacies, supermarkets, and mass merchant stores and Roberto et al. (2019) analyze 185 of these store types.) Thus, we hypothesize that the differences in our store counts for Pennsylvania stores are due to how we define this geography. Roberto et al. (2019) analyze cross-border shopping in "zip codes within approximately 3 miles of Philadelphia's border in 3 Pennsylvania counties (Bucks, Delaware, and Montgomery)." In contrast, we observe precise store addresses for all pharmacies, supermarkets, and mass merchant stores, and measure distance from the city border using this precise location information.

${ }^{64}$ The longer panel also allows us to show that the important force of cross-shopping is not just a short-run response to the tax.
} 
codes that surround Philadelphia. Price and quantity trends in both of our control groups seem fairly similar, so we do not expect this to drive substantial differences in our analyses.

7. We conduct some data cleaning (described in Appendix E) to remove stores and products that are observed infrequently and to fill in missing prices in weeks when no purchase is made. Differences in how we clean the data could generate slight differences in the samples that we analyze. For example, Roberto et al. (2019) drop energy drinks from their sample, but we retain these products because they were subject to the tax.

Price Pass-Through The aforementioned differences in our sample lead us to estimate differences in the effect of the tax on prices. Specifically, Roberto et al. (2019) estimate lower pre-tax prices and lower pass-through than we do65

In an effort to understand why the differences in our samples lead to different estimates of passthrough, we attempt to replicate Roberto et al. (2019)'s analysis of prices by restricting our sample of stores and time periods to be consistent with theirs. We retain the first 4 months after the tax went into effect and we drop the additional 9 months of data we have from 2018, so the post-tax period is all of 2017. We also remove the correction to the prices for Grocery $\mathrm{C}$ as described in footnote 11. In Table A2, we report pass-through estimates separately by retail format in order to facilitate comparison with Roberto et al. (2019). Column (1) reports Roberto et al. (2019)'s estimates. Column (2) reports our replication attempt in which we give equal weight to all UPCs. Column (3) reports our replication attempt where we make the aforementioned restrictions to our sample, but we use volume-based weights in the analysis. Finally, column (4) reports our estimates based on our own dataset using the full set of retail chains, time periods, product categories, and volume-weights.

Columns 2 and 3 help us understand what differences in the data are driving the differences in our results. Our replication shows that differences in pre-tax prices are largely due to the fact that Roberto et al. (2019) give equal weight to all UPCs, while we construct a volume-weighted price variable that gives more weight to the prices of UPCs that have higher pre-tax sales volume (and tend to be cheaper on a per oz basis). Furthermore, the correction we make to Grocery $\mathrm{C}$ prices does not fully account for the difference in estimated pass-through at grocery stores, but it does explain $85 \%$ of the difference. 66

After attempting to replicate Roberto et al. (2019)'s data to the best of our abilities, we still find some differences in pre-tax prices and estimated pass-through. Comparing columns 1 and 2, our calculated pre-tax prices still tend to be lower than Roberto et al. (2019)'s, and although

\footnotetext{
${ }^{65}$ The difference in estimated pass-through is notable because Roberto et al. (2019)'s finding of incomplete passthrough suggests that the city can extract some "free" revenue from companies without distorting market outcomes for consumers. In contrast, our estimate of complete pass-through suggests that this is not the case.

${ }^{66}$ With the Grocery C price adjustment, we estimate average pass-through at Philadelphia grocery stores to be 1.57 cents per oz. Without the price adjustment but holding the rest of our sample fixed, our estimate of pass-through is 0.79 cents per oz. Roberto et al estimate grocery pass-through of 0.65 cents per oz.
} 


\begin{tabular}{|c|c|c|c|c|}
\hline & $\begin{array}{c}(1) \\
\text { Roberto et al. } \\
(2019)\end{array}$ & $\begin{array}{c}(2) \\
\text { Replication } \\
\text { Simple Average }\end{array}$ & $\begin{array}{c}(3) \\
\text { Replication } \\
\text { Volume-Weighted }\end{array}$ & $\begin{array}{c}(4) \\
\text { Our Estimate }\end{array}$ \\
\hline \multicolumn{5}{|c|}{ Drug Stores / Pharmacies } \\
\hline Av. Pre-Tax Price/Oz & 6.60 & 6.79 & 5.56 & 5.52 \\
\hline Pass-Through & $\begin{array}{c}1.56 \\
(1.50,1.62)\end{array}$ & $\begin{array}{c}1.08 \\
(0.96,1.19)\end{array}$ & $\begin{array}{c}1.16 \\
(1.06,1.26)\end{array}$ & $\begin{array}{c}1.30 \\
(1.23,1.37)\end{array}$ \\
\hline$\%$ Price Change & $\begin{array}{c}23.5 \% \\
-\end{array}$ & $\begin{array}{c}21.1 \% \\
(18.5 \%, 23.8 \%)\end{array}$ & $\begin{array}{c}20.7 \% \\
(18.6 \%, 22.8 \%)\end{array}$ & $\begin{array}{c}23.7 \% \\
(22.0 \%, 25.3 \%)\end{array}$ \\
\hline Mass Merchandisers & & & & \\
\hline Av. Pre-Tax Price/Oz & 5.28 & 4.50 & 3.67 & 3.68 \\
\hline Pass-Through & $\begin{array}{c}0.87 \\
(0.72,1.02)\end{array}$ & $\begin{array}{c}0.72 \\
(0.51,0.93)\end{array}$ & $\begin{array}{c}0.80 \\
(0.63,0.98)\end{array}$ & $\begin{array}{c}0.88 \\
(0.68,1.08)\end{array}$ \\
\hline$\%$ Price Change & $\begin{array}{c}16.4 \% \\
-\end{array}$ & $\begin{array}{c}18.9 \% \\
(13.1 \%, 25.0 \%)\end{array}$ & $\begin{array}{c}22.1 \% \\
(16.0 \%, 28.4 \%)\end{array}$ & $\begin{array}{c}24.4 \% \\
(17.5 \%, 31.6 \%)\end{array}$ \\
\hline \multicolumn{5}{|c|}{ Grocery Stores / Supermarkets } \\
\hline Av. Pre-Tax Price/Oz & 5.43 & 4.23 & 3.33 & 3.28 \\
\hline Pass-Through & $\begin{array}{c}0.65 \\
(0.60,0.69)\end{array}$ & $\begin{array}{c}0.62 \\
(0.41,0.84)\end{array}$ & $\begin{array}{c}0.77 \\
(0.55,0.99)\end{array}$ & $\begin{array}{c}1.57 \\
(1.48,1.66)\end{array}$ \\
\hline$\%$ Price Change & $\begin{array}{c}11.8 \% \\
-\end{array}$ & $\begin{array}{c}16.1 \% \\
(10.7 \%, 21.8 \%)\end{array}$ & $\begin{array}{c}20.4 \% \\
(14.7 \%, 26.4 \%)\end{array}$ & $\begin{array}{c}46.3 \% \\
(42.9 \%, 49.9 \%)\end{array}$ \\
\hline Other Retail Format & & & & \\
\hline Av. Pre-Tax Price/Oz & - & 7.27 & 6.49 & 6.36 \\
\hline Pass-Through & $\begin{array}{l}- \\
-\end{array}$ & $\begin{array}{c}1.45 \\
(1.38,1.51)\end{array}$ & $\begin{array}{c}1.47 \\
(1.40,1.54)\end{array}$ & $\begin{array}{c}1.58 \\
(1.53,1.64)\end{array}$ \\
\hline$\%$ Price Change & $\begin{array}{l}- \\
-\end{array}$ & $\begin{array}{c}25.4 \% \\
(23.7 \%, 27.2 \%)\end{array}$ & $\begin{array}{c}25.9 \% \\
(23.9 \%, 27.59 \%)\end{array}$ & $\begin{array}{c}28.3 \% \\
(26.4 \%, 30.3 \%)\end{array}$ \\
\hline
\end{tabular}

Table A2: Estimated Pass-Through and Percent Price Increase by Retail Format. 95\% confidence intervals are reported in parentheses.

Roberto et al. (2019)'s estimated pass-through at mass merchandisers and supermarkets lies within our replication attempt's $95 \%$ CI, their estimate for pharmacies lies outside our confidence interval.

When we compute the percentage price increase that results from the tax (an input into the price elasticity calculation), we are able to come close to approximating Roberto et al. (2019)'s results. Comparing columns 1 and 2, Roberto et al. (2019)'s reported percentage price increase estimates lie within our $95 \%$ confidence intervals for all three retail formats where our samples overlap.

Quantity Effects Roberto et al. (2019) estimate that volume sales of taxed beverages in Philadelphia decrease by $51 \%$. We estimate a smaller $46 \%$ decrease in sales in Philadelphia. This is partially 


\begin{tabular}{lcccc}
\hline & Roberto et al. & $(2019)$ & Replication & Our Estimate \\
\hline $\begin{array}{l}\text { Change in \% of Pre-Tax Volume in } \\
\text { Philadelphia w/o Cross-Shopping }\end{array}$ & $-51 \%$ & $\begin{array}{c}-50 \% \\
(-69 \%,-32 \%)\end{array}$ & $\begin{array}{c}-46 \% \\
(-62 \%,-30 \%)\end{array}$ \\
\hline & $\begin{array}{c}\text { Roberto } \\
\text { et al. } \\
(2019)\end{array}$ & $\begin{array}{c}\text { Restricting to 51 stores } \\
\text { in PA 0-3 mile band }\end{array}$ & $\begin{array}{c}\text { Using all 72 stores } \\
\text { in PA 0-3 mile band }\end{array}$ \\
\hline $\begin{array}{l}\text { Change in \% of Pre-Tax } \\
\text { Volume in Philadelphia } \\
\text { w/ Cross-Shopping }\end{array}$ & $-38 \%$ & $-34 \%$ & $-28 \%$ & Our Estimate \\
\hline
\end{tabular}

Table A3: Estimated Quantity Response.

driven by the fact that our data includes additional retail formats, and the quantity response at these formats differs from the response at the sub-set of retail formats observed by Roberto et al. (2019). For example, convenience stores (which account for $19 \%$ of our pre-tax volume sales) experience only a $10 \%$ decrease in sales, which is substantially smaller than the decrease at grocery stores and mass-merchants (see Table 3). Furthermore, our main analyses drop the first four-months of the post-tax period. Dropping these months leads us to estimate a larger effect of the tax, because the quantity response in the first few months was smaller than the long-run response (see Appendix G. If we restrict our data to both the time periods and retail formats analyzed by Roberto et al. (2019), these two forces partially off-set each other and we estimate a $50 \%$ reduction in volume sales of taxed beverages in Philadelphia. This is very close to Roberto et al. (2019)'s estimate of $51 \%$ (see the top panel of Table A3).

Roberto et al. (2019) also test for cross-border shopping by analyzing Pennsylvania stores within 3 miles of the Philadelphia border; however, they do not observe data for stores more than 3 miles outside the city limits, nor do they observe nearby stores in New Jersey. They conclude that $24 \%$ of their estimated reduction in sales in Philadelphia is offset by an increase in sales in these border stores, resulting in an overall reduction of $38 \%$. We find that $52 \%$ of the sales reduction in Philadelphia is offset by cross-shopping, resulting in an overall reduction of $22 \%$. We find evidence of significant increases in sales up to 6 miles outside of the city limits, as well as evidence of crossshopping at stores in both Pennsylvania and New Jersey. When we restrict our sample to the retail formats observed by Roberto et al. (2019), the limited geographies, and the same time period they analyze, we estimate a $28 \%$ overall reduction. As we describe under bullet-point (2) above, within the Pennsylvania 0-3 mile band, we observe 72 stores, while Roberto et al. (2019) only observe 51 stores. If we "restrict" our sample to only have 51 stores in that band, and assume that these stores have the average per store increase from cross-shopping (i.e. assume stores are missing at random in Roberto et al. (2019)'s sample), we come close to replicating Roberto et al. (2019)'s quantity effects. Under this additional restriction, we estimate an overall reduction of $34 \%$ in volume sales, while they estimate an overall reduction of $38 \%$. This analysis indicates that failing to account 


\begin{tabular}{|c|c|c|c|}
\hline Dependent Variable & $\begin{array}{c}\text { Ounces } \\
\text { Sold } \\
\text { Taxed } \\
\text { Beverages }\end{array}$ & $\begin{array}{c}\text { \# Stores } \\
\text { in Geogr. } \\
\text { Area }\end{array}$ & $\begin{array}{c}\text { Share of } \\
\text { Cross-Shopped } \\
\text { Volume }\end{array}$ \\
\hline Philadelphia $\times$ After Tax & $\begin{array}{c}-56,193^{* * *} \\
(9,742)\end{array}$ & 357 & \\
\hline $\begin{array}{l}0-3 \text { Miles Outside City Border } \times \\
\text { PA } \times \text { After Tax }\end{array}$ & $\begin{array}{c}61,922^{* * *} \\
(17,407)\end{array}$ & 135 & $79 \%$ \\
\hline $\begin{array}{l}3-6 \text { Miles Outside City Border } \times \\
\text { PA } \times \text { After Tax }\end{array}$ & $\begin{array}{l}8,954^{*} \\
(4,898)\end{array}$ & 108 & $9 \%$ \\
\hline $\begin{array}{l}0-3 \text { Miles Outside City Border } \times \\
\text { NJ } \times \text { After Tax }\end{array}$ & $\begin{array}{l}11,908 \\
(9,262)\end{array}$ & 45 & $5 \%$ \\
\hline $\begin{array}{l}3-6 \text { Miles Outside City Border } \times \\
\text { NJ } \times \text { After Tax }\end{array}$ & $\begin{array}{l}6,985^{*} \\
(3,883)\end{array}$ & 107 & $7 \%$ \\
\hline Store FE & Yes & & \\
\hline Week FE & Yes & & \\
\hline Change in Aggregate & $-9,451^{* *}$ & & \\
\hline Quantity (Unit: 1,000 Ounces) & $(4,354)$ & & \\
\hline Change in $\%$ of Pre-tax Volume in & $-0.216^{* *}$ & & \\
\hline Philadelphia w/ Cross-Shopping & $(0.100)$ & & \\
\hline Change in $\%$ of Pre-tax Volume in & $-0.459^{* * *}$ & & \\
\hline Philadelphia w/o Cross-Shopping & $(0.080)$ & & \\
\hline Observations & 213,499 & & \\
\hline Stores & 1,227 & & \\
\hline Weeks & 176 & & \\
\hline
\end{tabular}

Table A4: Quantity Reaction in Stores Near the City Border.

for cross-shopping in other geographic regions, as well as missing stores in Pennsylvania 0-3 miles outside Philadelphia, both contribute to Roberto et al. (2019)'s under-estimate of the extent to which cross-shopping occurs in the data (see the lower panel of Table A3).

To further decompose the sources of the difference in our cross-shopping estimates, we breakdown the fraction of all cross-shopped volume that was substituted to different geographic regions (see Table A4). Specifically, we estimate a regression similar to what is reported in Table 5, but to facilitate comparison with Roberto et al. (2019), we separately measure cross-shopping at stores 0-3 and 3-6 miles outside the city border in both Pennsylvania and New Jersey. We perform these calculations working off our full sample of stores and time periods. We find that $79 \%$ of cross-shopped volume is to Pennsylvania stores 0-3 miles outside Philadelphia, 9\% of cross-shopped volume is to Pennsylvania stores 3-6 miles outside Philadelphia, and $12 \%$ of cross-shopped volume is to New Jersey stores.

Price Elasticities Differences in the estimated impact of the tax on both prices and quantities lead to substantially different elasticities. Roberto et al. (2019) report a price elasticity of -1.7 , which is the price elasticity of demand after accounting for cross-shopping. Because we estimate a 
smaller percent reduction in volume and a larger percent increase in price, we estimate the elasticity of overall consumption (i.e. net of cross-shopping) to be much smaller, $\eta_{q p}=-22 \% / 34 \%=-0.6$.

We attempt to replicate Roberto et al. (2019)'s elasticity calculation by restricting our sample of stores and time periods to be comparable. Using our "replication sample," the implied elasticity of overall consumption is $\eta_{q p}=-34 \% / 18 \%=-1.9$ when using simple average prices and $\eta_{q p}=$ $-34 \% / 21 \%=-1.6$ when using volume-weighted prices. These are reasonably close to Roberto et al. (2019)'s estimated elasticity of -1.7 .67$

\section{Heterogeneity in Price Recording Across Retailers}

As outlined in footnote 11, one retailer in our dataset reported the soda tax as a separate item on the checkout receipt rather than reporting the total price including the tax. Figure A1 shows two receipts from this retailer - one from $1 / 1 / 2017$ and a recent receipt from 10/18/2019 - in which the Philadelphia soda tax is reported as a separate item (see highlighted area of the receipt). In contrast, Figure A2 shows that on the shelf tags, this retailer reports the price inclusive of the tax, along with a note that that price includes the Philadelphia beverage tax. We have confirmed that the shelf tag price is equal to the sum of the price and the tax as reported on the receipt. Further, we compared receipts to the relevant prices in the IRI data to establish that throughout our sample period, our data reports price net of the tax for this retailer. Thus, in order to recover the effective price paid by consumers, we need to add the 1.5 cents/oz tax onto this retailer's prices starting in January 2017.

Figure A3 shows two additional receipts from two other retailers, where the tax is not broken out as a separate item, but the price includes the tax. We verified that all retailers except for the one in Figure A1 report the tax in this fashion. We also compared receipts from these retailers to the relevant prices in the IRI data to establish that our data reports total price inclusive of the tax for all retailers except the one in Figure A1.

\footnotetext{
${ }^{67}$ According to Roberto et al. (2019)'s supplementary appendix, they arrive at this estimate by separately computing an elasticity for each retail format - beverage size combination, and then computing the volume-weighted average of these elasticities. In contrast, we compute elasticities by dividing the overall reduction in quantity by the average increase in price.
} 

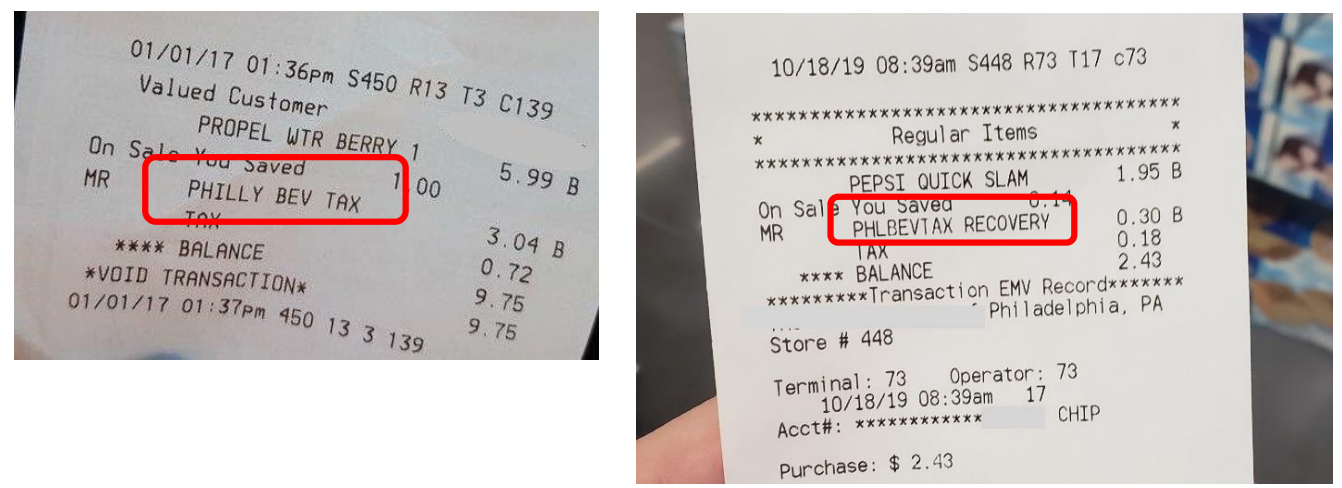

Figure A1: Sample Receipts with Separate Beverage Tax Reporting. The two receipts are from the same retailer on two different dates. (The day the tax was introduced $1 / 1 / 2017$ and a recent receipt from 10/18/2019. See dates in the top left corner of both receipts.)

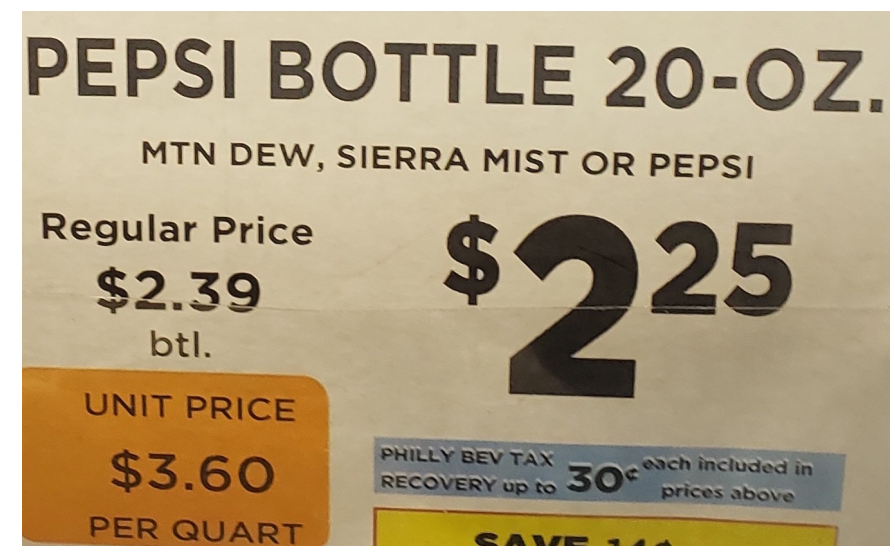

Figure A2: Sample Price Tag with Beverage Tax Included in Price. The price tag shown above is from the retailer that reports the tax separately on the receipt (see Figure A1). Unlike the reporting on the receipt, the shelf tag includes the tax in the product price. This shelf tag was photographed on 10/18/2019 and corresponds to the item purchased in the receipt on the right side of Figure A1. The shelf tag reports a price of $\$ 2.25$, which is the sum of the price $\$ 1.95$ and the tax $\$ 0.30$ reported on the receipt.

\section{Measurement Error in Demographic Variables}

As discussed in Section 3, we do not observe precise store addresses and instead only observe store zip codes for three types of stores that together account for $34 \%$ of pre-tax volume sales in Philadelphia. This coarser location information might lead to measurement error in our demographic variables (income and obesity) which are defined based on a catchment area of 1 mile around the store's location. For stores without precise location information, we use a radius around the 


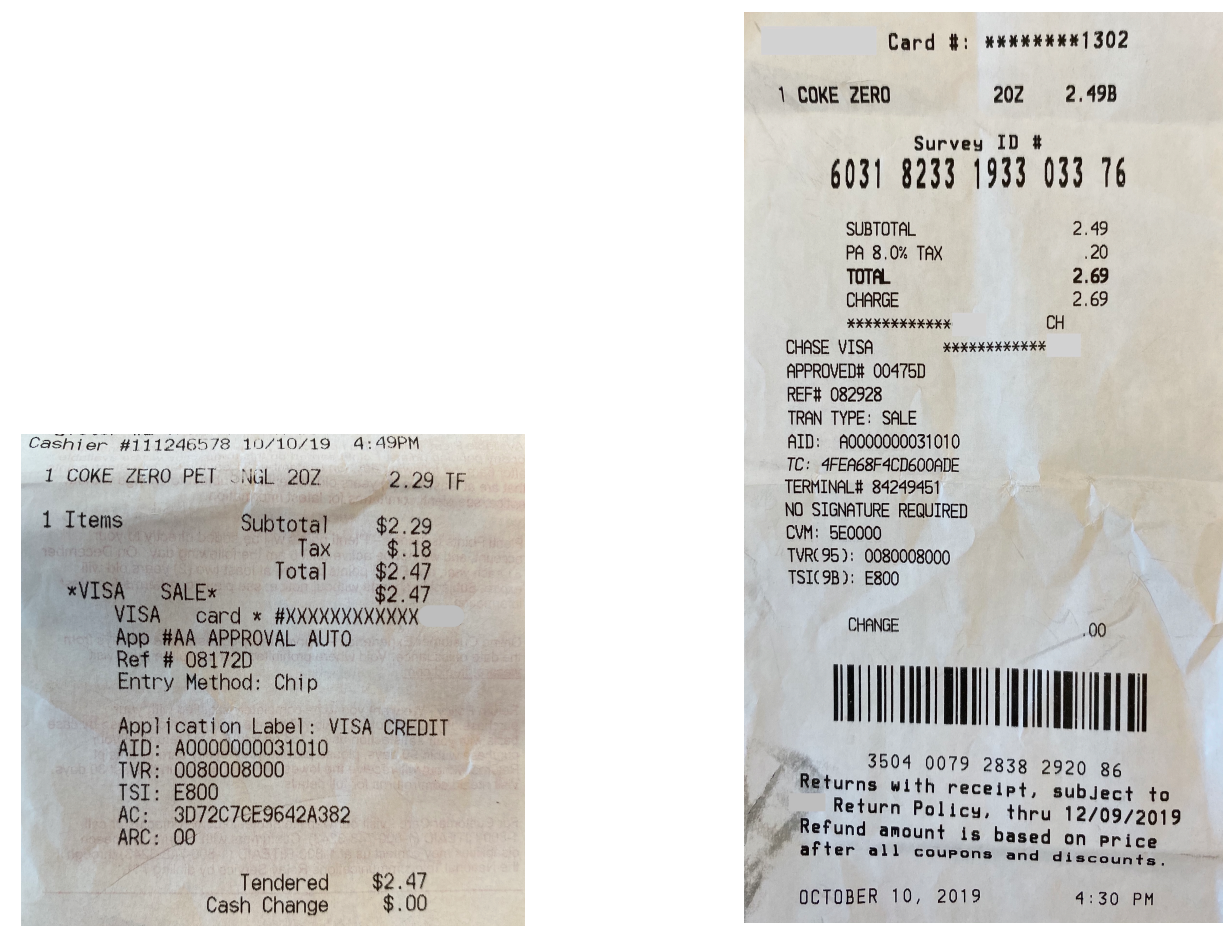

Figure A3: Sample Receipts from Two Retailers that Do Not Report the Beverage Tax Separately. These receipts were both obtained on 10/10/2019. Unlike the receipts in Figure A1. both retailers do not report the beverage tax as a separate item on the receipt or on the shelf tags. This method of reporting prices inclusive of the tax occurs at all retailers in our data except for the one retailer in Figure A1.

centroid of the zip code that they are located in. To help visualize the nature of our data, Figure A4 overlays the stores in our data with the median income across census tracts in Philadelphia. Stores with precise location information are represented by green circles, while stores without precise addresses in our data are represented by squares located at the centroid of the store's zip code. The map suggests that income is relatively homogenous within zip codes and hence imprecise location information is unlikely to lead to large measurement error. The three large zip codes in the south of Philadelphia (19153, 19145, and 19148) may be the most problematic in terms of measurement error because parts of these zip-codes are non-residential and hence the centroid approximation is less appropriate.

In Table A5 we explore the possibility that measurement error affects our estimates related to demographics. Specifically, we investigate the robustness of our findings for the income and obesity interactions in the price and quantity regressions in Tables 2 and 3 . Columns (1) and (5) in both panels replicate our baseline findings and correspond to columns (4) and (5) in Tables 2 and 3 . respectively. In columns (2) and (6) we restrict the sample to only stores for which we observe a precise address. In all cases, point estimates are similar and not significantly different from our baseline estimates. We then further probe robustness to using a wider catchment area radius of 1.5 or 2 miles (instead of 1 mile in our baseline specification). Again, for all income and obesity 


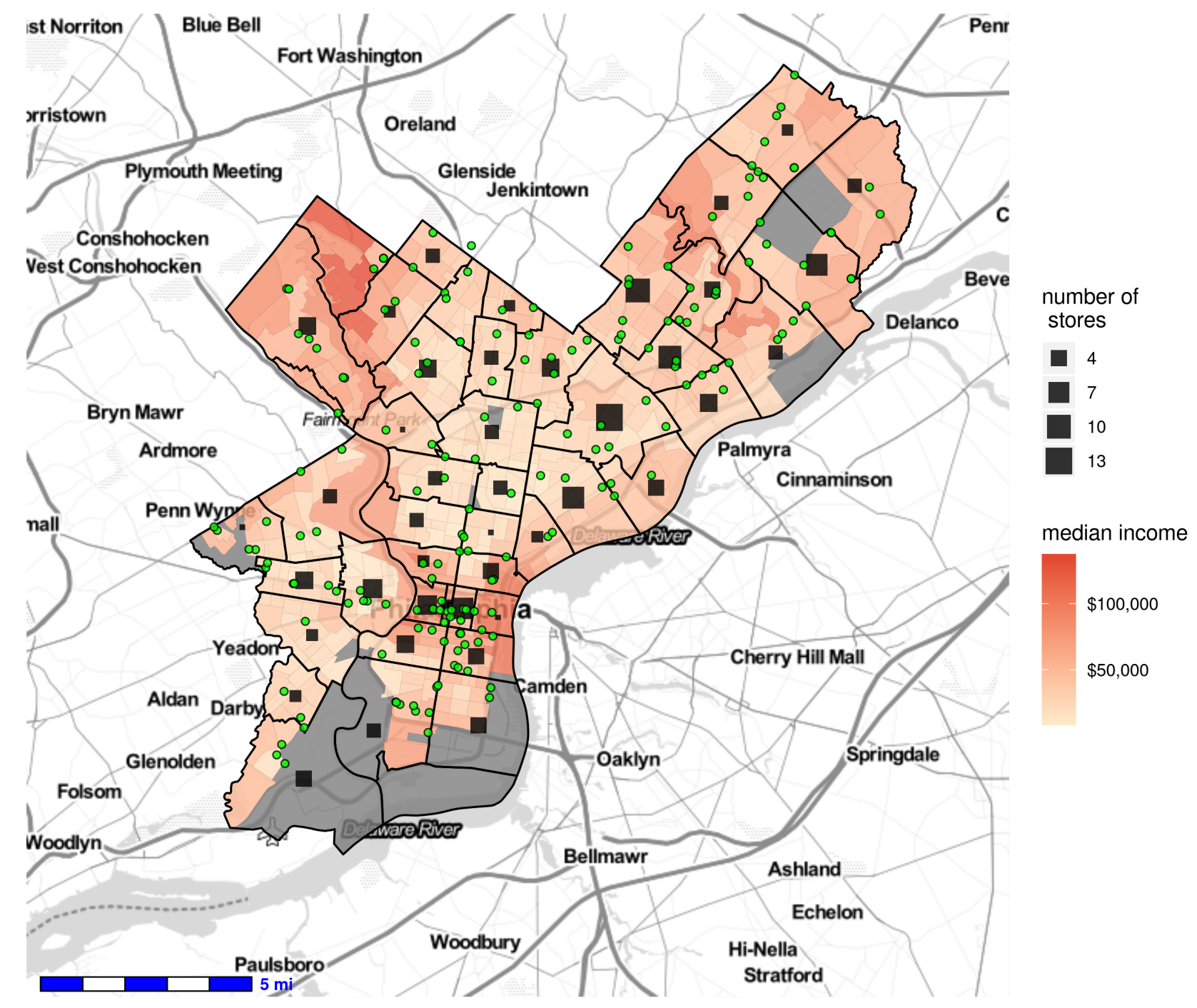

Figure A4: Store Locations and Median Income by Census Tract in Philadelphia. Stores with precise addresses are represented by green circles. Stores for which we only observe zip code are represented by squares. These stores are assumed to be located at the centroid of their zip code. The size of the square indicates the number of stores without precise addresses that are located in that zip code (the legend displays 4 examples showing how the number of stores corresponds to the size of the square). Black outlines denote zip code boundaries and the red fill indicates the median income across census tracts. Grey regions indicate census tracts where no income information is recorded because there is little or no residential population. 


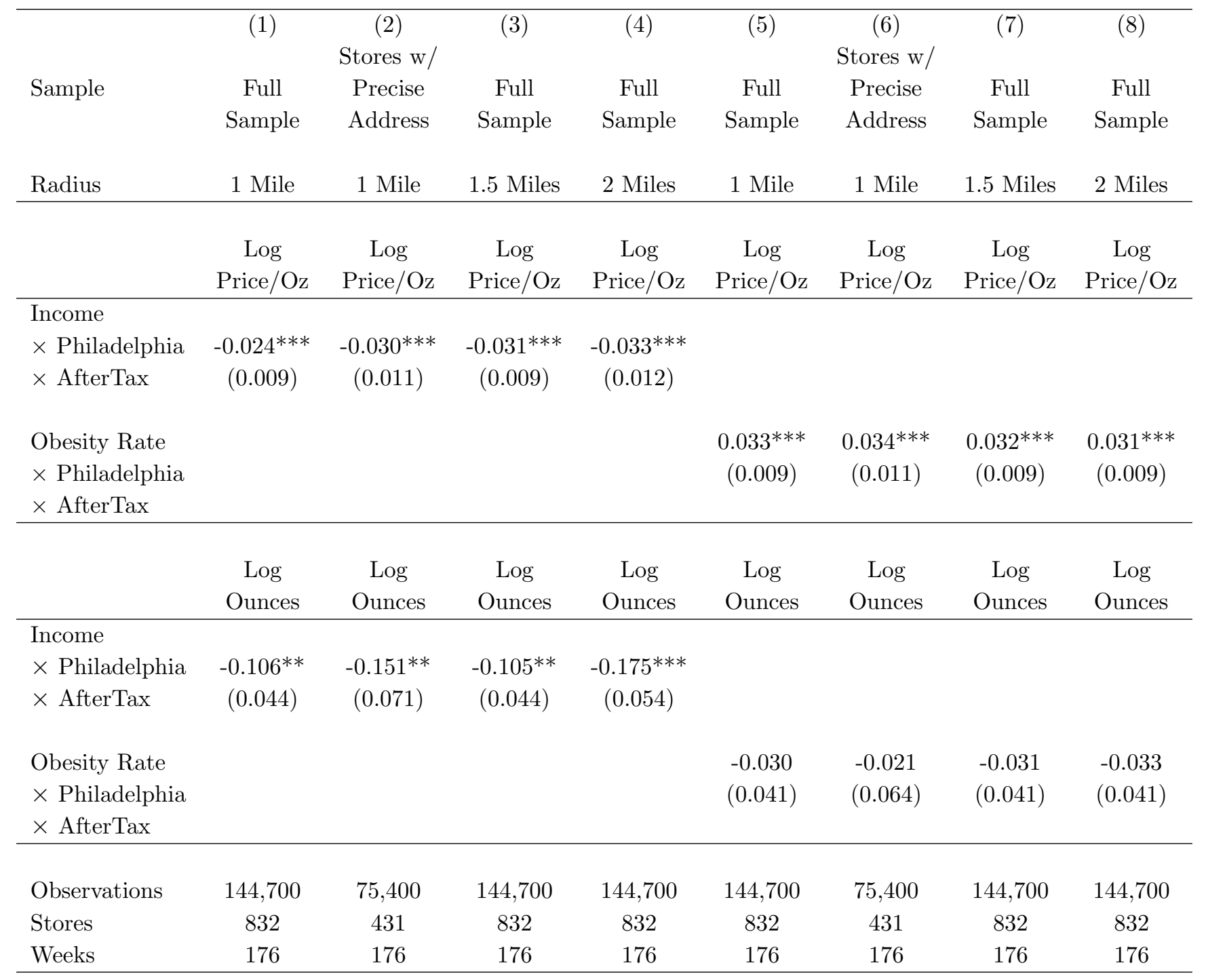

Table A5: Robustness to Different Catchment Area Definitions. Each column reports results from a regression on store and week fixed effects as well as chain-specific effects. We only report the the demographic interactions in each case. Columns (1) to (4) replicate the regression specification in column (4) of Tables 2 and 3 . Columns (5) to (8) replicate the regression specifications in column (5) of Tables 2 and 3.

interactions in the price and quantity regressions, we find results to be similar. The robustness to using a larger radius is particularly relevant because the measurement error presumably declines when the catchment area is large relative to the zip code used to define store location. Overall, these findings show that measurement error is not a major concern with regard to the estimated impact of demographics on price pass-through and quantity reaction. 


\section{E Selection of Stores and Products for the Analysis}

Our raw data cover geographic areas with three-digit ZIP codes of 080, 081, 190, 191, and 194, which cover Philadelphia and its surrounding areas in Pennsylvania and New Jersey. We remove 28 stores in Ocean County, NJ, which is 50 miles away from Philadelphia. The resulting data contain 1,538 stores and 17,582 UPCs that belong to 462 brands. A portion of the stores and UPCs are not contained in our final data set. We detail the criteria for dropping those observations below.

First, some stores enter or exit during the sample period. We choose to drop stores that entered after January 1, 2016, or exited before December 31, 2017. As a result, for each remaining store, we have at least one year of data both before and after the tax went into effect on January 1, 2017. Next, we remove stores affiliated with retail chains that only operate within Philadelphia or only in the areas more than 6 miles outside the city. (This selection criterion leads to a sample of retail chains that are present in all three geographic areas that are relevant to our analysis: Philadelphia, the area less than 6 miles outside of the city, and the area more than 6 miles outside of the city). Finally, some UPCs were purchased infrequently at a given store. Given the nature of scanner data, infrequent purchases render it difficult to reliably measure a product's price over time 68 We choose to only keep product/stores (a product is defined as a brand/diet-status/pack-size combination) that had sales in at least 40 weeks each year during 2016 and 2017 and to only keep UPC/storecombinations that had sales in at least $85 \%$ of the weeks that the corresponding product/store was observed in the data. 69 Our final data contain 1,227 stores and 5,070 UPCs that belong to 101 brands. This final dataset represents $89 \%$ of the unit sales in the raw data.

\section{F Additional Store Descriptive Statistics}

Figure A5 shows a map of Philadelphia stores, color-coded by retail format. The map shows the stores in our sample are geographically dispersed. Table A6 summarizes the within- and acrosschain variation in demographics. Looking at the average income across chains shows that Grocery A and Drugstore X stores are, on average, located in higher-income neighborhoods, whereas Grocery $\mathrm{C}$ and dollar stores tend to be located in lower-income neighborhoods. Moreover, the chain-specific standard deviations tend to be only slightly smaller than the standard deviations across all stores. Therefore, we are able to analyze the impact of demographics based on the variation in demographics within stores of the same chain. 


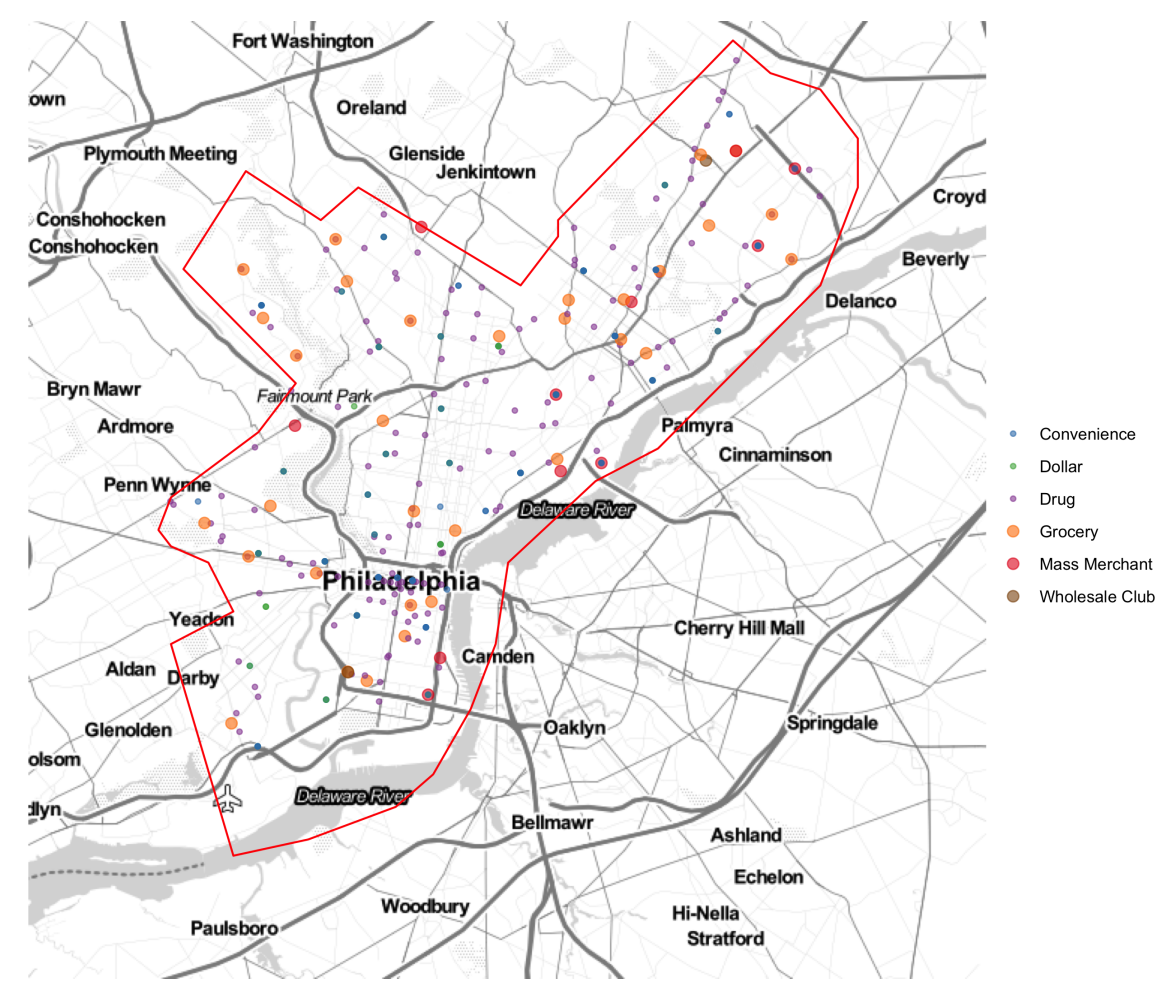

Figure A5: Philadelphia Stores by Retail Format

\section{G Dynamics}

Dynamic adjustment patterns could occur because retailers and consumers take some time to adjust their behavior in response to the tax. Furthermore, consumers might engage in tax avoidance via cross-shopping immediately after the tax goes into effect but find doing so in the long run is inconvenient. To investigate the importance of changes in the impact of the tax over time, we categorize the post-tax data into four time periods: January to April of 2017, May to August of 2017, September to December of 2017, and January 2018 to September 2018 (the end of our sample period). We then re-estimate several of our main regressions, allowing for different treatment effects in the four post-tax time periods. Table A7 reports the results of these analyses. For ease of comparison, in columns (1), (3), (5), and (7), we replicate the results in column (1) of Tables 2 , 3, 4, and 5, respectively (which exclude the first four months after the tax was introduced).

In column (2), we test for changes in the pass-through rate over time. Besides the interaction of the Philadelphia dummy with the after-tax dummy, we now add further interactions of the Philadelphia dummy with dummies for the time periods January-April of 2017, May-August of

\footnotetext{
${ }^{68}$ Price is not recorded in weeks in which a specific product was not sold in a given store. Therefore, prices need to be interpolated from adjacent weeks in which prices were recorded.

${ }^{69}$ If a UPC is dropped, but other UPCs belonging to the same product are maintained because they meet the criteria described above, we include quantity information for the dropped UPC in the aggregate-volume calculation for the specific product. We do not use its price information and only use maintained UPCs to form the product-level average price.
} 


\begin{tabular}{lccccc}
\hline & \# Stores & \multicolumn{2}{c}{ Median } & Income $(\$ 1,000 \mathrm{~s})$ & \multicolumn{2}{c}{ Obesity Rate } \\
& in Phil. & Mean & Std. Dev & Mean & Std. Dev \\
\hline Grocery A & 15 & 53.7 & 11.7 & 0.26 & 0.03 \\
Grocery B & 1 & 41.6 & - & 0.26 & - \\
Grocery C & 16 & 37.9 & 11.2 & 0.32 & 0.06 \\
& & & & & \\
Mass Merchant M & 6 & 47.7 & 7.7 & 0.28 & 0.05 \\
Other Mass Merchants & 5 & 45.8 & 10.5 & 0.28 & 0.04 \\
& & & & & \\
Drugstore X & 45 & 50.9 & 14.5 & 0.27 & 0.05 \\
Drugstore Y & 80 & 43.2 & 14.7 & 0.30 & 0.06 \\
Drugstore Z & 17 & 44.0 & 15.6 & 0.29 & 0.07 \\
& & & & & \\
Convenience St. & 116 & 45.2 & 14.6 & 0.28 & 0.06 \\
Wholesale Club W & 2 & 41.4 & 7.8 & 0.27 & 0.05 \\
Dollar Stores & 54 & 36.1 & 11.8 & 0.33 & 0.05 \\
& & & & & \\
All Stores & 357 & 44.1 & 14.5 & 0.29 & 0.06 \\
\hline
\end{tabular}

Table A6: Within and Across-Chain Variation in Demographics.

2017, and September-December of 2017. Accordingly, the Philadelphia times after-tax coefficient now captures the long-run impact of the tax on prices for the final period of our sample from January to September 2018. The other three interaction terms capture differences in short-term price adjustments relative to the long-run pass-through rate. The interaction term of JanuaryApril of 2017 is equal to -0.31 and significant, which indicates that the pass-through rate was at a slightly lower level during the first four months after the tax. In comparison, the interaction terms for May-August and September-December of 2017 are small in magnitude and not significantly different from the pass-through rate in 2018, which implies pass-through remained stable after May 2017.

The remaining columns present similar specifications regarding the impact of the tax on quantity sales of taxed products, quantity sales of untaxed products, and cross-shopping behavior. In the case of quantity sold, we find the sales reduction in the first four months is smaller than the long-run decrease of 55,600 ounces. After May 2017, the change in quantity is not distinguishable from the long-run decrease. Sales of untaxed products are unresponsive in the long run and show no shortrun reaction to the tax either. With regard to cross-shopping effects, we find most estimates to be insignificant for the various time periods in 2017. A few individual coefficients in this regression are significant. When we run a set of joint-significance tests of the three distance-band coefficients in each time period, we find that in all cases, we cannot reject that the three coefficients are equal to zero. We conclude that after a brief adjustment period of four months, prices and quantities sold stabilized and show no sign of further adjustments between May 2017 and September 2018.

We also investigate whether there are changes over time in the lack of reaction of prices to competitive pressure (measured by the distance to the nearest untaxed store). As documented in 


\begin{tabular}{|c|c|c|c|c|c|c|c|c|}
\hline & \multicolumn{4}{|c|}{ Taxed Products } & \multicolumn{2}{|c|}{ Untaxed Products } & \multicolumn{2}{|c|}{ Cross-shopping } \\
\hline & $(1)$ & $(2)$ & $(3)$ & $(4)$ & $(5)$ & (6) & $(7)$ & $(8)$ \\
\hline Dependent & Price/Oz & Price/Oz & Ounces & Ounces & Ounces & Ounces & Ounces & Ounces \\
\hline Variable & & & Sold & Sold & Sold & Sold & Sold & Sold \\
\hline Philadelphia & $1.449^{* * *}$ & $1.451^{* * *}$ & $-56,192^{* * *}$ & $-55,612^{* * *}$ & $-4,521$ & $-5,437$ & $-56,193^{* * *}$ & $-55,612^{* * *}$ \\
\hline$\times$ AfterTax & $(0.022)$ & $(0.025)$ & $(9,742)$ & $(10,164)$ & $(7,125)$ & $(7,046)$ & $(9,742)$ & $(10,163)$ \\
\hline Philadelphia & & $-0.309^{* * *}$ & & $18,982^{* * *}$ & & 3,847 & & $18,982^{* * *}$ \\
\hline × Jan-April 2017 & & $(0.064)$ & & $(5,147)$ & & $(4,099)$ & & $(5,146)$ \\
\hline Philadelphia & & -0.002 & & $-6,230$ & & 4,990 & & $-6,230$ \\
\hline × May-Aug 2017 & & $(0.020)$ & & $(4,793)$ & & $(3,195)$ & & $(4,795)$ \\
\hline Philadelphia & & -0.008 & & 3,537 & & -929 & & 3,537 \\
\hline × Sept-Dec 2017 & & $(0.015)$ & & $(4,663)$ & & $(3,274)$ & & $(4,669)$ \\
\hline 0-2 Miles Outside & & & & & & & $63,650^{* * *}$ & $61,787^{* * *}$ \\
\hline$\times$ AfterTax & & & & & & & $(20,734)$ & $(20,164)$ \\
\hline 0-2 Miles Outside & & & & & & & & $-12,196$ \\
\hline$\times$ Jan-April 2017 & & & & & & & & $(8,009)$ \\
\hline 0-2 Miles Outside & & & & & & & & 2,846 \\
\hline × May-Aug 2017 & & & & & & & & $(2,651)$ \\
\hline 0-2 Miles Outside & & & & & & & & $4,736^{* *}$ \\
\hline × Sept-Dec 2017 & & & & & & & & $(2,009)$ \\
\hline 2-4 Miles Outside & & & & & & & $18,364^{* * *}$ & $17,017^{* *}$ \\
\hline$\times$ AfterTax & & & & & & & $(7,032)$ & $(6,663)$ \\
\hline 2-4 Miles Outside & & & & & & & & $-2,538$ \\
\hline × Jan-April 2017 & & & & & & & & $(3,184)$ \\
\hline 2-4 Miles Outside & & & & & & & & 3,029 \\
\hline × May-Aug 2017 & & & & & & & & $(2,558)$ \\
\hline 2-4 Miles Outside & & & & & & & & $2,544^{* *}$ \\
\hline × Sept-Dec 2017 & & & & & & & & $(988)$ \\
\hline 4-6 Miles Outside & & & & & & & $8,640^{* *}$ & $7,819^{*}$ \\
\hline$\times$ AfterTax & & & & & & & $(4,198)$ & $(4,266)$ \\
\hline 4-6 Miles Outside & & & & & & & & 1,334 \\
\hline$\times$ Jan-April 2017 & & & & & & & & $(2,737)$ \\
\hline 4-6 Miles Outside & & & & & & & & 2,800 \\
\hline × May-Aug 2017 & & & & & & & & $(2,932)$ \\
\hline 4-6 Miles Outside & & & & & & & & 617 \\
\hline × Sept-Dec 2017 & & & & & & & & $(1,774)$ \\
\hline Store FE & Yes & Yes & Yes & Yes & Yes & Yes & Yes & Yes \\
\hline Week FE & Yes & Yes & Yes & Yes & Yes & Yes & Yes & Yes \\
\hline Observations & 144,700 & 159,676 & 144,700 & 159,676 & 144,209 & 159,131 & 213,499 & 235,585 \\
\hline Stores & 832 & 832 & 832 & 832 & 832 & 832 & 1,227 & 1,227 \\
\hline Weeks & 176 & 194 & 176 & 194 & 176 & 194 & 176 & 194 \\
\hline
\end{tabular}

Table A7: Dynamic Adjustment Patterns. Columns (1), (3), (5), and (7) replicate earlier results and are based on a sample that excludes the first four months after the tax was introduced.

Section 4.1, we find that firms do not charge different prices when a store is located close to the city border, despite the fact that such stores experience stronger competition and a stronger decline in 


\begin{tabular}{lccccc}
\hline & $(1)$ & $(2)$ & $(3)$ & $(4)$ & $(5)$ \\
Dependent & Ounces & Ounces & Ounces & Ounces & Ounces \\
Variable & Sold & Sold & Sold & Sold & Sold \\
\hline Philadelphia $\times$ AfterTax & $-56,192^{* * *}$ & $-55,434^{* * *}$ & $-55,699^{* * *}$ & $-56,050^{* * *}$ & $-56,158^{* * *}$ \\
& $(9,742)$ & $(9,750)$ & $(9,785)$ & $(9,731)$ & $(9,752)$ \\
Philadelphia $\times$ & & 4,519 & & & \\
$0-4$ months BeforeTax & & $(2,790)$ & & & \\
Philadelphia $\times$ & & 3,847 & & \\
$0-3$ months BeforeTax & & $(3,211)$ & & \\
Philadelphia $\times$ & & & 1,802 & \\
0-2 months BeforeTax & & & $(4,319)$ & \\
Philadelphia $\times$ & & & & 865 \\
0-1 months BeforeTax & & & & & $(7,072)$ \\
& & & & & \\
Store FE & Yes & Yes & Yes & Yes \\
Week FE & Yes & Yes & Yes & Yes & Yes \\
\hline Observations & 144,700 & 144,700 & 144,700 & 144,700 & 144,700 \\
Stores & 832 & 832 & 832 & 832 & 832 \\
Weeks & 176 & 176 & 176 & 176 & 176 \\
\hline
\end{tabular}

Table A8: Impact on Quantity Sold Before the Tax.

sales after the tax is implemented. This finding is surprising, and we hence investigate whether firms start charging different prices depending on a store's distance to the city border in the later part of our sample period. In order to analyze such patterns, we implement a similar regression to the ones outlined above, but also include an interaction of the distance to the nearest store with dummies for the various time periods used above. We find that for the time periods used in our main sample, the coefficients on the distance interaction terms are small in magnitude and not statistically significant. Therefore, it appears that the firms in our data do not learn to charge different prices in more or less competitive markets over time.

Finally, we also test whether there are changes in quantity sold before the tax goes into effect. Because the tax was publicly discussed and salient to consumers, one might expect consumers to stockpile, i.e. purchase larger quantities, immediately before the tax goes into effect. In Table A8 we report results from regressions that allow for separate effects for $0-4$ months, 0-3 months, 0-2 months, and 0-1 month before the tax. In all cases, we find no evidence of a significant change in quantity sold prior to the tax.

\section{H Volatility of Purchases and Changes in Price Sensitivity}

Figure 3 shows that in the case of 2-liter bottles of a popular soda brand, purchase volume decreases in Philadelphia relative to the control group. Furthermore, the volatility of sales in stores in Philadelphia also decreases after the tax goes into effect. In this section, we show this pattern occurs for taxed beverages more broadly, and it is driven by the fact that the most price-sensitive 
consumers start to engage in cross-shopping after the tax went into effect. Therefore, the set of consumers who continue to purchase taxed beverages in Philadelphia after the tax constitutes a selected set of less price-sensitive consumers. Those price-insensitive consumers react less to temporal movements in price, and therefore the volatility in sales decreases.

We first turn to analyzing the change in volatility across all taxed beverages. To this end, we compute the variance of sales for each store/product combination separately for the pre- and post-tax period. We find that in Philadelphia, the standard deviation of sales decreased by more than $50 \%$, falling from 1,270 to 443 , whereas in control stores outside of the city (excluding the buffer zone), the variance of sales decreased only slightly from 1,204 to 1,128 . We also note that during the same time, the volatility of price movements remained unchanged in Philadelphia and outside of the city. This finding suggests the nature of demand changed in a way that led to a decrease in the volatility of sales over time.

To assess the cause of this change more directly, we estimate the average product-level elasticity separately for the pre-/post-tax period and for stores inside and outside of the city. We estimate the elasticity by regressing (at the product level) log quantity on log price, store/product-pair fixed effects, and week fixed effects. We find the product-level elasticity of demand dropped from -2.00 to -1.23 at stores in Philadelphia, whereas at control-group stores, it decreased by a more modest amount from -2.21 to -1.87 . We therefore conclude that consumers who continue to purchase taxed beverages in Philadelphia are less price sensitive than the average pre-tax consumer who purchased in Philadelphia. This pattern is consistent with the idea that the consumers who start to engage in cross-shopping are the most price-sensitive consumers. Hence, consumers who continue to purchase sweetened beverages in Philadelphia will tend to be less price sensitive.

We also find that price sensitivity in the area 0-6 miles outside of Philadelphia decreases, but by a smaller amount than in the control group. (The elasticity changes from -2.22 to -2.02 in the 0-6 mile band versus a change from -2.21 to -1.87 in the control group). Moreover, the volatility of sales increases slightly in the 0-6 mile band (the standard deviation of sales changes from 1,208 to 1,374 ) whereas it decreases in the control group (the standard deviation of sales changes from 1,204 to 1,128). These patterns provide further evidence that price sensitive customers stop purchasing taxed beverages in Philadelphia and start shopping at stores in the 0-6 mile band 70

\section{Robustness Check: Parallel Time Trends}

Our difference-in-differences approach to estimating the impact of the tax relies on the assumption that the treatment and control groups would follow the same time trend in the absence of treatment. In order to assess the plausibility of the parallel trends assumption, we provide three pieces of analysis, which are reported in Table A9. First, we test whether the outcomes of interest follow similar trends in the pre-tax period. To do this, we restrict our sample to the pre-tax time period

\footnotetext{
${ }^{70}$ We find that in the case of soda (the category for which consumers are more likely to engage in cross-shopping) the volatility of sales in the area 0-6 miles outside of Philadelphia increases more relative to the volatility of sales of all taxed beverages.
} 


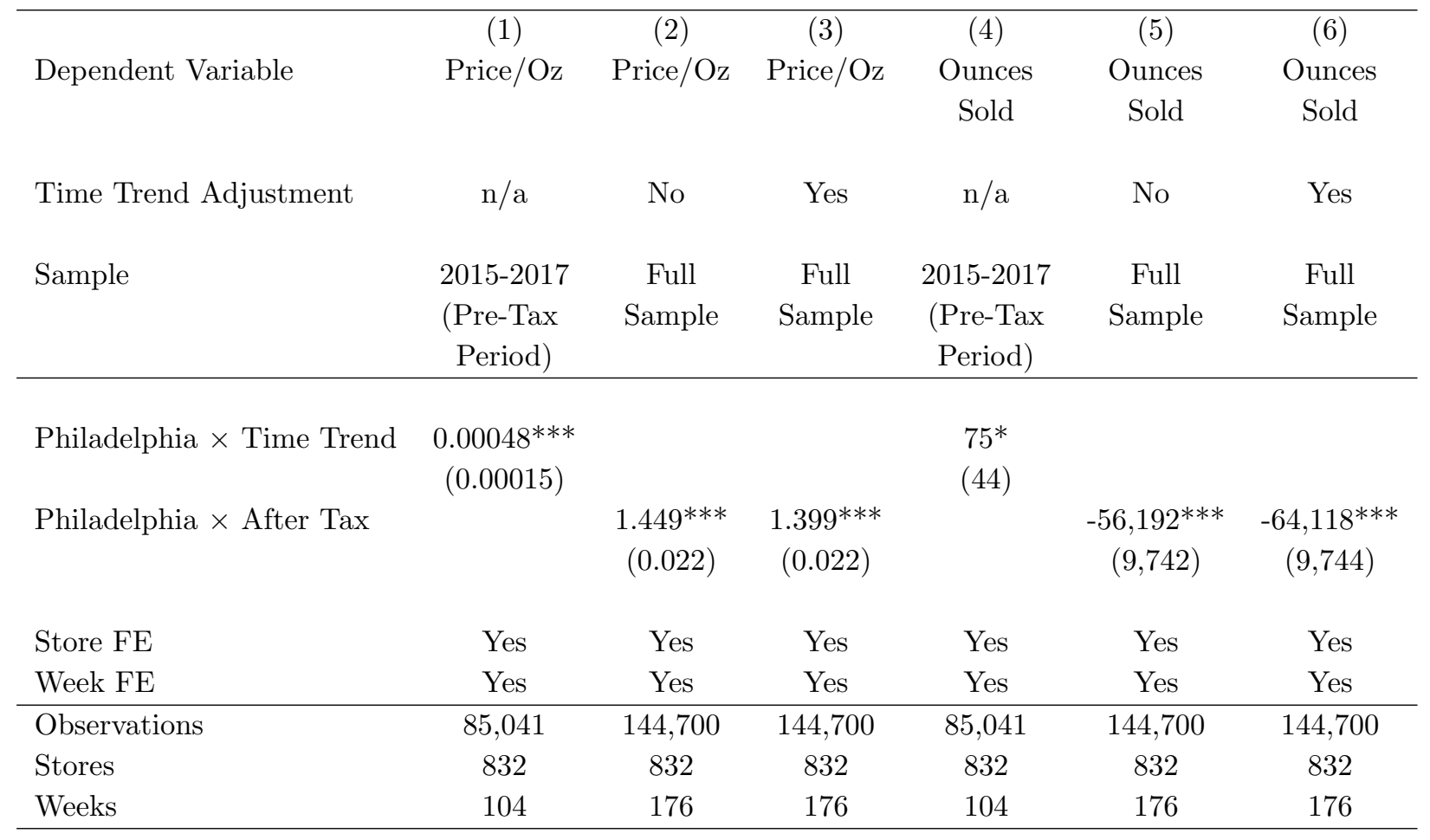

Table A9: Analysis of Differential Pre-Tax Trends. Columns (1) and (4) analyze only pre-tax data. "Time Trend" is a variable ranging from 0 in the first week of the sample to 103 in the week before the tax is implemented. Columns (3) and (6) adjust the outcome variable for the differential time trend in Philadelphia estimated in Columns (1) and (4) respectively (see text for more details on the adjustment to the outcome variable).

only and regress each outcome on a set of store and week fixed effects as well as an interaction of the Philadelphia dummy with a linear time trend (i.e. a variable that runs from 0 in the first week of the sample to 103 in the last week of the pre-tax period). Second, to assess the impact of any differential time trends on our estimates, we assume that the estimated pre-tax trend persists in the post-tax period and obtain de-trended outcomes by subtracting the linear trend from outcomes in Philadelphia stores. We then re-estimate our baseline regression using the de-trended data and compare the results using de-trended data to our main regression results.

Focusing on price/oz first, we find a positive and statistically significant, but economically small differential time-trend in prices in Philadelphia relative to the control group. The point estimate is equal to 0.00048 and corresponds to a $0.025 \mathrm{cents} / \mathrm{oz}(\approx 52 \times 0.00048)$ increase in prices per year. This change is several orders of magnitude smaller than the price increase of $1.45 \mathrm{cents} / \mathrm{oz}$ that we estimated as the causal impact of the tax. Next, in order to assess the impact of the time trend on our estimate, we remove the Philadelphia-specific time trend by subtracting the estimated differential trend from prices in all Philadelphia stores. Columns (2) and (3) report estimates from our baseline regression and from a regression where prices in Philadelphia were adjusted for the differential time trend. As expected, given the small magnitude of the time trend, the change in magnitude of the difference-in-difference estimate is small. 

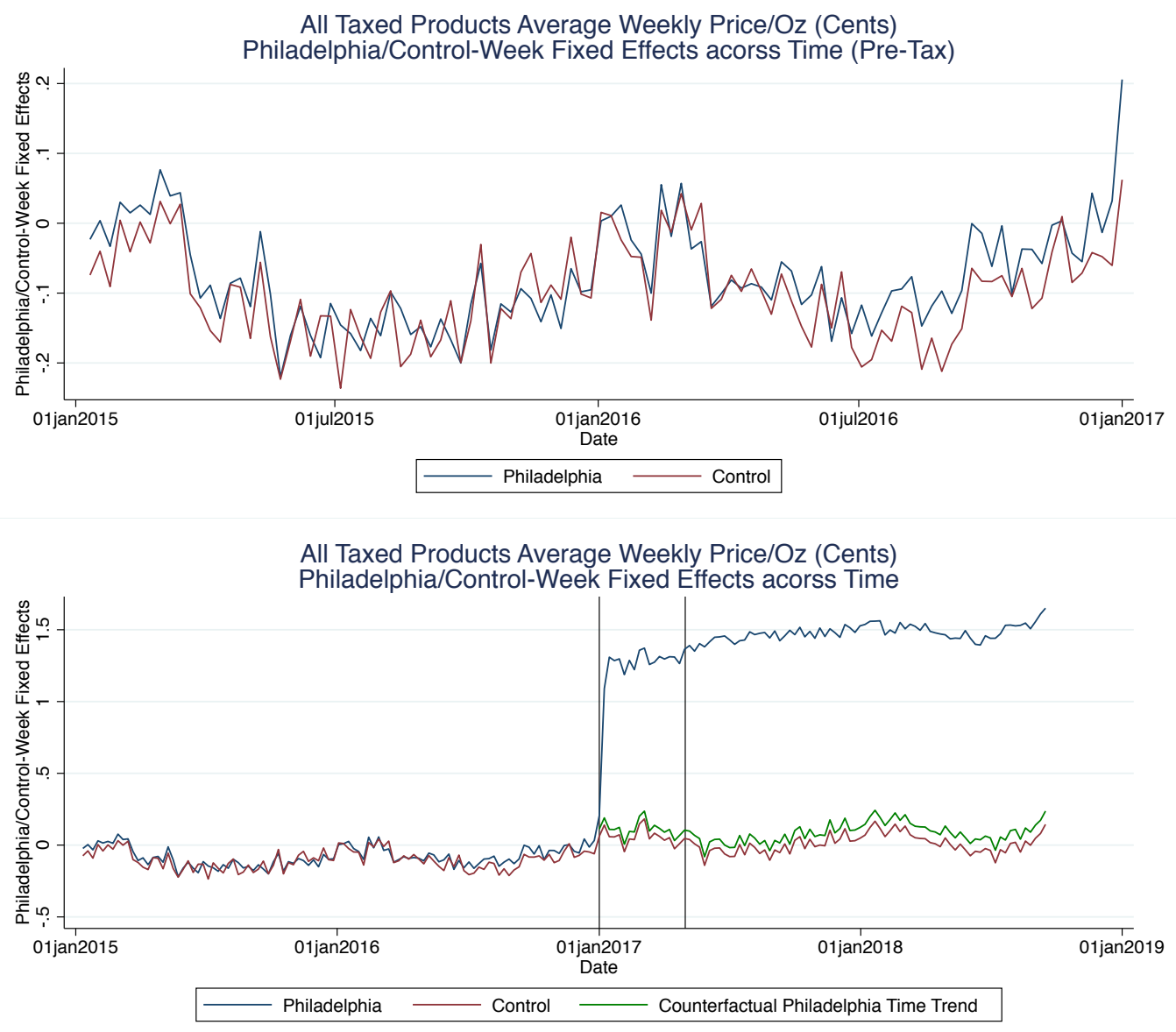

Figure A6: Differential Pre-Tax Time Trends: Price/Oz. The black vertical lines indicate the tax's introduction and the end of the four month "adjustment period" that we omit from our main analyses (see Section 4 and Appendix G).

Figure A6 further illustrates the influence of the time trend in prices relative to the change in price that is triggered by the tax. In order to isolate the time trends in Philadelphia and the control group, we regress price on store fixed effects and separate sets of week dummies for Philadelphia and the control group. We then plot the coefficients on the Philadelphia weekly dummies and the control group's weekly dummies over time. The top graph reports the estimated time-trends in pre-tax prices in Philadelphia and in the control group, and shows that the two time-series track each other closely. The bottom graph plots the entire time series for treatment and control and shows that the price increase caused by the tax eclipses any pre-tax price movements. The green line overlaid on the plot shows the counterfactual post-tax time trend for Philadelphia stores based on the estimated differential pre-tax time trend (i.e. we add the estimated differential time trend in Philadelphia stores to the estimated weekly dummies for the control group in the post-tax time period). Consistent with the regression analysis discussed above, the counterfactual post-tax time series of prices lies only slightly above the post-tax price series for the control group, and hence the small pre-existing time trend cannot account for the large change in prices caused by the tax. 

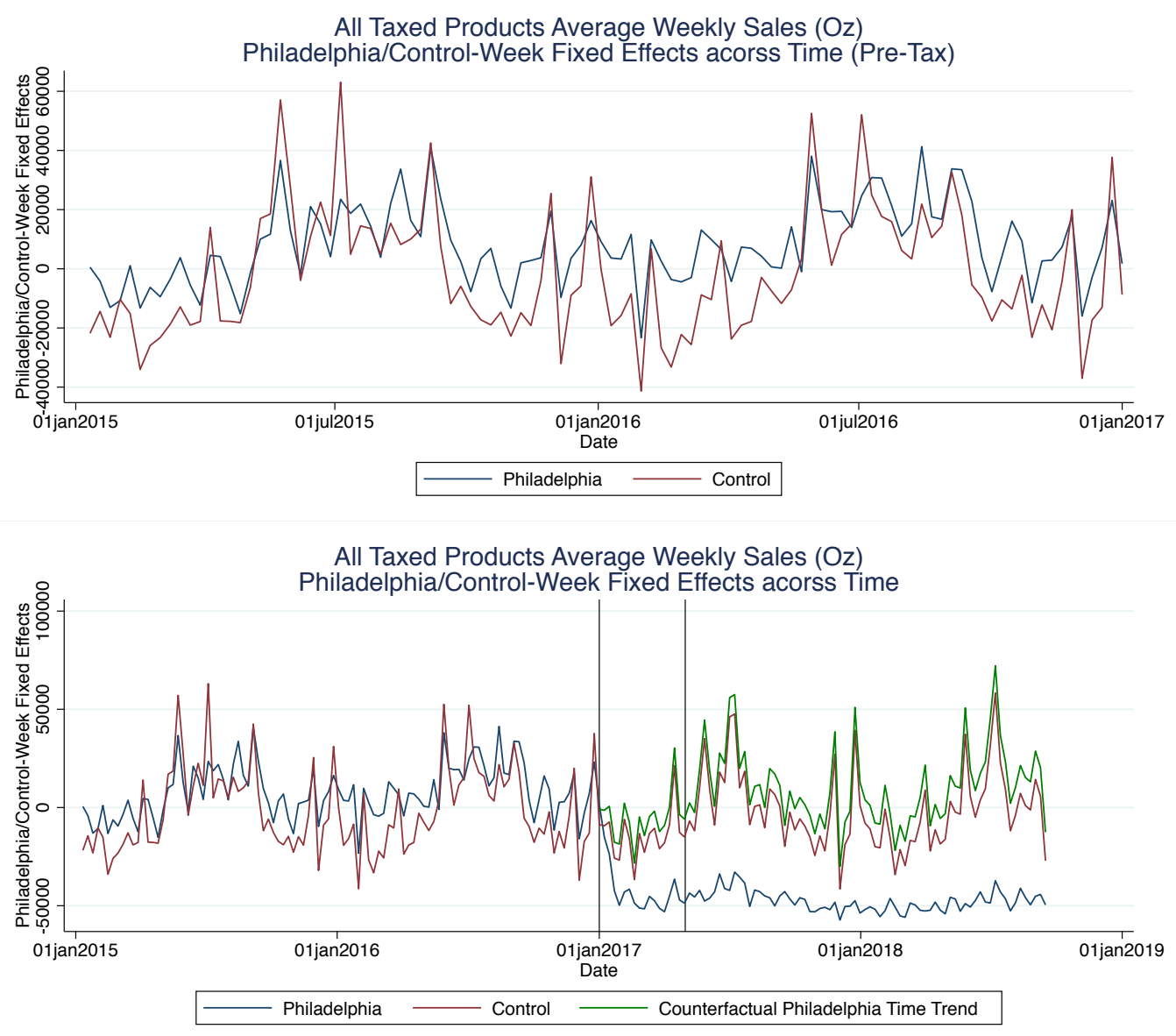

Figure A7: Differential Pre-Tax Time Trends: Quantity (Ounces). The black vertical lines indicate the tax's introduction and the end of the four month "adjustment period" that we omit from our main analyses (see Section 4 and Appendix G).

We repeat the same set of regressions using quantity as the outcome variable as well. In the case of the quantity regression, we do not find a significant pre-tax time trend (see Table A9 Column (4)). The magnitude of the point estimate of the time trend coefficient is again small in magnitude and removing the time trend leads to a small increase (in absolute terms) in the difference-in-difference coefficient in our main regression. We also report graphs that depict the pre-tax and overall time trends for quantities in Figure A7. Similar to the patterns for prices, we find that quantity movements in Philadelphia and the control group track each other closely in the pre-tax period. Compared to prices, quantities show a larger amount of seasonal fluctuations, but seasonality patterns are similar in Philadelphia and outside of the city. The green line shows that the counterfactual post-tax time trend in Philadelphia (based on the estimated pre-tax time trend) lies slightly above above the post-tax time series for the control group. 


\begin{tabular}{|c|c|c|c|c|c|c|c|c|}
\hline \multirow{4}{*}{$\begin{array}{l}\text { Dependent } \\
\text { Variable }\end{array}$} & \multicolumn{4}{|c|}{ Taxed Products } & \multicolumn{2}{|c|}{ Untaxed Products } & \multicolumn{2}{|c|}{ Cross-shopping } \\
\hline & (1) & (2) & (3) & (4) & $(5)$ & (6) & (7) & (8) \\
\hline & Price/Oz & Price/Oz & Ounces & Ounces & Ounces & Ounces & Ounces & Ounces \\
\hline & & & Sold & Sold & Sold & Sold & Sold & Sold \\
\hline Clustering & $\begin{array}{l}\text { Store and } \\
\text { Week }\end{array}$ & $\begin{array}{l}\text { Store and } \\
\text { Month }\end{array}$ & $\begin{array}{l}\text { Store and } \\
\text { Week }\end{array}$ & $\begin{array}{l}\text { Store and } \\
\text { Month }\end{array}$ & $\begin{array}{c}\text { Store and } \\
\text { Week }\end{array}$ & $\begin{array}{l}\text { Store and } \\
\text { Month }\end{array}$ & $\begin{array}{l}\text { Store and } \\
\text { Week }\end{array}$ & $\begin{array}{c}\text { Store and } \\
\text { Month }\end{array}$ \\
\hline Philadelphia & $1.449^{* * *}$ & $1.449^{* * *}$ & $-56,192^{* * *}$ & $-56,192^{* * *}$ & $-4,521$ & $-4,521$ & $-56,193^{* * *}$ & $-56,193^{* * *}$ \\
\hline$\times$ After Tax & $(0.022)$ & $(0.024)$ & $(9,742)$ & $(9,871)$ & $(7,125)$ & $(7,080)$ & $(9,742)$ & $(9,868)$ \\
\hline 0-2 Miles Outside & & & & & & & $63,650^{* * *}$ & $63,650^{* * *}$ \\
\hline City $\times$ After Tax & & & & & & & $(20,734)$ & $(20,707)$ \\
\hline 2-4 Miles Outside & & & & & & & $18,364^{* * *}$ & $18,364^{* *}$ \\
\hline City $\times$ After Tax & & & & & & & $(7,032)$ & $(7,026)$ \\
\hline 4-6 Miles Outside & & & & & & & $8,640^{* *}$ & $8,640^{* *}$ \\
\hline City $\times$ After Tax & & & & & & & $(4,198)$ & $(4,172)$ \\
\hline Store FEs & Yes & Yes & Yes & Yes & Yes & Yes & Yes & Yes \\
\hline Week FEs & Yes & Yes & Yes & Yes & Yes & Yes & Yes & Yes \\
\hline Observations & 144,700 & 144,700 & 144,700 & 144,700 & 144,209 & 144,209 & 213,499 & 213,499 \\
\hline Stores & 832 & 832 & 832 & 832 & 829 & 829 & 1,227 & 1,227 \\
\hline Weeks & 176 & 176 & 176 & 176 & 176 & 176 & 176 & 176 \\
\hline Months & 41 & 41 & 41 & 41 & 41 & 41 & 41 & 41 \\
\hline
\end{tabular}

Table A10: Robustness Check: Store/Month Clustering. Some stores do not offer all categories of beverages and hence the number of observations differs slightly across columns.

\section{J Robustness Check: Clustering}

In our main specification, we use two-way clustering at the store and week level. As an additional robustness check, we explore the sensitivity of our results to clustering at a higher level of aggregation. Table A10 reports results for our main specifications, when clustering standard errors at the store and month level. In columns (1), (3), (5), and (7), we replicate our earlier results with store/week clustering, and the remaining columns show results when using a higher level of clustering. Across all four regressions, standard errors only change minimally. In most cases, they are slightly larger when clustering at the month level, but not uniformly so (see, e.g., the three distance-band coefficients in the cross-shopping regression). We also probed robustness to clustering at the county rather than the store level (not reported in the table). We find that county-level clustering (combined with either week- or month-level clustering) leads to lower standard errors in almost all regressions. 


\section{K Cross-shopping and Basket-level Effects}

When engaging in cross-shopping to purchase sweetened beverages, consumers might also start purchasing other products outside of Philadelphia. Thomassen et al. (2017) highlight the importance of such basket-level substitution effects.71 To assess the importance of basket-level substitution effects, we study purchase patterns for milk in Philadelphia, as well as in border stores. We choose this category because milk is one of the most frequently purchased consumer packaged goods categories and not a direct substitute for or complement to sweetened beverages. Because we are not able to obtain data across an exhaustive set of categories in all stores, we treat milk as a stand-in for other items in a consumer's basket. We use the same specification as in our cross-shopping regression (see column (1) of Table 5), but use milk sales as the dependent variable. We start by examining all types of stores in Philadelphia, and find that store-level demand for milk decreases by a small amount of 1,100 ounces per week relative to an average pre-tax level of 58,870 ounces per week. The effect is not statistically significant ${ }^{72}$ In line with this finding, we also find no evidence that milk sales at stores near the city border experience a change in demand, 73

If we focus only on grocery stores and wholesale club stores, where consumers tend to buy large pack sizes and engage more in cross-shopping, we find a statistically significant substitution effect. However, even for this subset of stores, the effect is small in magnitude and corresponds to a substitution of $5 \%$ of milk sales from stores in Philadelphia to stores just outside the city. Based on these findings, we conclude that only to a very limited extent do consumers substitute other parts of their basket to stores just outside the city.

\section{Non-Price Effects of the Tax}

Apart from prices, other marketing variables such as advertising and in-store product displays might also adjust in response to the tax, and these marketing variables could have an impact on quantity sales. In terms of advertising, all stores in the treatment and control groups are located in the Philadelphia DMA, and hence the effects we measure are not driven by differences in television ad exposure. Moreover, feature advertising conducted by retailers is typically implemented uniformly across large geographies and hence it is also likely to be the same for treatment and control stores (Seiler and Yao (2017); Blattberg and Neslin (1990)). Therefore, the only marketing activities that might change more locally and could affect treatment and control differently are changes to in-store displays and shelf layouts. We do not have data on display advertising or in-store planograms and hence cannot directly investigate changes in these marketing activities, but in-store displays are typically used less frequently than price promotions and feature advertising and thus are a tool

\footnotetext{
${ }^{71}$ To the extent that consumers substitute purchases of other products to stores outside of the city, this could lead to lower overall sales-tax revenue in Philadelphia and lower revenue for Philadelphia retailers. The city of Philadelphia charges a $2 \%$ sales tax but food (not ready to eat), candy, and gum are excluded from the tax.

${ }^{72}$ We also find no price adjustment for milk either inside or outside the city.

${ }^{73}$ The changes in average weekly milk sales in the 0 - to 2-mile, 2- to 4-mile, and 4- to 6-mile distance bands are 1,553 ounces, $-1,131$ ounces, and -336 ounces, respectively, and none of these estimates are statistically significant at the $5 \%$ level.
} 
that generally plays a more minor role relative to price changes (Seiler and Yao (2017)). To the extent that in-store displays or product availability do change when the tax goes into effect, we anticipate that the availability of taxed products would decrease in Philadelphia stores relative to control stores. The best source of data on this comes from Cawley et al. (2020), who manually collected data from 65 stores in Philadelphia and found that the probability that a Philadelphia store carried a given taxed product fell by 4 percentage points $(\mathrm{p}<0.1)$. Thus, while unobserved changes in product assortment could lead us to over-estimate the demand elasticity, we believe any such bias would be small.

In addition, the tax was discussed publicly before it was passed and was therefore likely salient to many consumers. We might expect that the announcement of the tax and the discussion surrounding health effects of sweetened beverages might lead consumers to switch to healthier beverages independent of price changes (Taylor et al. (2019)). However, the null effect we find with regard to substitution to healthier beverages speaks against such a salience effect playing a large role, because we would expect salience to trigger switches to healthier beverages, but not cross-shopping for sweetened beverages. We also find no evidence that demand for taxed beverages in Philadelphia decreased in the months prior to January 2017 (see Table A8), when the upcoming introduction of the tax would already have been salient to consumers. For these reasons, we believe that the quantity decreases we observe are primarily a direct response to price changes.

\section{Additional Tables}




\begin{tabular}{|c|c|c|c|c|c|c|}
\hline & (1) & $(2)$ & $(3)$ & $(4)$ & $(5)$ & (6) \\
\hline Dependent & & & $\log$ & $\log$ & $\log$ & $\log$ \\
\hline Variable & Price/Oz & Price/Oz & Price/Oz & Price/Oz & Price/Oz & Price/Oz \\
\hline Philadelphia $\times$ AfterTax & $\begin{array}{c}1.459^{* * *} \\
(0.020)\end{array}$ & & & & & \\
\hline $\begin{array}{l}\text { Grocery A } \\
\times \text { Philadelphia } \times \text { AfterTax }\end{array}$ & & $\begin{array}{c}1.308^{* * *} \\
(0.025)\end{array}$ & $\begin{array}{c}0.344^{* * *} \\
(0.010)\end{array}$ & $\begin{array}{c}0.343^{* * *} \\
(0.015)\end{array}$ & $\begin{array}{c}0.351^{* * *} \\
(0.012)\end{array}$ & $\begin{array}{c}0.342^{* * *} \\
(0.010)\end{array}$ \\
\hline $\begin{array}{l}\text { Grocery B } \\
\times \text { Philadelphia } \times \text { AfterTax }\end{array}$ & & $\begin{array}{c}1.518^{* * *} \\
(0.006)\end{array}$ & $\begin{array}{c}0.414^{* * *} \\
(0.002)\end{array}$ & $\begin{array}{c}0.412^{* * *} \\
(0.015)\end{array}$ & $\begin{array}{c}0.417^{* * *} \\
(0.005)\end{array}$ & $\begin{array}{c}0.411^{* * *} \\
(0.004)\end{array}$ \\
\hline $\begin{array}{l}\text { Grocery C } \\
\times \text { Philadelphia } \times \text { AfterTax }\end{array}$ & & $\begin{array}{c}1.838^{* * *} \\
(0.055)\end{array}$ & $\begin{array}{c}0.466^{* * *} \\
(0.015)\end{array}$ & $\begin{array}{c}0.465^{* * *} \\
(0.018)\end{array}$ & $\begin{array}{c}0.469^{* * *} \\
(0.017)\end{array}$ & $\begin{array}{c}0.461^{* * *} \\
(0.017)\end{array}$ \\
\hline $\begin{array}{l}\text { Mass Merchant M } \\
\times \text { Philadelphia } \times \text { AfterTax }\end{array}$ & & $\begin{array}{c}1.441^{* * *} \\
(0.270)\end{array}$ & $\begin{array}{c}0.318^{* * *} \\
(0.061)\end{array}$ & $\begin{array}{c}0.317^{* * *} \\
(0.066)\end{array}$ & $\begin{array}{c}0.323^{* * *} \\
(0.061)\end{array}$ & $\begin{array}{c}0.314^{* * *} \\
(0.060)\end{array}$ \\
\hline $\begin{array}{l}\text { Mass Merchant N } \\
\times \text { Philadelphia } \times \text { AfterTax }\end{array}$ & & $\begin{array}{c}1.084^{* * *} \\
(0.029)\end{array}$ & $\begin{array}{c}0.303^{* * *} \\
(0.008)\end{array}$ & $\begin{array}{c}0.302^{* * *} \\
(0.013)\end{array}$ & $\begin{array}{c}0.308^{* * *} \\
(0.009)\end{array}$ & $\begin{array}{c}0.299^{* * *} \\
(0.009)\end{array}$ \\
\hline $\begin{array}{l}\text { Drugstore } \mathrm{X} \\
\times \text { Philadelphia } \times \text { AfterTax }\end{array}$ & & $\begin{array}{c}1.536^{* * *} \\
(0.039)\end{array}$ & $\begin{array}{c}0.300^{* * *} \\
(0.012)\end{array}$ & $\begin{array}{c}0.299^{* * *} \\
(0.016)\end{array}$ & $\begin{array}{c}0.306^{* * *} \\
(0.014)\end{array}$ & $\begin{array}{c}0.297^{* * *} \\
(0.013)\end{array}$ \\
\hline $\begin{array}{l}\text { Drugstore } Y \\
\times \text { Philadelphia } \times \text { AfterTax }\end{array}$ & & $\begin{array}{c}1.321^{* * *} \\
(0.020)\end{array}$ & $\begin{array}{c}0.250^{* * *} \\
(0.007)\end{array}$ & $\begin{array}{c}0.249^{* * *} \\
(0.011)\end{array}$ & $\begin{array}{c}0.254^{* * *} \\
(0.009)\end{array}$ & $\begin{array}{c}0.245^{* * *} \\
(0.009)\end{array}$ \\
\hline $\begin{array}{l}\text { Drugstore Z } \\
\times \text { Philadelphia } \times \text { AfterTax }\end{array}$ & & $\begin{array}{c}0.935^{* * *} \\
(0.068)\end{array}$ & $\begin{array}{c}0.179^{* * *} \\
(0.008)\end{array}$ & $\begin{array}{c}0.177^{* * *} \\
(0.015)\end{array}$ & $\begin{array}{c}0.183^{* * *} \\
(0.010)\end{array}$ & $\begin{array}{c}0.174^{* * *} \\
(0.010)\end{array}$ \\
\hline $\begin{array}{l}\text { Wholesale Club } \\
\times \text { Philadelphia } \times \text { AfterTax }\end{array}$ & & $\begin{array}{c}1.411^{* * *} \\
(0.073)\end{array}$ & $\begin{array}{c}0.439^{* * *} \\
(0.009)\end{array}$ & $\begin{array}{c}0.437 * * * \\
(0.018)\end{array}$ & $\begin{array}{c}0.442^{* * *} \\
(0.010)\end{array}$ & $\begin{array}{c}0.436^{* * *} \\
(0.009)\end{array}$ \\
\hline $\begin{array}{l}\text { Dollar Stores } \\
\times \text { Philadelphia } \times \text { AfterTax }\end{array}$ & & $\begin{array}{c}1.456^{* * *} \\
(0.042)\end{array}$ & $\begin{array}{c}0.360^{* * *} \\
(0.012)\end{array}$ & $\begin{array}{c}0.358^{* * *} \\
(0.017)\end{array}$ & $\begin{array}{c}0.362^{* * *} \\
(0.012)\end{array}$ & $\begin{array}{c}0.353^{* * *} \\
(0.016)\end{array}$ \\
\hline $\begin{array}{l}\text { Convenience Stores } \\
\times \text { Philadelphia } \times \text { AfterTax }\end{array}$ & & $\begin{array}{c}1.602^{* * *} \\
(0.025)\end{array}$ & $\begin{array}{c}0.197^{* * *} \\
(0.005)\end{array}$ & $\begin{array}{c}0.196^{* * *} \\
(0.012)\end{array}$ & $\begin{array}{c}0.202^{* * *} \\
(0.007)\end{array}$ & $\begin{array}{c}0.193^{* * *} \\
(0.007)\end{array}$ \\
\hline $\begin{array}{l}\text { Distance (in Miles) to Nearest } \\
\times \text { Philadelphia } \times \text { AfterTax }\end{array}$ & taxed Store & & & $\begin{array}{c}0.001 \\
(0.005)\end{array}$ & & \\
\hline $\begin{array}{l}\text { Income } \\
\times \text { Philadelphia } \times \text { AfterTax }\end{array}$ & & & & & $\begin{array}{l}-0.013 \\
(0.012)\end{array}$ & \\
\hline $\begin{array}{l}\text { Obesity Rate } \\
\times \text { Philadelphia } \times \text { AfterTax }\end{array}$ & & & & & & $\begin{array}{c}0.010 \\
(0.014)\end{array}$ \\
\hline$\left(\right.$ AfterTax $\left._{t} \times \mathbf{X}_{s}^{\prime}\right)$ Interactions & $\mathrm{n} / \mathrm{a}$ & Yes & Yes & Yes & Yes & Yes \\
\hline Store FE & Yes & Yes & Yes & Yes & Yes & Yes \\
\hline Week FE & Yes & Yes & Yes & Yes & Yes & Yes \\
\hline Observations & 144,700 & 144,700 & 144,700 & 144,700 & 144,700 & 144,700 \\
\hline Stores & 832 & 832 & 832 & 832 & 832 & 832 \\
\hline Weeks & 176 & 176 & 176 & 176 & 176 & 176 \\
\hline
\end{tabular}

Table A11: Impact on Prices / Pass-through Rate Estimates for the Soda Category. Interactions with an after-tax dummy (the $\left(\right.$ AfterTax $\left.\times \mathbf{X}_{s}^{\prime}\right)$ term) are included in columns (2) (6), but not reported separately. One exception is the obesity variable in column (6). We have no obesity data outside of Philadelphia, and hence no $\left(\right.$ Obesity $_{s} \times$ AfterTax $\left._{t}\right)$ term is included. 


\begin{tabular}{|c|c|c|c|c|c|c|}
\hline & (1) & $(2)$ & $(3)$ & (4) & $(5)$ & (6) \\
\hline Dependent & Ounces & Ounces & $\log$ & $\log$ & $\log$ & $\log$ \\
\hline Variable & Sold & Sold & Ounces & Ounces & Ounces & Ounces \\
\hline Philadelphia $\times$ AfterTax & $\begin{array}{c}-18,713^{* * *} \\
(3,910)\end{array}$ & & & & & \\
\hline $\begin{array}{l}\text { Grocery A } \\
\times \text { Philadelphia } \times \text { AfterTax }\end{array}$ & & $\begin{array}{c}-103,199^{* * *} \\
(18,693)\end{array}$ & $\begin{array}{c}-0.810^{* * *} \\
(0.080)\end{array}$ & $\begin{array}{c}-0.904^{* * *} \\
(0.093)\end{array}$ & $\begin{array}{c}-0.671^{* * *} \\
(0.091)\end{array}$ & $\begin{array}{c}-0.826^{* * *} \\
(0.083)\end{array}$ \\
\hline $\begin{array}{l}\text { Grocery B } \\
\times \text { Philadelphia } \times \text { AfterTax }\end{array}$ & & $\begin{array}{c}-163,577^{* * *} \\
(5,472)\end{array}$ & $\begin{array}{c}-0.891^{* * *} \\
(0.014)\end{array}$ & $\begin{array}{c}-1.021^{* * *} \\
(0.059)\end{array}$ & $\begin{array}{c}-0.787^{* * *} \\
(0.032)\end{array}$ & $\begin{array}{c}-0.909^{* * *} \\
(0.020)\end{array}$ \\
\hline $\begin{array}{l}\text { Grocery C } \\
\times \text { Philadelphia } \times \text { AfterTax }\end{array}$ & & $\begin{array}{c}-237,319^{* * *} \\
(42,436)\end{array}$ & $\begin{array}{c}-1.024^{* * *} \\
(0.087)\end{array}$ & $\begin{array}{c}-1.109^{* * *} \\
(0.088)\end{array}$ & $\begin{array}{c}-0.928^{* * *} \\
(0.088)\end{array}$ & $\begin{array}{c}-1.057^{* * *} \\
(0.093)\end{array}$ \\
\hline $\begin{array}{l}\text { Mass Merchant M } \\
\times \text { Philadelphia } \times \text { AfterTax }\end{array}$ & & $\begin{array}{l}-33,289 \\
(20,205)\end{array}$ & $\begin{array}{c}-0.554^{* *} \\
(0.222)\end{array}$ & $\begin{array}{c}-0.632^{* *} \\
(0.254)\end{array}$ & $\begin{array}{l}-0.427^{*} \\
(0.225)\end{array}$ & $\begin{array}{c}-0.578^{* * *} \\
(0.211)\end{array}$ \\
\hline $\begin{array}{l}\text { Mass Merchant N } \\
\times \text { Philadelphia } \times \text { AfterTax }\end{array}$ & & $\begin{array}{c}-130,308^{* * *} \\
(26,802)\end{array}$ & $\begin{array}{c}-0.492^{* * *} \\
(0.104)\end{array}$ & $\begin{array}{c}-0.579 * * * \\
(0.113)\end{array}$ & $\begin{array}{c}-0.378^{* * *} \\
(0.105)\end{array}$ & $\begin{array}{c}-0.515^{* * *} \\
(0.106)\end{array}$ \\
\hline $\begin{array}{l}\text { Drugstore } \mathrm{X} \\
\times \text { Philadelphia } \times \text { AfterTax }\end{array}$ & & $\begin{array}{c}-2,692^{* * *} \\
(781)\end{array}$ & $\begin{array}{c}-0.229 * * * \\
(0.047)\end{array}$ & $\begin{array}{c}-0.318^{* * *} \\
(0.063)\end{array}$ & $\begin{array}{l}-0.098^{*} \\
(0.055)\end{array}$ & $\begin{array}{c}-0.250^{* * *} \\
(0.052)\end{array}$ \\
\hline $\begin{array}{l}\text { Drugstore } Y \\
\times \text { Philadelphia } \times \text { AfterTax }\end{array}$ & & $\begin{array}{c}-427^{* * *} \\
(145)\end{array}$ & $\begin{array}{c}0.004 \\
(0.038)\end{array}$ & $\begin{array}{l}-0.084 \\
(0.054)\end{array}$ & $\begin{array}{l}0.110^{* *} \\
(0.048)\end{array}$ & $\begin{array}{l}-0.026 \\
(0.045)\end{array}$ \\
\hline $\begin{array}{l}\text { Drugstore Z } \\
\times \text { Philadelphia } \times \text { AfterTax }\end{array}$ & & $\begin{array}{c}16,053^{* * *} \\
(3,048)\end{array}$ & $\begin{array}{c}0.701^{* * *} \\
(0.104)\end{array}$ & $\begin{array}{c}0.590^{* * *} \\
(0.110)\end{array}$ & $\begin{array}{c}0.806^{* * *} \\
(0.101)\end{array}$ & $\begin{array}{c}0.676^{* * *} \\
(0.106)\end{array}$ \\
\hline $\begin{array}{l}\text { Wholesale Club } \\
\times \text { Philadelphia } \times \text { AfterTax }\end{array}$ & & $\begin{array}{c}-73,161^{* * *} \\
(6,732)\end{array}$ & $\begin{array}{c}-0.802^{* * *} \\
(0.065)\end{array}$ & $\begin{array}{c}-0.940 * * * \\
(0.091)\end{array}$ & $\begin{array}{c}-0.679^{* * *} \\
(0.083)\end{array}$ & $\begin{array}{c}-0.821^{* * *} \\
(0.067)\end{array}$ \\
\hline $\begin{array}{l}\text { Dollar Stores } \\
\times \text { Philadelphia } \times \text { AfterTax }\end{array}$ & & $\begin{array}{c}-8,085^{* * *} \\
(1,349)\end{array}$ & $\begin{array}{c}-0.416^{* * *} \\
(0.039)\end{array}$ & $\begin{array}{c}-0.513^{* * *} \\
(0.057)\end{array}$ & $\begin{array}{c}-0.338^{* * *} \\
(0.044)\end{array}$ & $\begin{array}{c}-0.453^{* * *} \\
(0.049)\end{array}$ \\
\hline $\begin{array}{l}\text { Convenience Stores } \\
\times \text { Philadelphia } \times \text { AfterTax }\end{array}$ & & $\begin{array}{c}385 \\
(322)\end{array}$ & $\begin{array}{l}-0.024 \\
(0.021)\end{array}$ & $\begin{array}{c}-0.121^{* *} \\
(0.048)\end{array}$ & $\begin{array}{c}0.094^{* *} \\
(0.039)\end{array}$ & $\begin{array}{l}-0.048^{*} \\
(0.027)\end{array}$ \\
\hline $\begin{array}{l}\text { Distance (in Miles) to Nearest } \\
\times \text { Philadelphia } \times \text { AfterTax }\end{array}$ & taxed Store & & & $\begin{array}{c}0.044^{* *} \\
(0.020)\end{array}$ & & \\
\hline $\begin{array}{l}\text { Income } \\
\times \text { Philadelphia } \times \text { AfterTax }\end{array}$ & & & & & $\begin{array}{c}-0.202^{* * *} \\
(0.053)\end{array}$ & \\
\hline $\begin{array}{l}\text { Obesity Rate } \\
\times \text { Philadelphia } \times \text { AfterTax }\end{array}$ & & & & & & $\begin{array}{c}0.062 \\
(0.052)\end{array}$ \\
\hline$\left(\right.$ AfterTax $\left._{t} \times \mathbf{X}_{s}^{\prime}\right)$ Interactions & $\mathrm{n} / \mathrm{a}$ & Yes & Yes & Yes & Yes & Yes \\
\hline Store FE & Yes & Yes & Yes & Yes & Yes & Yes \\
\hline Week FE & Yes & Yes & Yes & Yes & Yes & Yes \\
\hline Observations & 144,700 & 144,700 & 144,700 & 144,700 & 144,700 & 144,700 \\
\hline Stores & 832 & 832 & 832 & 832 & 832 & 832 \\
\hline Weeks & 176 & 176 & 176 & 176 & 176 & 176 \\
\hline
\end{tabular}

Table A12: Impact on Quantity Sold for the Soda Category. Interactions with an aftertax dummy (the $\left(\right.$ AfterTax $\left.\times \mathbf{X}_{s}^{\prime}\right)$ term) are included in columns (2) - (6), but not reported separately. One exception is the obesity variable in column (6). We have no obesity data outside of Philadelphia, and hence no $\left(\right.$ Obesity $_{s} \times$ AfterTax $\left._{t}\right)$ term is included. 


\begin{tabular}{|c|c|c|c|c|}
\hline Dependent Variable & $\begin{array}{c}(1) \\
\text { Ounces } \\
\text { Sold }\end{array}$ & $\begin{array}{c}(2) \\
\text { Ounces } \\
\text { Sold }\end{array}$ & $\begin{array}{c}(3) \\
\text { Ounces } \\
\text { Sold }\end{array}$ & $\begin{array}{c}(4) \\
\text { Ounces } \\
\text { Sold }\end{array}$ \\
\hline Philadelphia $*$ After Tax & $\begin{array}{c}-56,193^{* * *} \\
(9,742)\end{array}$ & $\begin{array}{c}-56,193^{* * *} \\
(9,742)\end{array}$ & $\begin{array}{c}-56,194^{* * *} \\
(9,742)\end{array}$ & $\begin{array}{c}-56,194^{* * *} \\
(9,742)\end{array}$ \\
\hline $\begin{array}{l}\text { 0-1 Miles Outside City Border } \\
\times \text { After Tax }\end{array}$ & & & $\begin{array}{c}182,184^{* *} \\
(71,962)\end{array}$ & $\begin{array}{l}-176,298 \\
(143,948)\end{array}$ \\
\hline $\begin{array}{l}0-1 \text { Miles Outside City Border } \\
\times \text { After Tax } * \text { Income-in-Philadelphia }\end{array}$ & & & & $\begin{array}{c}1,157,703^{* *} \\
(576,934)\end{array}$ \\
\hline $\begin{array}{l}\text { 1-2 Miles Outside City Border } \\
\times \text { After Tax }\end{array}$ & & & $\begin{array}{l}22,420 * * * \\
(8,257)\end{array}$ & $\begin{array}{c}16,258 \\
(14.781)\end{array}$ \\
\hline $\begin{array}{l}\text { 1-2 Miles Outside City Border } \\
\times \text { After Tax } * \text { Income-in-Philadelphia }\end{array}$ & & & & $\begin{array}{c}13,747 \\
(27,738)\end{array}$ \\
\hline $\begin{array}{l}\text { 0-2 Miles Outside City Border } \\
\times \text { After Tax }\end{array}$ & $\begin{array}{c}63,650^{* * *} \\
(20,734)\end{array}$ & $\begin{array}{c}35,957 \\
(32,678)\end{array}$ & & \\
\hline $\begin{array}{l}\text { 0-2 Miles Outside City Border } \\
\times \text { After Tax } * \text { Income-in-Philadelphia }\end{array}$ & & $\begin{array}{c}67,140 \\
(75,752)\end{array}$ & & \\
\hline $\begin{array}{l}\text { 2-4 Miles Outside City Border } \\
\times \text { After Tax }\end{array}$ & $\begin{array}{c}18,364^{* * *} \\
(7,032)\end{array}$ & $\begin{array}{c}12,126 \\
(10,415)\end{array}$ & $\begin{array}{c}18,364^{* * *} \\
(7,032)\end{array}$ & $\begin{array}{c}12,124 \\
(10,415)\end{array}$ \\
\hline $\begin{array}{l}\text { 2-4 Miles Outside City Border } \\
\times \text { After Tax } * \text { Income-in-Philadelphia }\end{array}$ & & $\begin{array}{c}13,049 \\
(17,325)\end{array}$ & & $\begin{array}{c}13,050 \\
(17,325)\end{array}$ \\
\hline $\begin{array}{l}\text { 4-6 Miles Outside City Border } \\
\times \text { After Tax }\end{array}$ & $\begin{array}{l}8,640^{* *} \\
(4,198)\end{array}$ & $\begin{array}{c}8,640 * * \\
(4,198)\end{array}$ & $\begin{array}{l}8,640^{* *} \\
(4,198)\end{array}$ & $\begin{array}{c}8,640^{* *} \\
(4,198)\end{array}$ \\
\hline Store FE & Yes & Yes & Yes & Yes \\
\hline Week FE & Yes & Yes & Yes & Yes \\
\hline Observations & 213,499 & 213,499 & 213,499 & 213,499 \\
\hline Stores & 1,227 & 1,227 & 1,227 & 1,227 \\
\hline Weeks & 176 & 176 & 176 & 176 \\
\hline
\end{tabular}

Table A13: Cross-Shopping as a Function of Income in Nearby Philadelphia Census Tracts. Column (1) replicates column (1) in Table 5. Income-in-Philadelphia is computed by taking the average of the median income level in all census tracts in Philadelphia that are within a 4 mile radius around a store (outside of the city). The median income level is re-scaled such that it varies between 0 and 1 across all census tracts in Philadelphia. The standard deviation of the Income-in-Philadelphia variables is equal to $0.15,0.20$, and 0.30 for stores within $0-1$ miles, 1-2 miles, and 2-4 miles outside of Philadelphia respectively. For the 0-1 miles distance band, the income variable varies between 0.20 and 0.66 . 


\begin{tabular}{|c|c|c|c|}
\hline & $\begin{array}{c}\text { All Beverages } \\
\text { (1) }\end{array}$ & $\begin{array}{c}\text { Low Sugar } \\
\text { Taxed Beverages } \\
(2)\end{array}$ & $\begin{array}{c}\text { High Sugar } \\
\text { Taxed Beverages } \\
(3)\end{array}$ \\
\hline Dependent Variable & $\begin{array}{l}\text { Gram of } \\
\text { Sugar }\end{array}$ & $\begin{array}{l}\text { Ounces } \\
\text { Sold }\end{array}$ & $\begin{array}{l}\text { Ounces } \\
\text { Sold }\end{array}$ \\
\hline Average Pre-Tax & & & \\
\hline Quantities / Grams of Sugar & 342,807 & 54,290 & 69,832 \\
\hline Philadelphia $\times$ After Tax & $\begin{array}{c}-132,129^{* * *} \\
(24,318)\end{array}$ & $\begin{array}{c}-26,132^{* * *} \\
(4,409)\end{array}$ & $\begin{array}{c}-30,164^{* * *} \\
(5,741)\end{array}$ \\
\hline 0-2 Miles Outside & $166,074^{* * *}$ & $20,613^{* * *}$ & $43,207^{* * *}$ \\
\hline City Border $\times$ After Tax & $(53,315)$ & $(7,741)$ & $(13,773)$ \\
\hline 2-4 Miles Outside & $50,600 * * *$ & $5,633^{*}$ & $12,766^{* * *}$ \\
\hline City Border $\times$ After Tax & $(18,030)$ & $(2,954)$ & $(4,220)$ \\
\hline 4-6 Miles Outside & $24,572^{* *}$ & 2,751 & $5,866^{* *}$ \\
\hline City Border $\times$ After Tax & $(11,091)$ & $(1,851)$ & $(2,501)$ \\
\hline Store FE & Yes & Yes & Yes \\
\hline Week FE & Yes & Yes & Yes \\
\hline Change in Aggregate Quantity & $-18,821^{*}$ & $-5,946^{* * *}$ & $-3,527$ \\
\hline (Unit: 1,000 Ounces / Grams of Sugar) & $(10,982)$ & $(1,907)$ & $(2,635)$ \\
\hline Change in $\%$ of Pre-tax Volume in & $-0.154^{*}$ & $-0.311^{* * *}$ & -0.143 \\
\hline Philadelphia w/ Cross-Shopping & $(0.090)$ & $(0.100)$ & $(0.107)$ \\
\hline Change in $\%$ of Pre-tax Volume in & $-0.386^{* * *}$ & $-0.487^{* * *}$ & $-0.438^{* * *}$ \\
\hline Philadelphia w/o Cross-Shopping & $(0.071)$ & $(0.082)$ & $(0.083)$ \\
\hline Observations & 213,499 & 212,871 & 213,499 \\
\hline Stores & 1,227 & 1,223 & 1,227 \\
\hline Weeks & 176 & 176 & 176 \\
\hline
\end{tabular}

Table A14: Impact on Nutritional Intake: Sugar. High-sugar-content beverages are defined as products with $\geq 2.4$ grams/oz (the median value for sugar content across all taxed products). 